Redaktionskollek tiv Gewerkschaften

\title{
ZUM ZUSAMMENHANG VON KAPITALAKKUMULATION, VER- ANDERUNGEN IN DEN FORMEN DER PROFITPRODUKTION UND DER ROLLE NEUERER ENTLOHNUNGSMETHODEN IN DER BRD (TEIL II)
}

\section{Vorbemerkung}

Im Teil I des vorliegenden Aufsatzes (PROKLA 4/72) haben wir skizzenartig versucht, ausgehend von den Phasen der Akkumulation des westdeutschen Kapitals die allmähliche Verlagerung des Schwergewichts in den Methoden der Profitproduktion von der extensiven (Produktion des absoluten Mehrwerts) auf die intensive (Produktion des relativen Mehrwerts) nachzuweisen. Waren bis 1955/57 der Anstieg in der absoluten Masse der Arbeitskraft, hohe tarifliche Arbeitszeiten, eine hohe Exploitationsrate und das somit hohe akkumulationsfähige Mehrprodukt Voraussetzungen der beschleunigten Akkumulation des westdeutschen Kapitals und seiner Stellung auf dem Weltmarkt, so stößt in dem Zeitraum 1955/57 bis 1960/62 mit dem Erreichen der „Vollbeschäftigung" das Kapital an die Grenze der Ausdehnung der im Produk tionsprozeß angewandten Arbeitskräfte und ist damit im verstärkten Maße auf die Entfaltung der Produktivkraft der Arbeit mittels der Umwälzung der technologischen Basis der Produktion und der Intensifikation der Arbeit hingewiesen. Dieser Prozeß war vermittelt über die Konkurrenz der Kapitale auf dem Weltmarkt, die Konzentrations- und Zentralisationsbewegung und die zyklische Akkumulationsbewegung des nationalen Kapitals und ist als äußerst widerspruchsvoller zu begreifen. Aus diesem historischen Zusammenhang heraus wurden von uns die Formen der Okonomie in der Anwendung des konstanten und variablen Kapitals und deren Auswirkung auf die Lage der Arbeiterklasse entwickelt, wobei besonders die technologischen Veränderungen in ihrer Wirkung auf die Schichtung in der Arbeiterklasse dargestellt wurden.

Im folgenden sollen die Funktionen der in der Entwicklung der Kapitalakkumulation in den 60er Jahren eingeführten neueren Entlohnungsmethoden analysiert werden, um dann (unter Punkt 4) den Zusammenhang von typischen Arbeitsformen, technologischen Veränderungen und wachsender Belastung der Arbeiter herauszuarbeiten. Im Punkt 5 soll dann die in der Einleitung aufgeworfene Frage nach der politischen Bedeutung der Abwehraktionen der Arbeiter gegen schlechte Arbeitsbedingungen und Intensifikationen der Arbeit wiederaufgenommen und als Problem in den Gewerkschaften entwickelt werden. Es soll hier aber noch darauf hingewiesen werden, daß die als Resultat sich entwickelnder Konflikte im Akkumulationsprozeß $\beta$ sich herausbildenden Freisetzungs- und Umsetzungsprozesse in unserem $\mathrm{Zu}-$ sammenhang zunächst nur benannt und erst in weiteren Untersuchungen im einzelnen dargestellt und analysiert werden können. 


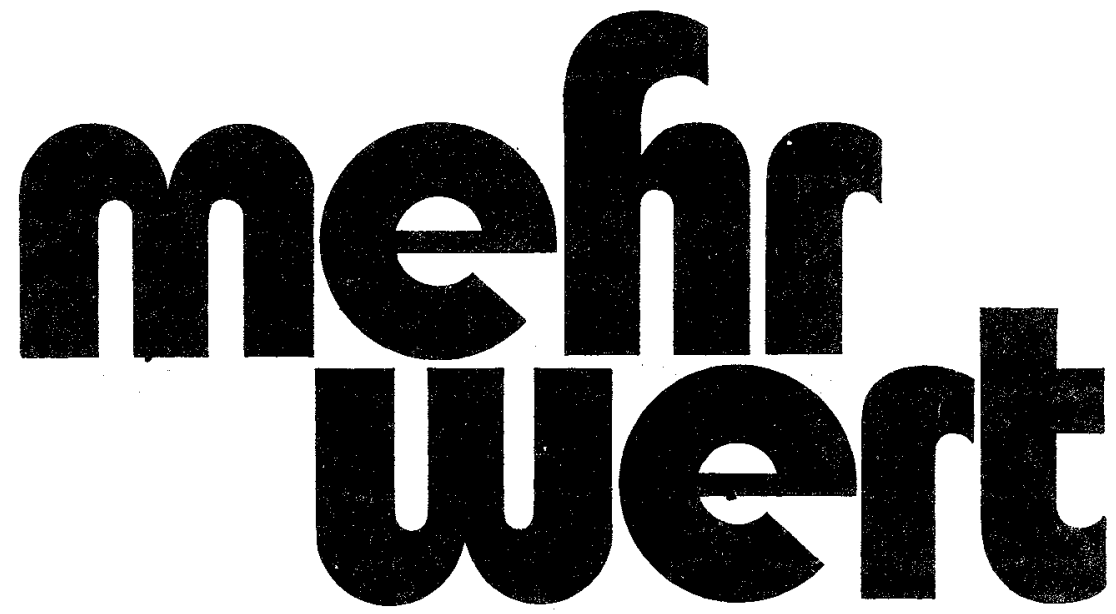

\section{beiträge zur kritik der politischen ökonomie}

mehrwert 2

erscheint demnächst. Auf ca. 130 Seiten enthält er die folgenden Beiträge:

Winfried Vogt, Regensburg

Zur Kritik der herrschenden Wirtschaftstheorie

Rudolf Hickel, Bremen

Zur materialistischen Interpretation der

Marxschen Reproduktionsschemata

Bertram Schefold, Basel/Cambridge

Wert und Preis

in der marxistischen und neokeynesianischen

Akkumulationstheorie

mehrwert 1

ist z.Zt. vergriffen. Neuauflage im I. Quartal '73. Bitte ebenfalls vorbestellen! mehrwert

wird herausgegeben in Westberikn und Bremen und erscheint im Verlag des POLTLADEN ERLANGEN 
„Daß nun der Arbeiter aber auch wirklich mehr Arbeitskraft flüssig macht, dafür sorgt das Kapital durch die Methode der Zahlung." (66)

In der Form des Lohns erhält der Arbeiter in der kapitalistischen Gesellschaft seinen Anteil an dem von ihm produzierten Wertprodukt; es ist die einzig für ihn mögliche Form der Teilhabe am gesellschaftlichen Reichtum. Der Umfang dieses Anteils ist grundsätzlich durch die zur Reproduktion der Arbeitskraft sowie der Erhaltung der „Arbeiterrasse". notwendigen Lebensmittel bestimmt, womit gleichzeitig die Funktion des Arbeitslohns im Reproduktions- und Akkumulationsprozeß des Kapitals beschrieben ist. In die Bestimmung des Quantums notwendiger Lebensmittel gehen historische und moralische Momente ein.

Wir wissen nun, daß das Wertprodukt z.B. eines Arbeiters bestimmt ist nicht vom Wert der Arbeitskraft, sondern von der Zeitdauer ihrer Verausgabung. Gerade die Tatsache, daß der Kapitalist die Arbeitskraft stets länger fungieren läßt, als zur Reproduktion ihres Werts notwendig, ist die Ursache dafür, daß er sich unbezahlte Arbeit aneignen kann. Das gesellschaftliche Verhältnis von Kapital und Arbeit ist aber in der allgemeinen Form des Arbeitslohns verschleiert: „Die Form des Lohns löscht ... jede Spur der Teilung des Arbeitstages in notwendige und Mehrarbeit, in bezahlte und unbezahlte aus. Alle Arbeit erscheint als bezahlte." (67) Denn der Austausch zwischen Kapital und Arbeit stellt sich dar als Tausch von Waren $(\mathrm{G}-\mathrm{A})$.

66) MEW 23, S. 433

67) MEW 23, S. 562; vgl. zur Frage des Lohnfetischs auch noch den letzten Teil des Aufsatzes 
Der darin begründete Schein des Äquivalententauschs wird in der nachträglichen Bezahlung der Arbeit befestigt. Weiter: Es ist nicht der ,Gebrauchswert", ,den der Arbeiter dem Kapitalisten liefert, in der Tat nicht seine Arbeitskraft, sondem ihre Funktion, eine bestimmte nützliche Arbeit... Daß diesselbe Arbeit nach einer Seite hin allgemeines wertbildendes Element ist, eine Eigenschaft, wodurch sie sich von allen anderen Waren unterscheidet, fällt außerhalb des Bereichs des gewöhnlichen Bewußtseins." (68) Damit ist im Lohn das wesentliche Verhältnis, daß Kapital Kommando über unbezahlte Arbeit ist, (69) ausgelöscht, ein Umstand, der durch die mannigfaltigen Formen des Arbeitslohns noch bestätigt wird. (70) Auf der Oberfläche der Bürgerlichen Gesellschaft erscheint der Arbeitslohn als Preis der vom Arbeiter geleisteten Arbeit, als ,ein bestimmtes Quantum Geld, das für ein bestimmtes Quantum Arbeit gezahlt wird."(71) Diese seine verkehrte Oberflächengestalt ist selbst wieder der Ansatzpunkt für die mannigfaltigen Formen bzw. Methoden der Zahlung des Arbeitslohns, welche eine unterschiedliche Art und Weise der Messung des verausgabten Arbeitsquantums zur Grundlage haben und welche vom Kapitalisten selbst wiederum als Mittel der Auspressung von Mehrarbeit und der Senkung des Preises für ein bestimmtes Quantum Arbeit angewendet werden.

Die Formverschiedenheiten in der Zahlung des Arbeitslohns werden von Marx in ihren Grundformen als Zeitlohn und Stücklohn entwickelt. Der Zeitiohn stellt die verwandelte Form des Wertes respektive Preises der Arbeitskraft dar. Der Stücklohn ist nur eine verwandelte Form des Zeitlohns. Er trägt den besonderen Schein an sich, als werde die vergegenständlichte Arbeit verkauft. Beim Zeitlohn wird das Quantum verausgabter Arbeit unmittelbar an ihrer Zeitdauer, z.B. einer Stunde gemessen, beim Stücklohn am Produktenquantum. Stück oder Stunde dienen als Maßeinheit der vom Arbeiter verausgabten Arbeit. Die Formverschiedenheiten des Arbeitslohns sind in ihrer Anwendung mehr oder weniger begünstigt durch die besondere stoffliche Gestalt des Arbeitsprozesses sowie die technischen Veränderungen, welche in diesem stattfinden. (72)

Es soll nun darum gehen, die Funktionen neuerer Entlohnungsmethoden durchsichtig zu machen. Zu diesem Zweck ist es notwendig, einen kurz zusammenfassenden Überblick darüber zu geben, aus welchen Gründen bestimmite Lohnformen veralten, d.h. ihre vom Kapital ihnen zugedachte Funktion verlieren. Diese Funktion wird im RKW Band 6 von Koch u.a. folgendermaßen benannt: ,Die Leistungsentlohnung dient allgemein der Förderung der Lohngerechtigkeit. In

68) Ebda., S. 562

59) Vgl. ebda, S. 556

70) Für unsere weitere Untersuchung wird gerade die Tatsache, daß die, wirkliche Bewegung des Arbeitslohns Phänomene (zeigt), die zu beweisen scheinen, daß nich $\uparrow$ der Wert der Arbeitskraft bezahlt wird, sondern der Wert ihrer Funktion, der Arbeit selbst'" (MEW 23, S. 564) relevant, weil diese Phänomene auch als Momente in die neueren Entlohnungsmethoden eingehen: „Diese Phänomene können wir auf zwei große Klassen zurückführen. Erstens: Wechsel des Arbeitslohns mit wechselnder Länge des Arbeitstags ... Zweitens: Der individuelle Unterschied in den Arbeitslöhnen verschiedener Arbeitcr, welche dieselbe Funktion verrichten." (Ebda.)

71) MEW 23, S. 557 (Hervorhebung Redaktionskollektiv)

72) Vgl. dazu die Darstellung insbesondere des Stücklohns im Kapital Bd. I, MEW 23, S. 574-582, vgl. auch Tilo Damm im Neuen Roten Forum a.a.O. 
dieser Zweckbestimmung ist die Leistungsentlohnung ein Mittel, eine Übereinstimmung bzw. Annäherung der Interessen von Arbeitgeber und Arbeitnehmer herbeizuführen. Der leistungsbedingte Lohn bedeutet für den Arbeitnehmer zugleich Anerkennung und Ansporn für eine durch besonderen Leistungswillen gesteigerte Arbeitsleistung. Für den Arbeitgeber ist die Leistungsentlohnung betriebswirtschaftlich von Interesse, da sie ein geeigne tes Mittel sein kann um 1. die Leistungshergabe der Arbeiter zu steigern (Anreizfunktion der Leistungsentlohnung) 2. ein angemessenes Leistungniveau aufrechtzuerhalten (Regulierungsfunktion der Leistungsentlohnung) ${ }^{6}$. (73) Soweit zur Lohnform, von welcher Koch u.a. an anderer Stclle hervorheben, daß sie von der Arbeitsbewertung unterschieden werden müsse. Die Arbeitsbewertung gelte der Art der menschlichen Leistung, die Lohnform ihrem Umfang. (74) Insgesamt soll eine als angemessen empfundene Differenzierung de: Löhne nach der Arbeitsschwierigkeit (Arbeitsbewertung) und nach den individuellen Leistungsunterschieden (Lohnform) erreicht werden. Diese in der bürgerlichen Arbeitswissenschaft vorgenommene Differenzierung läßt sich allerdings, wie noch zu zeigen sein wird, wiederum auf verschiedene Methoden, einen Mafsstab für das verausgabte Arbeitsquantum zu finden, reduzieren.

Die traditionelle Differenzierung der Löhne richtete sich hinsichtlich der ,Arbeitsbewertung ${ }^{6}$ auf die Qualifikationen (ungelernte, angelernte und Facharbeit) und auf die Unterscheidung zwischen körperlich schwerer und leichter Arbeit; die Messung der vom einzelnen Arbeiter erbrachten Leistung erfolgt durch Stïck - bzw. Geldakkord. Diese traditionellen Lohnformen geraten zum einen durch die aufgrund technischer Umstellungen stattfindenden Veränderungen traditioneller Qualifikationsstrukturen, zum anderen durch das veränderte Verhältnis zwischen Maschinerie und menschlicher Arbeit in die ,Krise'. In dem Maß, in dem der Arbeiter auch zeitlich bis in die kleinste Handbewegung hinein dem Ablauf der Maschinerie untergeordnet ist, nirnmt der Bereich der vom Arbeiter beeinflußbaren Arbeitszeit $\mathrm{ab}$. Wenn weiterhin Leistungen eher Beschickungs-, Überwachungs- und Steuerfunktionen darstellen, als Verausgabung quantitativ meßbarer und individuell beeinflußbarer Arbeiten, wird den auf der Meßbarkeit individueiler Leistung basierenden Lohnformen die Basis entzogen. Die in der bürgerlichen Arbeitswissenschaft bejammerte „Krise des Leistungslohns“ ist daher allerdings richtiger als eine Krise besonderer Methoden, die Leistung dem Arbeiter abzupressen, zu bezeichnen.

Von der „Krise des Leistungslohns" wird dann gesprochen, wenn der Charakter der individuell unterscheidbaren Leistung durch Rationalisierungsprozesse zugunsten von der Maschine subsummierter Spezial- bzw. Detailarbeit zurïcktritt. Lutz/Willener schreiben in einer für die Montanunion angefertigten Untersuchung, „daß das Prinzip der Leistungsentlohnung überhaupt, närnlich das Prinzip, den Ver dienst des Arbeiters von seiner eigenen Leistung, von der Leistung und dern Ausnutzungsgrad der von ihm bedienten Anlage und letzten Endes vom wirtschaftlichen Ertrag seiner Árbeit abhängig zu machen", in eine Krise geraten ist. (75) Denn die „Legitimitätsbasis" des Leistungslohns sei nur dann gegeben, wenn der Arbeiter das Empfinden hat, daß das ihm vergütete Entgelt der von ihm vollzogenen Arbeitsleistung entspricht (Prinzip der Lohn-Leistungs-Aquivalenz).

73) RKW-Projekt, Band 6, a.a.O., S. 150

74) Vgl. ebda., S. 133

75) Lutz/Willener, Mechanisierungsgrad und Entlohnungsformen, Luxemburg $1959,3.164$ 
Nun erscheint aber der Arbeitslohn gerade als Åquivalent konkret-nützlich verausgabter Leistung im Produktionsprozeß. Die neueren Lohnformen knüpfen wie schon der Stiìcklohn - an dieser Vorstellung vom, leistungsgerechten ${ }^{6}$ Lohn an, um ihre Funktion zu erfüllen, speziell die Arbeitsintensität zu erhöhen. Auch die bisherigen Messungsmethoden vermitteln die Illusion, die jeweils individuelle Leistung werde bezahlt. So wird die als quasi natürlich eingewöhnte, in der Zirkulation erscheinende Tauschgerechtigkeit von Lohn und Arbeit in den Produktionsprozeß verlängert. Mit der technischen Veränderung verlieren traditionelle Akkordanreize ihre Basis, was häufig auf eine Verminderung ihrer Intensivierungsfunktion hinausläuft. In den Auseinandersetzungen um höhere Akkordentlohnung wird teilweise ein entsprechend höherer Anteil an der erhöhten Produktivität des Betriebes gefordert, ein Phänomen, was schon Marx im Kapitel über den Stücklohn registriert und das er mit dem Satz kommentiert: „Solchen Anspruch fertigt das Kapital mit Recht als groben Irrtum über die Natur der Lohnarbeit ab. Es zetert über die Anmaßung, Steuern auf den Fortschritt der Industrie zu legen, und erklärt rundweg, daß die Produktivität der Arbeit den Arbeiter überhaupt nichts angeht."'(75a) Auch der oft gelungene Versuch von Arbeitern, Verbesserungen im Arbeitsablauf für eine Erleichterung ihrer Arbeit bei gleichem Lohn zu nutzen, in der Betriebswirtschaftslehre als „schleichende Rationalisierung" oder "Arbeitszurückhaltung" benannt, ist Ausdruck verminderter Intensivierungsfunktion dieser Systeme. Neuere bzw. differenziertere Lohnformen waren also von daher für das Kapital notwendig und sollen nach den Vorstellungen der Arbeitswissenschaftler die Funktion einer wirksameren Abpressung von Arbeitsleistung erfüllen.

Die sich aus der technischen Entwicklung ergebende Differenzierung der Beschäftigten, das Veralten traditioneller Qualifikationen, die beschleunigte Veränderung von Arbeitsplatzanforderungen und die skizzierte Krise des Leistungslohns bringen, zusammen mit dem wichtigsten, dem Verwertungstrieb des Kapitals, Lohnformen hervor, die

- die Vorgabezeiten, also die Leistungsnorm, vor Beginn des Produktionsprozesses ,wissenschaftlich' ermitteln (Verfahren vorbestimmter Zeiten)

- den Grundlohn leistungsgerecht - differenziert nach den ,wissenschaftlich ${ }^{\circ}$ ermittelten Anforderungen des Arbeitsplatzes - festlegen (Analytische Arbeitsplatzbewertung)

- besondere individualisierte Leistungsanreize zum Erbringen von Spezialleistungen beinhalten (Prämienlohn).

Im folgenden beschränken wir unsere Darstellung auf diese wesentlichen Methoden der Verfahren vorbestimmter Zeiten (VvZ), der analytischen Arbeitsplatzbewertung (AA) und der Prämienzahlung. Analytische Arbeitsplatzbewertung und Prämienlohn können, dies sei noch angemerkt, unmittelbar als Antworten des Kapitals auf das Veralten von traditionellen Qualifikationen aufgrund der Veränderung der Arbeitsplatzstruktur und auf das veränderte Verhältnis zwischen lebendiger Arbeit und Maschinerie begriffen werden. Die Verfahren vorbestimmter Zeiten dagegen müssen als unmittelbar arbeitsorganisatorische Maßnahme zum Zweck der Intensifikation der Arbeit angesehen werden. Intensifikation der Arbeit bezweckt

75a) MEW 23, S. 582 
natürlich auch der Prämienlohn und die analytische Arbeitsplatzbewertung, der Prämienlohn, indem er aufgrund technischer Entwicklung obsolet gewordene Formen, diese Intensifikation zu erzwingen, ablöst, die AA, indem die Arbeitsbeschreibung, welche der Arbeitsplatzbewertung vorhergeht, vorhandene Reserven aufdeckt.

\subsection{Zur Funktion der Verfahren vorbestimmter Zeiten alis Methoden der Findung von Vorgabezeiten (Normfindungssysteme) (76)}

Die Verfahren vorbestimmter Zeiten (VvZ) analysieren Bewegungseinheiten, die nicht mehr durch einfache Zeitmeßinstrumente (Stoppuhr) erfaßt werden können. Mittels dieser Form der Erfassung menschlicher Bewegungen im Arbeitsprozeß und ihrer Zeitdauer soll eine äußerste Präzision in der Bestimmung der Vorgabezeiten erreicht werden.

Wir hatten schon darauf hingewiesen, daß die Formverschiedenheiten des Arbeitslohns in sich verschiedene Möglichkeiten bergen, den Preis der Arbeit als Preis eines bestimmten Arbeitsquantums herabzusetzen. Mit der Entwicklung der Arbeitswissenschaft verfeinern sich nun diese möglichen Methoden. Die Verfeinerung selbst zielt bei den $\mathrm{VvZ}$ vor allem dahin, Maßeinheiten für das ,gewöhnliche ${ }^{6}$ und, durchschnittliche ${ }^{6}$ Mafs der Verausgabung von Arbeit innerhalb einer bestimmten Zeiteinheit zu finden. Marx beschreibt noch einen Entwicklungsstand, bei dem ein erfahrungsgemäß durchschnittliches Quantum an Arbeit pro Stunde etwa die Grundlage zur Bestimmung des Stücklohns bildet, wobei die Kontrolle zur Leistung dieser gewohnheitsmäßigen Arbeit in den Arbeiter selbst verlegt wird. Beim Zeitlohn hat der Arbeitsaufseher für die Verausgabung des gewohnheitsmäßigen Quantums zu sorgen. Wird nun dieses gewohnheitsmäßige Quantum durch die arbeitswissenschaftlich gefundenen Methoden der VvZ erhöht, so bedeutet dies eine Methode der Senkung des Preises für ein bestimmtes Arbeitsquantum durch Erhöhung der Intensität der Arbeit. Diese Senkung wird einmal gerechtfertigt, in dem sie dem Arbeiter als wissenschaftlich ermittelte Normalzeit vorgespiegelt wird, zum anderen wird sie ihm schmackhaft gemacht, indem eine dem Maß der Verausgabung von Mehrarbeit nicht entsprechende Lohnerhöhung zugestanden wird.

Die Verfahren vorbestimmter Zeiten haben den Vorteil für den Kapitalisten, daß sie als Maß der verausgabten Arbeit weder eine Zeiteinheit, noch ein bestimmtes Stück, sondern die angeblich durchschnittliche Zeitdauer der im Arbeitsprozeß notwendigen Bewegungen bestimmen. Auf diese Weise ist - etw2 im Vergleich zum Stücklohn - das Messen des Arbeitsquantums unabhängig geworden von den Veränderungen in der Produktivkraft der Arbeit bei veränderter Maschine rie, welche bei der Methode der Stücklohnzahlung immer mögliche Konflikte zwischen Arbeiter und Kapitalist einschließt. Die VvZ stellen eine Methode dar, das durchschnittlich zu verausgabende Arbeitsquantum an der Zahl und der Form der Bewegungen zu messen, so wie beim Stïcklohn das durchschnittlich zu verausgabende Arbeitsquantum an der Zahl der Stücke gemessen wird. Ist beim Stücklohn der

76) Eine genauere Darstellung der Verfahrensweisen der VvZ findet sich in Anhang I 
Kapitalist noch auf die Konkurrenz der Arbeiter untereinander angewiesen als Hebel, den Preis der Arbeit zu senken, so gilt dies für die VvZ zunächst nicht.

Das System schließt aufgrund der am Arbeitsplatz vorgenommenen Bewegungsstudien gleichzeitig die Möglichkeit ein, das System der Arbeitsteilung zu verfeinern, und zwar einmal zum Zwecke der Anpassung der Arbeit an veränderte technische Bedingungen, zum anderen um die Arbeit intensivieren zu können. Die Intensivierung erfolgt durch Bewegungsvereinfachung und Bewegungsverdichtung. Durch Anwendung solcher Verfahren können Maschinen entsprechend konstruiert und eingerichtet bzw. oft mit relativ geringen Kosten entsprechend umgebaut werden. Als Work Factor (WF) und Methods-Time-Measurement (MTM) finden sie seit Anfang der sechziger Jahre zunehmende Anwendung in der BRD. Die im Jahre 1962 gegründete deutsche MTM-Vereinigung umfaßt beispielsweise Unternehmen der Automobilerzeugung, der Textil- und Bekleidungsindustrie, der chemischen Industrie und Werke der Schuh- und Lederindustrie mit zusammen etwa 350000 bis 400000 Beschäftigten. (77) Die Methoden setzen sich vor allem in Produktionszweigen mit Massenserienfertigungen und manuellen Eingriffsmöglichkeiten am Arbeitsplatz durch. Besonders in der elektronischen-, feinmechanischenund Automobilindustrie werden mit ihnen un- und angelernte, meistens kurz angelernte Arbeiterinnen und Arbeiter eingesetzt. Die vereinfachten Verfahren, also z.B. MTM Schnellverfahren, sind für die Fertigung vor- bzw. nachgelagerter Produktionsabteilungen wie Instandhaltung, Wartung sowie in der Verwaltung von zunehmender Bedeutung.

MTM und WF werden vor allem in Bereichen der Montage bzw. Fließbandtätigkeiten als arbeitstechnische Rationalisierungen bei nicht wesentlich veränderter Technologie, als ,Rationalisierung ohne Kapital' angewandt, doch erhalten diese Verfahren ihre Bedeutung gleichermaßen dadurch, daß mit ihnen auch neue Konstruktionen von Maschinen zwecks kostenoptimaler Kombination der Produktionsmittel mit der Arbeit beeinflußt werden; d.h. die VvZ dienen sowohl der Ökonomie auf einem gegebenen technischen Stand der Produktionsmittel wie auch der ökonomie auf neuer technologischer Stufenleiter. Sie bieten nach der Darstellung der Vertreter solcher Systeme enorme Kostenvorteile für die Unternehmer:

1. Die Kalkulation von Zeiten und Kosten wird systematisiert und teilweise von technischen Apparaturen übernommen (automatische Zeitmeßgeräte);

77) Über das WF System heißt es in einer kürzlichen Meldung der Frankfurter Rundschau: ,Wenn die japanische Industrie in relativ kurzer Zeit eine international wettbewerbsfähige Produktivität und Qualität erreicht hat, so verdankt sie das nach offiziellem Eingeständnis des Wirtschaftsministeriums in Tokio maßgeblich dem Work Factor System, das etwa die Hälf te aller japanischen Industriearbeiter anwendet. Mit diesem System, das sich vor allem zum Ziel gesetzt hat, den Arbeitsablauf nicht nur in gewerblichen, sondern auch in Dienstleistungsbereichen zeitlich $\mathrm{zu}$ verbessern ... haben sich in aller Welt Fertigungs- und Handlungsprozesse aber auch Produktionskosten vereinzelt bis um $50 \%$, um 20-30\% reduzieren lassen .... Das mit technischen Mitteln operierende Verfahren umfaßt neben der menschlichen Arbeitszeit auch die optimale Nutzung aller Produktionshilfen einschließlich Computer. Zur Zeit gehören der deutschen Vereinigung 110 Firmen und Verbände an, die etwa 680000 Beschäftigte repräsentieren, darunter viele bekannte Großbetriebe." 
2. Werkzeuge bzw. Maschinenteile können von vornherein ,anwendungsgünstiger $^{6}$ gestaltet werden, d.h. aber, der ökonomische Einsatz von konstantem Kapital wird verbessert.

3. Die Art der Aufgliederung der Arbeitsgänge gestattet es, vor Eintritt in den Arbeitsprozeß die rationellste Arbeitsmethode zu finden und bietet so Grundlagen für eine systematischere Produktionsplanung und -steuerung.

4. Nach den Systemen ist es möglich, im Durchschnitt 15 bis $30 \%$, teilweise bis zu $50 \%$ der früher verwandten Zeit einzusparen.

5. Das Anlernen von Arbeitskräften für die benötigten sensomotorischen Fertigkeiten wird exakter und in kürzerer Zeit möglich. (78)

6. Es entstehen Arbeitsformen, die je nach Kostenerwägung eine weitere Automatisierungsstufe ermöglichen. (79)

Insgesamt stellen die VvZ eine besonders entwickelte Form kapitalistischer Koordination von lebendiger Arbeit und Maschinerie dar. Zwar werden aufgrund der Bewegungsanalyse Bewegungen und Kraftausgabe je Fertigungsvorgang vermindert, bestimmte manuelle Tätigkeiten werden von der Maschine übernommen. Die Verfahren könnten also der Erleichterung und Verkürzung der Arbeit dienen. Kapitalistisch angewandt sind sie jedoch ein „System der Schweißauspressung nach allen Regeln der Wissenschaft.“ (80) Sie intensivieren die Arbeit durch Bewegungsvereinfachung und Beschleunigung der restlichen Bewegung. (81) Sie ermöglichen die Beseitigung sogenannter ,unproduktiver Zeiten", das systematische Ausmerzen von Stillstand und Störungsmöglichkeiten der Maschine, wobei gleichzeitig die Pausen reduziert werden. Auf ihrer Grundlage ist Arbeitsteilung bis auf kleinste, jeweils einfachste Teilbewegungen möglich, deren blinder Vollzug noch durch die Verwendung automatischer überwachungsmethoden vorangetrieben wird. Auf ihnen basiert die teilweise Einführung des Beidhand-Verfahrens, mit dem über eine ,optimale' Koordination der Funktion von Bewegungs- und Sinnesorganen (sensomotorische Leistung) die Leistung bis zu 50\% erhöht werden kann.

Der Arbeitsphysiologe Rutenfranz hält als Ergebnis einer Versuchsreihe an Arbeiterinnen(!) in einem Westberliner Betrieb lakonisch fest: „,Die Montage erfordert zu ihrer Mechanisierung und Automatisierung wegen der sehr speziellen, hier benötigten Funktionen einen großen technischen Aufwand. Jeder Montageautomat ist eine Spezialmaschine, die nur sehr geringe Anpassungsfähigkeit besitzt. Der Mensch ist dagegen sehr viel flexibler einsetzbar. Zum anderen haben die Studien der menschlichen Bewegung bei Montagearbeiten, der Anatomie, der Anthropometrie und der sensomotorischen Fertigkeiten in jüngster Zeit zu einer

78) Vgl. die in der Elektroindustrie angewandten Methoden des Anlerntrainings, mit denen innerhalb von wenigen Stunden eine optimale Endleistung herausgepreßt werden $\mathrm{kann}$, vgl. RKW-Projekt, Bd. 7, S. $270 \mathrm{ff}$.

79) „Diese Systeme sind interessant, wenn der Aufwand für die Arbeitsgestaltung, zusammen mit den Kosten der bei den aufgelegten Serien notwendigen Arbeitszeit wirtschaftlicher ist, als die Einführung halbautomatischer oder vollautomatischer Aggregate." (AFAInformation $9 / 101961$, S. 137

80) Lenin Werke Bd. 18, S. 589

81) „Erst wenn alle Möglichkeiten der arbeitstechnischen Rationalisierung erschöpft sind (maximale Bewegungsverdichtung) lohnt sich ein Übergehen zur Mechanisierung." RKW-Berichtsband, S. 241, vgl. auch ebda., S. 80 ! 
erheblichen Steigerung der menschlichen Montageleistung geführt, in denen die Bewegungsfolge verdichtet und die Bewegungsschwierigkeiten reduziert wurden." (82) Es heißt weiter, daß durch geschickte Kombination verschiedener Anlemformen ein ,optimales Mensch-Maschine-System ${ }^{6}$ und eine möglichst hohe Endleistung trainiert werden soll. (83) Geschickte Pausenregelungen sollen beispielsweise zentrale und muskuläre Ermüdung während der Arbeitszeit vermeiden und einen Leistungsgewinn hervorrufen, der mit der Länge der Pausen ,exponential' zunehme. Lernerfolge können noch einmal durch Geldprämien, hohe Gruppenkohäsion, aber auch durch Mißerfolgserlebnisse gesteigert werden. Pulsfrequenzerhöhungen als Symptome von Arbeitsüberanstrengung werden dabei in Kauf genommen. (84) Bei der angestrebten Aripassung des Menschen an eine bestimmte Arbeit geht es insgesamt um die ,Automatisierung ' der zu lernenden sensomotorischen Fähigkeiten und Fertigkeiten. (85)! „Das Ergebnis ist eine Änderung des Verhaltens des Menschen, vor allem seines Könnens und seiner sensomotorischen Leistung." (86)

An den Methoden der VvZ wird klar, daß die auf diese Weise ermittelte „Normalleistung c zur äußersten Beanspruchung der Arbeitskraft führt. Wird diese von den Einzelnen z.T. gar nicht erreichbare „Normalleistung“ dann noch als Grundlage eines Akkordlohns genommen, so tritt zur Belastung durch die außerordentliche Anspannung der Arbeitskraft und die Monotonie des Arbeitsprozesses noch das ständige Erlebnis des Mißerfolgs und der Angst vor Lohnverlust bis hin zum Verlust des Arbeitsplatzes. (87)

Auf der anderen Seite ist kein individueller Protest gegen diese Methode der Auspressung von Mehrarbeit möglich. Die Zeitnormen sind international festgelegt. Sie können als wissenschaftlich abgesicherte Ergebnisse angepriesen werden. Kommt einer nicht mit, so ist es sein rein individuelles Versagen. Kein Refa-Mann kann der falschen Zeitaufnahme beschuldigt werden. Der Widerstand ist hier kaum als Widerstand gegen Ungerechtigkeiten möglich. Formuliert sich aber Widerstand, so muß er sich gegen dieses gesamte System der Schweißauspressung richten. (88)

82) Ebda., S. 241

83) Ebda., S. 237

84) Eine Anzeige von Philips, welche elektronische Positionsanzeiger anpreist, empfiehlt: „,Sie müssen höhere Stückzahlen erzielen! Sie können es! . . Er wird erst nach Feierabend müde."

85) Vgl. RKW-Berichtsband, a.A.O., S. 274

86) Vgl. ebda., S. 272

87) So werden bei Bosch 1972 den Frauen erteilte Geld,,zuschriebe“ aus „Gnade“" gewährt, also ohne tarifvertraglichen Anspruch, weil deren MTM-Normwerte so hoch gesteigert sind, daß die Frauen durchschnittlich diese bei weitem nicht erreichen und so auch keinen Anspruch darauf haben, daß der ohnehin schon geringe, nach MTM errechnete Lohn gezahlt wird.

88) Über den gegenwärtigen Stand, die schlimmsten Folgen von MTM abzuwehren, gibt der Geschäftsbericht der IG Textil-Bekleidung, 1968/70, S. 214, Auskunft. Aufgrund yon Abwehrkämpfen konnten in einzelnen Betrieben Firmen-Tarifverträge abgeschlossen werden, die folgendes erthielren:

1. Organisierung bezahilter ${ }^{2}$ urzpausen von insgesamt 25 bis 30 Minuten je Schicht

2. ein Belastungsausgleich von $26 \%$ auf die Normzeiten der MTM-Tabelle;

3. die Sicherstellung der Mitbestimmung bei der Erstellung der Analysen (, zumut-

bare Arbeitsmethoden");

4. Schulung der Betriebsräte uber das MTM-System 


\subsection{Die Analy tische Arbeitsplatzbewertung (AA)}

Die traditionelle Form der Entlohnung ist die summarische Arbeitsbewertung. Hierbei galt der Weg, auf dem Fachkenntnisse erworben worden waren, als lohngruppenbestimmendes Kriterium: Facharbeiter, angelernte und ungelernte Arbeiter wurden in einer Skala von Lohngruppen eingestuft, z.B. in der Metallindustrie in 8 Lohngruppen. Weitere Kriterien der Einstufung waren körperlich leichte oder schwere Arbeit sowie Berufserfahrungen. Die analytische Arbeitsplatzbewertung geht dagegen von den jeweiligen Anforderungen und Arbeitsschwierigkeiten des Arbeitsplatzes aus, um zu einer arbeitsplatzgerechten Bewertung zu gelangen. Waren 1955 nach einer Umfrage der IG Metall nur 20\% der erfaßten Arbeiter in 6,5\% der erfaßten Betriebe nach der AA entlohnt worden(89), so setzte erst im folgenden Jahrzehnt sowie besonders seit der Krise '66/'67 sich die AA stärker, in der Metallindustrie fast vollständig, $\operatorname{durch}(90)$.

Die genaue Erfassung des Arbeitsplatzes und eine dem Arbeitsplatz entsprechende Bewertung wird für das Kapital im Zuge der technologischen Umwälzung zunehmend wichtig. Angesichts der mit dieser Umwälzung einsetzenden Veränderungen in der Arbeitsplatzstruktur, darüber vermittelten Dequalifizierungen traditioneller Facharbeiter und den Prozessen innerbetrieblicher Neuqualifizierungen von Angelernten wurden Entlohnungsstrukturen obsolet, die sich nach den herkömmlichen Lohngruppenkriterien summarischer Arbeitsbewertung richteten.

Das System der AA ist dagegen geeignet, die nicht mehr benötigen veralteten Qualifikationen im Zuge technischer Veränderungen auch tatsächlich abzuwerten, indem die Arbeitsschwierigkeiten niedriger gesetzt und dementsprechend die Löhne gekürzt werden. Sind die angebotenen, in der Lehre erworbenen Qualifikationen nicht mehr nachgefragt, so hat die AA die Funktion, den Preis der Ware Arbeitskraft dem gesunkenen Wert anzupassen. Dies entspricht der kapitalistischen Logik, die den Tauschwert der Ware Arbeitskraft nur realisiert, wenn der entsprechende Gebrauchswert auch wirklich benötigt wird.

Wird die bestimmte Qualifikation der Ware Arbeitskraft nicht mehr nachgefragt, ist sie darüberhinaus auch einem moralischen Verschleiß unterworfen bzw. hat mittels kapitalistischer Arbeitsteilung und Spezialisierung teilweise brachgelegen, so entspricht dem ein Preisverfall dieser Ware. In dem Moment, in dem die konkret nützliche Form der Arbeit nicht mehr nachgefragt wird, wären Kosten vergeudet, würde sie weiterhin bezahlt. Im Gegensatz zu jüngeren Arbeitskräften

89) Geschättsbericht aer IG Metall, 1955, S. 97

90) Zur Verbreitung der AA in der Metallindustrie: vgl. die Tarifverträge in den einzelnen Bezirken, z.B.:

a) Analytische Arbeitsbewertung für die Eisen- und Metallindustrie in Süd-Baden vom 11.3.63 zwischen Arbeitgeberverband der Badischen Eisen- und Metallindustrie e.V.; Freiburg i.B. und der IG Metall für die BRD, Bezirksleitung Stuttgart;

b) Analytische Arbeitsbewertung für die Metallindustrie in Nord-Württemberg und Nord-Baden zwischen Verband Württ.-Bad. Metallindustrieller e.V. und der IG Metall für die BRD, Bezirksieitung Stuttgart, vom 8.11.67;

Zur Verbreitung der AA in der Chemieindustrie: Hier zeigt sich gerade für die letzten Jahre die Einführung der AA etwa in einigen Großbetrieben der hessischen Chemicindustrie (z.B. Hoechst). 
sind hiervon vor allem ältere Arbeiter und Frauen in besonderem Maße betroffen, weil sie sich nicht oder nicht mehr eine neue Qualifikation entsprechend den Anforderungen aneignen können.

Ist so die Entwicklung der gesellschaftlichen Produktivkraft der Arbeit selbst zugleich die Entfaltung des allgemeinen Reichtums, so stellt sich im Kapitalismus derselbe Frozeß als Dequalifikation und Emiedrigung des Produzenten eben dieses Reichtums dar; ein Prozeß, der im besonderen Maße einzelne Schichten der Arbeiterklasse trifft.

Dieser Logik des Kapitals steht jedoch das Interesse der Arbeiterklasse auf eine normale Reproduktion gegenüber, um die beständige Verkaufbarkeit ihrer Ware Arbeitskraft zu ermöglichen.

Die AA hat also die Funktion, durch technische Veränderungen nicht mehr benötigte, veraltete oder moralisch verschlissene Qualifikationen auch nicht mehr zu entiohnen. Unter der Fahne analytischer Bewertung und entsprechend gerechtem Lohn soll die Lohnstruktur lediglich den vom Kapital gesetzten Anforderungen des Arbeitsplatzes entsprechen und darüberhinausgehende Forderungen nach Löhnen etwa auf Basis bestimnter Ausbildung, Berufserfahrung oder spezifischer Belastungen als unanaly tisch und im System der AA ungerechtfertigte Forderungen diskreditieren. Zugleich ist mit dem Konzept der arbeitsplatzgerechten Lohneinstufung die fuir das Kapital notwendige Mobilität, also der Einsatz des ,richtigen Marnes am richtigen Arbeitsplatz" ermöglicht. In dem Maße, in dem mit der Ausweitung der Arbeitswissenschaften im Betrieb die Personalpolitik rationalisiert wird, wird so auf Methoden der AA zurückgegriffen. Da sich dieser Prozeß auf der Basis veränderter Technologien erst in und mittels der Krise '66/'67, ihrer „,reinigenden" und ,die Arbeitsmoral hebenden" Wirkung durchzusetzen beginnt, so ist nur folgericitig, wenn sich im letzten Zyklus die tarifvertragliche Verbreitung der AA häufte.

Die AA fuhrt zu einer äußerst differenzierten Erfassung der Anforderungsstrukturen, welche die betriebliche bzw. überbetriebliche Lohnstruktur ebenfalls weiter differenziert. Die Hierarchie der Arbeitsplätze wird weiter ausgebaut, was einer weiteren Zersplitterung und Konkurrenz der Lohnarbeiter untereinander gleichkommt.

In welchem Maße es sich bei der AA nur um den Schein der Lohngerechtigkeit handelt, das System aber in Wirklichkeit darauf zielt, die Entlohnung den veränderten Technologien anzupassen, läßt sich anhand der Skizzierung der Funktionsweise der AA ablesen: (91) Auf der Grundlage einer ,analytischen Arbeitsbeschreibung des jeweiligen Arbeitsplatzes erfolgt eine Bewertung nach in der Regel 20 Bewertungsinerkmalen (wie z.B. Können, Verantwortung, Lärm, ... ); jedes einzelne Bewertungsmerkmal erhält eine Rangstufe zwischen 0 und 100 Punkten, also z.B. fir Können 10 Punkte und für Lärm 30 Punkte. Da die Bewertungsmerkmale unterschiedlich gewichtet sind, so z.B. Können, in das die Ausbildungskosten eingegangen sind, mehr ,wert" ist als etwa Gesundheitsgefährdung durch einen unerträglichen Lämpegel, haben die einzelnen Bewertungsmerkmale unterschiedliche ,Wichteschlisses: 
Können 1,0

Lärm 0,4

Eine entsprechende Multiplikation für beide hier aufgeführten Bewertungsmerkmale mit diesen Wichteschlïsseln ergibt also:

$\begin{array}{ll}\text { Können } & 10 \times 1,0=10 \text { Teilarbeitswerte } \\ \text { Lärm } & 30 \times 0,4=12 \text { Teilarbeitswerte }\end{array}$

Die Summe der Teilarbeitswerte, der Einfachheit halber durch 10 geteilt, ergibt den Arbeitswert, der dann einer bestimmten Lohngruppe zugeordnet wird.

Auf allen Ebenen dieses Bewertungsprozesses kommt es bezeichnenderweise zu Konflikten zwischen Arbeitern und Kapitalisten: sowohl bei der Rangstufung der Arbeitsplätze nach den einzelnen Bewertungsmerkmalen, als auch bei der Formulierung und Gewichtung der Bewertungsmerkmale sowie schließlich bei der Zuordnung der Arbeitswerte zu einer bestimmten Lohngruppe.

Obwohl z.B. der Monotonie- und Belastungsgrad der Frauen an Montagearbeitsplätzen außerordentlich hoch ist, geht speziell diese Form der ,Belastung der Sinne und Nerven" in die Bestimmung des Gesamtarbeitswerts und damit der Lohngruppe lediglich in einer ganz untergeordneten Form, wenn überhaupt ein. Hat diese Belastung zumal an Akkordarbeitsplätzen einen progressiven Verschleiß und letztlich die Verkürzung der Lebenserwartung dieser Arbeitskräfte zur Folge, so verbleiben gleichwohl auch nach der ach so gerechten AA diese Arbeitsplätze in den untersten Lohngruppen. Hieran zeigt sich also recht deutlich, daß die Arbeitsanforderungen prinzipiell nur soweit von Bedeutung sind, als sie die jeweilige vom Kapital geforderte arbeitsplatzspezifische Qualifikation bzw. entsprechende Arbeitsschwierigkeiten erfassen sollen, dabei nicht aber etwa von den besonderen Formen der Verausgabung von Arbeit, also etwa einer besonderen Intensität der Arbeit ausgehen.

Vielmehr ist mit der arbeitsplatzspezifischen Entlohnung und entsprechend ausgearbeiteten Strategien des ,richtigen Manns am richtigen Arbeitsplatz" die Möglichkeit für den Kapitalisten erleichtert, Umbesetzungen in der Hierarchie der Arbeitsplätze vorzunehmen und so die Konkurrenz unter den Arbeitern anzustacheln. Selbst Überlegungen, nur darin die Leistungsanreizfunktion der AA zu sehen, sind nicht ausgeschlossen. So heißt es in der RKW-Studie: „Die Anreizfunktion für die Arbeiter - sofern sie noch eine Rolle spielt - besteht dabei weitgehend in der Aussicht, den Arbeitsplatz mit diesem ,A rbeitswert' ${ }^{\prime}$ zu behalten, um u.U. früher oder später auf einen Platz mit höherem ,Arbeitswert' aufzusteigen." $(92)$

Die Beschreibung der Anforderungsart "Umgebungseinflüsse" weist in die gleiche Richtung: „Man kann die Umgebungseinflüsse nach ihren Ursachen oder nach ihren Folgen unterscheiden. Die Folgen der Einwirkung von Beanspruchung aller Art, besonders auch von Umgebungseinflüssen (z.B. Schwerhörigkeit aufgrund eines zu hohen Lärmpegels oder die immer häufiger auftretenden Kreislauferkrankungen von Frauen an hochbelastenden Arbeitsplätzen - d.Verf.) können nicht durch die Arbeitsbewertung erfaßt werden. Die Beseitigung oder Verringerung solcher Belastungen ist Aufgabe der Technik, die Behandlung Aufgabe der Medizin, ihre Entgeltung Aufgabe der Sozialversicherungseinrichtungen. " (93)

92) RKW-Projekt, Bd. 6

93) Euler/Stevens, Die Analytische Arbeitsplatzbewertung als Hilfsmittel zur Bestimmung der Arbeitsschwierigkeit, Düsseldorf 1952, S. 10 
Nervliche Belastungen als Ausdruck zerstörerischer Lebensbedingungen des Arbeiters durch die Ökonomie in der Anwendung des konstanten Kapitals gehen so nach der Arbeitsbewertung weitgehend nicht in das Quantum des gezahlten Lohns ein. Auch erhöhte Verschleißquoten etwa an MTM-Arbeitsplätzen sollen nicht gewertet werden.

Der Arbeitswissenschaftler Wibbe gesteht denn auch, selten freimütig den Verfall dieser Sparte der bürgerlichen Wissenschaft beschreibend, daß es auch lediglich um den Schein leistungsgerechter Lohndifferenzierung geht, wenn er schreibt: „Die Bedeutung der Bewertungsmerkmale für das Ergebnis der Arbeitsbewertung ist wissenschaftlich nicht $\mathrm{zu}$ finden und zu begründen,... Das Lohngefüge muß nach Einführung und Anwendung der AA von allen Beteiligten als richtig empfunden und anerkannt werden." (94)

Den gegenwärtigen Zustand hält in naivem Optimismus die RKW-Studie fest, wenn sie schreibt: ,Was den an vielen modernen Arbeitsplätzen auftretenden zunehmenden Anteil an psychischen Beanspruchungen betrifft, so steht hier die Arbeitswissenschaft vielfach noch vor der Aufgabe, fundierte Einsichten und Richtlinien für solche Maßnahmen zu erarbeiten, die zur Vermeidung psychischer Belastung und der durch sie verursach ten Ermüdung führen.“ (95)

Die Vorstellung von der Äquivalenz von Lohn und Leistung bei der AA scheint mit der Entwicklung der Arbeitskämpfe in und seit der Rezession in zunehmendem Maße brüchig zu werden. Waren in der Krise gleichzeitig die Arbeitsmoral verbessert, also die Arbeitshetze gesteigert und die Löhne gekürzt worden, so folgte im Aufschwung eine Steigerung der Intensität der Arbeit, die durch die geringen Lohnerhöhungen trotz zum Teil neu eingeführter analytischer Begrïndung mittels der AA erst recht nicht kompensiert werden konnte. Aber nicht nur die die Zersplitterung der Arbeiter zunächst durchbrechenden Septemberstreiks waren die Konsequenz, sondern es wuchsen - zum Teil mit den Streiks vermittelt - die Auseinandersetzungen um Einführung und Anwendung der AA und ähnlicher Systeme an.

$\mathrm{Zu}$ welchen Schwierigkeiten solidarischen Arbeitskampfes dieses System beiträgt und wie aber der Schein der Gerechtigkeit der Bewertung in diesem System auch von den Interessen der Arbeiter her durchbrochen worden ist, sei an einem u.E. bezeichnenden Beispiel ausgeführt:

Seit August '70 versuchten die Kranführer bei Klöckner in Bremen, den Arbeitsplatzbewertungsschlïssel zu durchbrechen. „Vor allem Kollegen aus dem KW (Kaltwalzwerk - d.Verf.) reichten zur Neueinstufung der Arbeitsplätze immer wieder Lohneinsprüche bei der paritätischen Lohnkommission ein. Alle Lohneinsprüche wurden abgelehnt, da der Lohnrahmen wohl die höhere Qualifikation eines Arbeitsplatzes bewertet, aber keine Mehrbelastung ..."(96) Die Ablehnung war in den letzten Jahren auch von dem als relativ fortschrittlich bekannten Betriebsrat mit dem Argument begründet worden, damit zerstöre man das ganze System (der AA), das man mühsam der Geschäftsleitung abgerungen habe. ,Jeder Kran sollte (deshalb) eine Gruppe höher eingestuft werden (um die Mehrbelastung ein wenig zu

94) Wibbe, Arbeitsbewertung, 1966, S. 58

95) RKW-Projekt, Bd. 6, S. 156

96) Arbeiterpolitik Nr. 5 vom 5.10.72, Bremen, S. 26 
kompensieren - d.Verf.). Das war die Forderung, unter der die unterschiedlichsten Vorstellungen der Kranführer jetzt im Kampf überwunden wurden." (97) Diesmal streikten die Kranführer und die Belegschaft ließ sich auch trotz Aussperrung nicht in einen Gegensatz zu den Kranführem maneuvrieren - so daß dem Unternehmen eine wenn auch recht unterschiedliche Lohnerhöhung abgerungen werden konnte. Doch, ,die Folgen dieser Auseinandersetzung werden erst in ihrem Ausmaß in den nächsten Monaten sichtbar werden, wenn die Kollegen der anderen Abteilungen auf der Basis der Quervergleiche ihre Positionen denen der Kranführer anzugleichen versuchen. Der seit '64 bestehende Lohnrahmen ist gesprengt." (97) Ahnliche Kämpfe haben übrigens in den letzten Jahren auch bei Mannesmann oder bei Daimler-Benz in Stuttgart und Mannheim stattgefunden.

An diesen Auseinandersetzungen, insbesondere der von den Unternehmen jeweils zugestandenen Uberprüfbarkeit der eigentlich als analytisch ausgegebenen Prinzipien dieses Systems wird ganz klar, daß dieses System mehr der jeweilige Ausdruck von Arbeitsmarktsituation einerseits und dem Kräfteverhältnis in den Betrieben andererseits darstellt als es ein gerechtes System ist. Andererseits ist der Kampf um die Entlohnung durch die ungeheuer zersplitterten Entlohnungsstrukturen bedeutend erschwert.

Es ist zu fragen, ob gerade im Zuge der Wahrnehmung des Scheins von Gerechtigkeit in diesem System durch die Arbeiter selbst in den letzten Jahren die Forderung nach gleicher Lohnerhöhung angesichts gleicher Belastungen in der Produktion und gleicher Steigerung der Reproduktionskosten resultiert. $\mathrm{Ob}$ in diesen Forderungen die Wahmehmung der Arbeiter erscheint, sie ständen gleichermaßen im Klassenkampf um die normale Reproduktion und gegen den wachsenden Verschleiß, müßte ebenfalls genauer geklärt werden.

\subsection{Die Prämienlohnformen}

Die RKW-Studie Bd. 6, welche das Verhältnis von technischen und arbeitsorganisatorischen Veränderungen zum Gegenstand hat, stellt bei der Analyse des Obsole twerdens alter und des Aufkommens neuer Lohnformen den Prämienlohn eine Kombination von Zeitlohn und Zusatzprämien - in den Mittelpunkt ihrer Betrachtung. Diese Lohnform wird von den Verfassern der Studie dargestellt als der z.T. fragwürdige und in sich widersprüchliche Versuch der Unternehmer zur Lösung des Problems, daß mit der veränderten Technik die individuelle und quantitativ meßbare Beeinflussung des Arbeitsergebnisses durch den Arbeiter abnimmt oder ganz fortfällt, auf der anderen Seite aber der Arbeiter zur Aufrechterhaltung eines möglichst hohen Leistungsniveau motiviert werden soll. Der Lohn ,soll der vom

97) Ebda.

98) entfällt 
Menschen hergegebenen Leistung entsprechen" (99), seine Form soll den Arbeiter $\mathrm{zu}$ möglichst hoher Leistungshergabe anreizen, wie aber kann ein ,leistungsgerechter Lohn bei ständig sich verwandelnden technischen Bedingungen verwirklicht werden"? (99)

Die mit den technischen Veränderungen der Maschinerie sich verringernden, vom Arbeiter unmittelbar beeinflußbaren Zeiten vermindern die Bedeutung des Akkordlohns oder lassen ihn gar völlig inadäquat werden. Seine entgegen den technischen Bedingungen z.T. auf der Grundlage der VvZ stattfindende Beibehaltung etwa an Fließbändern führt zur völligen Undurchsichtigkeit der Lohnfestsetzung für den Arbeiter. (100) Wo der Arbeiter gar selbst neben den eigentlichen Produktionsprozeß tritt und nur noch Überwachungs-, Beschickungs- und Kontrolltätigkeiten gegenüber der Maschinerie wahrnimmt - und dies ist oft der Fall -, ist das Produktionsergebnis in einer Weise durch den gesellschaftlichen Charakter des Produktionsprozesses vermittelt, daß es auch seiner stofflichen Gestalt nach nicht mehr als Ergebnis eines individuellen Arbeitsprozesses identifiziert werden kann. Andererseits soll der Arbeiter als Privatindividuum das Quantum seiner Teilhabe am gesellschaftlichen Reichtum in der Geldform, also in Höhe des Lohns, als Äquivalent seiner individuell und von seiner individuellen Arbeitsanstrengung abhängigen Arbeitsleistung begreifen. Im Verhältnis zwischen Kapital und Arbeiter ist dabei eingeschlossen, daß den Arbeiter eben nichts zu interessieren hat als die Höhe seines Lohns als Ergebnis solch individuellen Verkaufs seiner Ware Arbeit. Die Produktionsmittel, sowohl Arbeitsmittel als auch Arbeitsgegenstände gehören dem Kapitalisten. Und nicht der Arbeiter, dem die Produktionsmittel als feindliche Potenz gegenüberstehen, sondern der Kapitalist ist am möglichst ökonomischen Umgang mit ihnen interessiert. Gerade auf diesen möglichst ökonomischen Umgang muß es aber dem Kapitalisten beim wachsenden Umfang der im Produktionsprozeß angewandten Arbeitsmittel und Arbeitsgegenstände ankommen.

Solange das Arbeitsergebnis noch als Ergebnis eines individuellen Arbeitsprozesses identifiziert werden kann, gelingt es dem Kapitalisten, dem Arbeiter über dessen Privatinteresse an einem möglichst hohen Lohn das Interesse des Kapitals an möglichst intensiver Arbeitsverausgabung und sorgfältiger Arbeitsausführung (schlechte Stücke werden nicht bezahlt) aufzuzwingen. „Den Stücklohn gegeben, ist es natürlich das persönliche Interesse des Arbeiters, seine Arbeitskraft möglichst intensiv anzuspannen." (101) Je mehr jedoch die Macht der Agentien anwächst, welche als entwickelte Maschinerie zwischen den Arbeiter und das Produkt seiner Arbeit treten, je mehr die Rolle der unmittelbar im Produktionsprozeß vom einzelnen Arbeiter aufgewandten Arbeit für das schließliche Endprodukt zuriicktritt und an ihrer Stelle die in der Maschinerie vergegenständlichte gesellschaftliche Arbeit den unmittelbaren Produktionsprozeß beherrscht, je dringender wird für den Kapitalisten die Notwendigkeit, dem Arbeiter vor allem das Privatinteresse des Kapitals an einer möglichst ökonomischen Vernutzung der vom Kapitalisten für den gesamten Produktionsprozeß gekauften Waren als sein individuelles Privatinteresse aufzuzwingen. Betrachten wir die verschiedenen Formen des Prämienlohns, so läßt

99) RKW-Projekt, Bd. 6, a.a.O., S. 133

100) Ebda., vgl. S. 147

101) MEW 23, S. 577 
sich zeigen, daß sie den Versuch einer Antwort des Kapitals auf die angedeuteten Probleme und Widersprüche seines eigenen Produktionsprozesses bilden.

Prämien werden für den ökonomischen Umgang mit dem vom Kapitalisten angewandten konstanten Kapital gezahlt. Im Kapitel über den Arbeits- und Verwertungsprozeß im 1. Bd. des Kapital heißt es: „,Der Kapitalist paßt auf, daß die Arbeit ordentlich vonstatten geht und die Produktionsmittel zweckmäßig verwandt werden, also kein Rohmaterial vergeudet und das Arbeitsinstrument geschont, d.h. nur soweit zerstört wird, als sein Gebrauch in der Arbeit ernötigt." (102) An diesen Aufgaben des Kapitalisten soll nun der Arbeiter selbst interessiert werden.

$\mathrm{Zu}$ diesem $\mathrm{Zweck}$ sind verschiedene Formen von Prämien entwickelt worden: die Quantitätsprämie hat die Steigerung des quantitativen Produktionsergebnisses zum Ziel. Bezugsbasis ist die höhere Mengenleistung aufgrund der Sicherung maschineller oder technischer Laufgeschwindigkeiten zur optimalen Mengenausbringung durch die Arbeiter. Die Qualitätsprämie soll dem Arbeiter ein Interesse daran vermitteln, für eine optimale Qualität des Produktes durch die Art der Fertigung und für geringen Ausschuß zu sorgen. Bei der Ersparnisprämie geht es um die sparsame Verwendung von Roh- und Hilfsstoffen, Halbfertigwaren, z.B. geringen Verbrauch von Schrauben, Farbstoffen, Strom usw. . Die Nutzungsprämie zielt auf die optimale Nutzung der Betriebsmittel, also auf eine hohe Kapazitätsauslastung, und erhält mit dem Ansteigen des Anteils von Fixkapital immer größere Bedeutung. In dieser Prämie ist die Verminderung, unproduktiver' Wartezeiten, Maschinenstillstandszeiten oder Wartungszeiten eingeschlossen. Sie will einen möglichst reibungslosen Produktionsablauf zum Interesse des Arbeiters machen.

$\mathrm{Zu}$ diesen Prämienformen führt der bürgerliche Ökonom Wiesner aus: „Sie (können) verschiedene Anreizfaktoren wie Quantität, Qualität, Einsatz und Verbrauch von Material oder die Nutzung der gesamten maschinellen oder technischen Anlagen als kombinierte Form enthalten. .. Steigerung des Verdienstes der Arbeitnehmer folgt durch höhere Leistung innerhalb der normalen Arbeitszeit, wobei der Mehrverdienst für den Betrieb nicht eine Lohnkostenbelastung, sondern -entlastung ist. . . Höhere Auslastung der Betriebsmittel und der Arbeitskräfte innerhalb der normalen Arbeitszeit ist das eindeutige Ziel mit einem positiven Kostenergebnis für den Betrieb. " (103) Der Versuch, dem Arbeiter die Kostenökonomie des Kapitals als sein eigenes Interesse aufzuzwingen geht hin bis zur Form der sogenannten Lohnkostenprämie (wie sie z.B. bei Dyckerhoff Zementwerke A.G. Wiesbaden angewandt wird). Ziel dieser Prämie ist, die Lohnabhängigen selbst an einer Standardisierung des Personalaufwandes je Produktionseinheit sowie der Senkung von Lohnkostenanteilen, die als nicht dringend angesehen werden, $\mathrm{zu}$ interessieren. Konkret sieht das so aus, daß in der Mehrzahl aller Fälle diejenigen, die - wenn auch kurz in einem Monat krank warell, ihrer Prämie verlustig gehen, unabhängig davon, wie lange die Krankheit dauerte.

Fassen wir zusammen: Mit den Zusatzprämien hat der Kapitalist ein flexibles Instrument in der Hand, welches auf der einen Seite den Arbeiter bzw. eine Gruppe

102) MEW 23, S. 299/300

103) Wiesner, Produktionsprämie, S. 225f.

104) entfällt

105) entfällt

106) entfällt 
von Arbeitern zur Verausgabung eines möglichst hohen Arbeitsquantums entsprechend der besonderen stofflichen Gestalt des Arbeitsprozesses initiiert, zum anderen aber jederzeit Lohnsenkungen und erhöhungen je nach der Knappheit oder dem Überschuß von Arbeitskräften bzw. bestimmter Schichten der Arbeiter ermöglicht. Höhe, Art und Form der Prämien sind je nach Betrieb und je nach den betrieblichen Besonderheiten des Arbeitsprozesses verschieden. Demgemäß ist es auch gar nicht möglich, alle Formen, die in den einzelnen Betrieben entwickelt wurden, hier aufzuführen; ganz abgesehen davon, daß ihre wirkliche Erfassung noch umfassender empirischer Studien in den einzelnen Betrieben bedürfte. Stellt so zum einen die Veränderung im Verhältnis von lebendiger Arbeit und Maschinerie sowie die relative Ausdehnung solcher Bereiche der Lohnarbeit welche traditionell nicht der Leistungsentlohnung unterworfen waren (z.B. Angestellte) den Kapitalisten unterm Zwang der Kapitalverwertung vor das Problem, neue Formen der Abpressung von Arbeitsleistung zu entwickeln, so schließt dieser Prozeß für das Kapital auf der anderen Seite zunächst den außerordentlichen Vorteil ein, sich dem gewerkschaftlichen, tarifvertraglich - also gesetzlich - abgesicherten System der Lohnfestsetzung zu entziehen. Der tatsächlich gezahlte Lohn wird auf Betriebsebene festgelegt und verliert damit seine gesetzliche Sanktionierung d.h. Absicherung durch den Tarifvertrag. Welche Probleme sich daraus für die gewerkschaftliche Politik ergeben und wie die Gewerkschaften historisch auf dieses Problem Antworten gesucht haben, darauf soll noch im letzten Teil des Aufsatzes eingegangen werden.

Wir hatten zu Anfang der Darstellung der Prämienlohnformen erwähnt, daß die Verfasser der RKW Studie Bd. 6 den Prämienlohn selbst als eine prekäre Form der Ablösung des Akkordlohns bezeichnen. In den Betrieben, in denen technische Umwälzungen stattgefunden haben, registrieren sie zwar eine rückläufige Tendenz des reinen Akkordlohns, stellen aber auch immer wieder formales Festhalten an Akkordlohnformen, insbesondere am Gruppenakkord fest, auch wenn dieser dem Charakter des Arbeitsprozesses nicht mehr entspricht. Als Grund geben sie die Schwierigkeit an, den „Betroffenen die Angemessenheit der für ihre Tätigkeit zur Anwendung kommenden Form des Prämienlohns einsichtig zu machen." (107) An anderer Stelle heben sie hervor, daß die Kriterien für die Prämienvergabe und deren Höhe „unscharf" seien, daß die Prämien selbst die Gefahr in sich bergen, als „Scheinprämien lediglich eine versteckte Lohnerhöhung herbeizuführen," (108) was wohl nichts anderes heißt, als daß sie vom Kapital auch als Mittel der Konkurrenz um die besten Arbeitskräfte eingesetzt werden oder als Befriedigungs- bzw. Disziplinierungsmittel. Statt der Prämien schlagen die Autoren der Studie vor, den Lohn aufgrund der Beschreibung der Anforderungen des Arbeitsplatzes zu bestimmen und als Leistungsanreiz den Aufstieg einzelner Arbeiter auf bessere Arbeitsplätze bei besonders hoher Verausgabung von Arbeitsleistung durch den einzelnen Arbeiter in Aussicht stellen. Ihnen schwebt also eine aufgrund analytischer Arbeitsplatzbewertung hergestellte hochdifferenzierte Hierarchie der Arbeitsplätze als Hebel der Arbeitsauspressung vermittelt über die Konkurrenz unter den Arbeitern um die besten Arbeitsplätze vor. Dabei reflektieren sie selbst wieder nicht die Schwierig-

107) RKW-Projekt, Bd.6, S. 582

108) Ebda., S. 149 
keiten, mit Hilfe der Arbeitsplatzbewertung das „Empfinden eines leistungsgerechten Lohns" zu erzeugen, die sie andererseits andeuten, wenn sie auf die Uneinheitlichkeit der angewandten Systeme analytischer Arbeitsplatzbewertung hinweisen sowie die Auseinandersetzungen um die Gewichtung bestimmter Anforderungen des Arbeitsplatzes. (109)

In welchem Maße das neben der Auspressung von Mehrarbeit durch die Form der Entlohnung vom Kapital angestrebte Ziel, das „Empfinden“ der LohnLeistungsäquivalenz zu erzeugen, verfehlt wird, zeigt das Ergebnis einer Befragung, welche Kern/Schumann im 9. Bd. der RKW-Studien, „Der soziale Prozeß bei technischen Umstellungen," anführen. (110) Dort heißt es: „Die Konsequenzen dieser Umstellung der Arbeitsleistung für das Verhältnis von Leistung und Lohn wurden freilich unterschiedlich eingeschätzt: 33\% der Befragten sprechen von einer Verbesserung, nahezu ebensoviele (30\%) von einer Verschlechterung der Relation." $30 \%$ der Arbeiter gehen demnach davon aus, daß im Vergleich zu ihrer früheren Leistung der Lohn für ihre jetzige Leistung schlechter ist, 33\% gehen davon aus, daß er relativ besser ist, was nichts anderes als die völlige Verunsicherung des Prinzips der Lohn-Leistungsäquivalenz in ihrer Befriedungs- und Anreizfunktion besagt. Mit den differenzierten Methoden der Zahlung des Arbeitslohns ist es dem Kapital demnach nicht gelungen, eine in seinem Sinne befriedigende Lösung des Problems der Verunsicherung des Empfindens der Lohn-Leistungsäquivalenz angesichts technischer Veränderungen und im Zuge von Versuchen zur Intensifikation der Arbeit zu finden. Schließen nun die differenzierteren Formen der Lohnzahlung insgesamt zunächst eine weitere Zërsplitterung und Konkurrenz unter den Lohnabhängigen ein, was besonders für solche Schichten gilt, welchen ihrer Tradition nach der Arbeitskampf unbekannt ist (Angestellte) (111), so stellt sich doch die Frage, ob nicht aufgrund des sich verändernden Verhältnisses zwischen lebendiger Arbeit und Maschinerie die wirkliche Grundlage der individuellen Leistungsentlohnung soweit ins Wanken gerät, daß die neuen Lohnformen nur brüchige und in sich selbst widersprüchliche Formen darstellen, das Prinzip der individuellen Lohn-Leistungsäquivalenz als Prinzip der Lohnfestsetzung aufrechtzuerhalten. Genauere Untersuchungen müßten sich demnach darauf richten, herauszufinden, in welchen Formen sich der Widerspruch niederschlägt zwischen dem Versuch des Kapitals, durch Beibehaltung oder gar Neueinführung des allgemeinen Prinzips des individuellen Leistungslohns die Auspressung von Mehrarbeit, vermittelt u.a. über die verschärfte Konkurrenz und Zersplitterung der Lohnabhängigen untereinander $\mathrm{zu}$ bewerkstelligen, und dem tatsächlichen entwickelten Stand des gesellschaftlichen Arbeitsprozesses. Schon entwickelte Formen des Widerstands der Arbeiter müßten auf diesen Widerspruch hin untersucht werden.

109) Vgl. ebda., S. 136ff.

110) erschienen in Frankfurt/Main, 1972, S. 65

111) Mit Ausnahme der Angehörigen dieser Schicht, welche aus der Schicht der Produktionsarbeiter aufgestiegen sind und übrigens auch den Kern gewerkschaftlich organisierter Angestellter innerhalb der Industriegewerkschaften bildet. 


\section{Kontraktlohnformen}

Immer wichtiger werden verschiedene Formen des Kontraktlohns, die dazu bestimmt sind, vom Arbeiter oder der Arbeitsgruppe ein bestimmtes Arbeitsprogramm in einem kontraktlich festgelegten (meist gegenüber dem traditionellen Stiickakkord) größeren Zeitraum zu verlangen und die Lohnhöhe von der Ableistung des vertraglich bestimmten Pensums abhängig zu machen (wie z.B. im sog. Pensumlohn, den verschiedenen Arten des Kontraktlohns oder dem im Schiffsbau verwandten Programm-Prämienlohn).

Mit diesen Lohnarten soll die Erhöhung der Intensität über die Zusicherung eines konstanten Verdienstes in einem bestimmten Zeitraum erreicht werden. Es wird eine Mehrleistung, etwa 30\% mehr als im Akkordrichtsatz festgelegt ist, vertraglich vereinbart, damit zum Programm erhoben und dessen Realisierung der persönlichen, individuellen Leistungsfähigkeit des Einzelnen oder der Gruppe auferlegt. Der über den Akkord noch mögliche Spielraum, ,mal ganz auf die Süß̉ ${ }^{\text {"6 }}$ arbeiten zu können, also das Tempo zumindest zu variieren, ist auf Gefahr des Verlustes der Höhe des gesamten bisherigen Kontraktlohns zerstört. Der Arbeiter bzw. die Gruppe ist dabei weit mehr als beim Akkord bis ins einzelne ,,verantwortlich" für das jeweils vereinbarte Pensum. Das Interesse des Kapitals an einer kontinuierlichen Mehrleistung soll zum Interesse des Arbeiters gemacht werden.

Über den Anreiz, sich den Kontrakt und die entsprechende Lohnhöhe zu erhalten, wird der Einzelne dazu veranlaßt, nicht nur sich selbst gegenüber, sondern auch auf die Arbeitsgruppe Druck auszuüben. Damit wird die Gesellschaftlichkeit des Arbeitsprozesses selbst vom Kapital ausgebeutet, die Formen der Kooperation der Arbeiter untereinander zugunsten eines optimalen Leistungsergebnisses forciert.

Kollektive Prämien führen also zur Disziplinierung einzelner Arbeiter durch das Kollektiv. Damit wird aber Kollektivität und Solidarität diskreditiert, muß doch dem Einzelnen durch eine derart verkehrte Solidarität diese unglaubwürdig werden. Die Folge ist eine Verstärkung der Konkurrenz und Spaltung der Arbeiter.

Die häufig auf der Basis vorbestimmter Zeiten festgelegten Kontraktlohnarten verhindern gegenüber dem traditionellen Zeitakkord Leistungsschwankungen, da sich der einzelne Arbeiter bzw. die Arbeitsgruppe innerhalb einer größeren Zeiteinheit, etwa von einem Monat, verpflichtet haben und ggf. entstehende Produktionshemmnisse aus eigenem Interesse beseitigen müssen. Damit können z.B. in technisch komplizierten Produktionsformen die Arbeiter auf ihre selbst eingegangenen Verpflichtungen verwiesen werden, was die Kontrolle untereinander einschließt.

Das ermöglicht für das Kapital erstens die im Zuge verschärfter Kostenkalkulation notwendig werdende exakte Produktionsplanung und -abstimmung der einzelnen Produktionsabschnitte auf bestimmte Termine hin und zweitens die Verpflichtung der Arbeiter auf die Konstanz einer hohen Leistung, so daß beim Akkord möglich gewesene Spielräume, die Intensität der Arbeit zu variieren, reduziert sind, sowie drittens die Begrenzung der Lohnerhöhung auf die maximal mögliche Prämie von meistens nicht mehr als $30 \%$ des jeweiligen Grundlohns, so daß ein ,unkontrollierbares ${ }^{66}$ betriebliches oder überbetriebliches Aufschaukeln von (Akkord)löhnen (eine sog. innerbetriebliche Lohn-Lohn-Drift) abgewehrt werden kann. Gerade in konjunkturellen Aufschwungphasen wie '69 erreichten die Arbeiter häufig angesichts besserer Arbeitsmarktbedingungen (Verschwinden der fließenden Form der Reservearmee) mit dem Argument höhere Löhne, an der jedem offensichtlich gewordenen Steigerung der Produktivkraft der Arbeit auch teilzuhaben. 
Kombiniert mit den oben angegebenen Prämienlohnformen werden Zulagen vergeben, die an verschiedene Arten der Vorgesetztenbeurteilung gebunden sind. Kam es aufgrund dieser sog. Nasenprämien häufig zu Auseinandersetzungen mit den Agenten des Kapitals, so versuchen die neueren Verfahren persönlicher Leistungsbewertung diesen $\mathrm{zu}$ entgehen durch alle möglichen Formen der Systematisierung und Katalogisierung von Leistungskriterien ausgesprochen normativen Charakters. Mit ihnen werden nicht „objektiv“ meßbare Größen des Produktionsprozesses, sondern „Fähigkeiten“ wie Einsatzbereitschaft, Zuverlässigkeit, Pünktlichkeit, Unterwürfigkeit, Betriebstreue oder unternehmerisches Denken bewertet; sie hängen im wesentlichen von der Identifikation mit dem Unternehmer, also mit dem Grad der bewußtseins- und verhaltensmäßigen Anpassung an das Kapitalinteresse ab.

Sondernummer 4

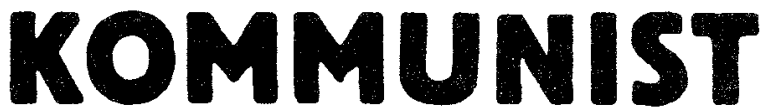

THEORETISCHES ORGAN KOMMUNISTISCHER BUND WESTBERLIN

A UFLÖSUNG UND

LER NPROZESSE EINES

ML - Z I R K E LS

Politische Erklärung von Genossen des ehemaligen $\mathrm{KB} / \mathrm{ML}$

Ca. 56 Seiten, DM 1,80, erscheint Ende Januar '73.

Vertrieb an den Buchhandel und Einzelversand:

POLITLADEN ERLANGEN 852 Erlangen, Wemer von SiemensStr.8 T 24850 
Die neueren Entlohnungsformen erhalten im Zusammenhang mit der erfolgten bzw. erfolgenden technologischen Umwälzung des Produktionsprozesses die Funktion, die durch die technischen Veränderungen noch nicht (kostenoptimal) intensivierten Arbeitsvollzüge durch finanzielle Anreize möglichst vollständig zu erfassen und damit die Intensifikation der Arbeit weiter yoranzutreiben. Es geht uns daher nun um die Skizzierung einiger für die Intensifikation der Arbeit auf Basis technologischer Umwälzung typische Entwicklungen. Daß sich ähnliche Tendenzen im Angestelltenbereich ergeben und (gerade in den letzten Jahren) dort die Rationa lisierungsbemühungen forciert werden und zur Einführung entsprechender (Arbeits)Bewertungssysteme gefuhrt haben, sei hier nur angemerkt. Generell sollen aber an dieser Stelle die bisherigen Aussagen insoweit relativiert werden, als die Einfuihrung neuerer Entlohnungsmethoden, wie sie im letzten Abschnitt in ihren Funktionen entwickelt wurden, nicht unmittelbares Resultat der technologischen Umwäzung des Froduktionsprozesses sind. Die hier feststellbare zeit liche Verzögerung gilt allgew mein für die, Arbeitsorganisation ${ }^{65}$ im Betrieb, die zunächst in nicht nennenswertem Maße von den technischen Veränderungen tangiert wurde: ,Dies ist darauf zurückzurîhren, daß bei den Umstellungen zunächst technische Probleme im Vordergrund gestanden haben. Erst später wird die Notwendigkeit einer Organisationsveränderung erkannt und bis zur Verwirklichung vergeht nochmals eine längere Zeitspanne." (112) Diese Verzögerungen sind laut Koch u.a. (im RKW-Forschungsprojekt Bd. 6) in ihren Ursachen,, teils . . rein organisatorischer Natur, teils sind sie auch darin begründet, dałs der Mensch als Träger der Organisation oft nur schwer zur Abgabe von altgewohnten Aufgaben und zur Ubemahme neuer Verantwortungsbereiche zu bewegen ist." ${ }^{6}$ (113)

Als weiteres wichtiges Moment sind in diesem Zusammenhang sicherlich die ökonomischen Erwägungen der Kapitalisten zu erwähnen (die aber Koch u.a. prinzi-

112) RKW-Projekt, Bd. 6, S. 26

113) a.a.O., S. 42 
piell verschlossen bleiben müssen, da sie nur den einfachen Arbeitsprozeß untersuchen (114)). Diese allgemeine Tendenz läßt sich am Beispiel der neueren Entlohnungsformen konkretisieren. Deren Einführung wird dabei nicht nur durch den jeweilig erreichten technisch-organisatorischen Entwicklungsstand begrenzt, sondern dariberhinaus unmittelbar durch, rechtliche Bindungen sowie die Regelungen innerhalb des Tarifvertrages, ferner $z$.B. die Tradition des Betriebes oder die in der Branche vorherrschende Lohnform. ${ }^{6}$ (115) So ist es zu erklären, daß, grundlegende Auswirkungen der technischen Anderungen auf die Methoden der Lohnfindung und damit möglicherweise auf die Lohnstruktur ${ }^{66}$ sich in den (untersuchten) Betrieben, relativ selten und zumeist nur über einen längeren Zeitraum (zeigten)." (116) Ist die Durchsetzung der (neueren) Lohnfomen also nicht unmittelbares Resultat technologischer Veränderungen und wird ihre Einführung (nicht zuletzt auch durch den Widerstand der Arbeiter und der Gewerkschaften) verzögert, so führten allerdings diese technischen Umstellungen in den Betrieben „,häufiger zu einer Ånderung in der Einstufung bzw. Bewertung von Arbeitsplätzen。 ${ }^{6}$ (117) In diesen Fällen sind die technologischen Veränderungen schon unmittelbar mit Veränderungen im Reproduktionsniveau der Arbeiter verknüpft (in den untersuchten Betrieben kam eine solche Neueinstufung in der Mehrzahl der Fälle keiner (absoluten) Lohnsenkung gleich, was allerdings nichts iber eine Tendenz aussagt, da der Zeitpunkt der Untersuchung nicht bekannt ist). Fir einen längeren Zeitraum kann dariberhinaus an der oben behaupteten Tendenz festgehalten werden, daß die herkömmlichen Nethoden der Leistungsentiohnung an Gültigkeit verlieren, während mit der technischen Entwicklung (auf Basis der ökonomischen!) die Anwendung der neueren Entlohnungsmethoden begünstigt wird, die ,die Aufrechterhaltung eines im betrieblichen Sinne optimalen Leistungsniveaus zum Ziele haben." (118) Dies gilt umso mehr, als die hier benutzte RKW-Studie sich auf den Zeitraum 1963-1968 bezieht, die gerade über die Krise vermittelte technologische Unwälzung der Produktion (wie oben entwickelt, vgl. Fußnote 36!) nur noch bedingt in die Untersuchung einbeziehen konnte und schon gar nicht die auf dieser Basis verzögert einsetzenden Veränderungen in der Arbeitsorganisation der Betriebe.(119)

114) Vgl. die Kritik bei S. Herkommer, Vom Elend der Industriesoziologie, in: SOPO 16/1972 (der sich insbes auf die später zitierte $\mathrm{Kern} / \mathrm{Schumann-Studie} \mathrm{bezieht)}$

115) RKW.Projekt, Bd.6, a.a.0., \$. 146

116) a.a.0., S. 152

117) a.a.0., S. 203

118) a.0., S. 209

119) Dies soll am Beispiel der Eintihrung der Computertechnik verdeuticht werden: Nach der RKW-Studic, Bd. 6, a.a.O., ergaben sich besonơers einschneidende Anderungen in der Arbeitsorganisation dann, wenn der betreffende Betrieb die Elektronische Datenver arbeitung einfiihrte. Nach dem Sachverständigenratsgutachten (1969) ist es aber gerade für die Zeit nach der Krise 1966/1967 charakteristisch, daf , viele neue arbeitssparende Techniken und Verfahren entwickelt und zur Produktionsteife gebracht worden sind (wie zum Beispiel der Einsatz von Computem bei der Planung, Steuerung und Kontrolle des Produktionsprozesses), die sich in der Auf̂schwungphase dieses Zyklus erstmals vol auf die Kapitalproduktivitüt ausgewiokt haben." Vgl. RKW-Projekt, Bd. 6, S. 202 and SVG 1969, Ziff. 54. Allein dieser Sachvertalt läft vermuten, das die von uns aufgezeigue Tendenz erst im Auschwung $1968 / 69$ sich voll durchzusetzen beginnt, ein Zeitiaum also, der von den RKW-Studien gar nicht mehr erfaßt werden konnte. 


\subsection{Zur Fließbandarbeit und ihrer Intensifikation}

Mit der Fließbandarbeit als Mittel der Kapitalverwertung ist die Unterordnung des Arbeiters unter die Maschine handgreifliche Wirklichkeit; das Diktat der Maschine entscheidet über die Intensität der Verausgabung von Hirn, Muskel und Nerv; in immer entwickelterer Arbeitsteilung der ohnehin schon reduzierten Detailoperationen wird der Arbeiter zu einer vergegenständlichten Funktion im kapitalistisch organisierten Maschinensystem. Der Arbeitsprozeß ist in kleinste Einheiten zerstückelt, die in ermüdender Monotonie und unter extremer Belastung oft tausendfach täglich wiederholt werden müssen (repetitive Teilarbeit). Je ausgeprägter die Arbeitsteilung, desto einfacher die Operation, desto schneller ihre Abfolge, desto eingeübter die Bewegungen - und desto mehr können Stillstands-, „unproduktive Wartezeiten ", Störungsquellen ausgeschaltet werden: „Die Arbeit am Band ist bestimmt vom sogenannten Takt des Bandes. Alle 45 Sek. muß z.B. ein Arbeiter einen neuen Wagen an einem PKW-Montageband übernehmen und dort den Stoßdämpfer an die Hinterachse festschrauben: Schraubenschlüssel auf die erste Mutter setzen - anziehen - auf die zweite Mutter setzen - wieder anziehen ... auf die letzte Mutter setzen und wieder anziehen - abstoßen und zur Ausgangsstellung zurückfahren. Jetzt sind etwa 40 Sek. vergangen und der Arbeiter hat etwa 5 Sek. Zeit bis zur Ưbernahme des nächsten Wagens. Bei diesem wiederholt sich der Vorgang: Schraubenschlüssel auf die erste Mutter setzen - anziehen usw. Das ist das typische der repetitiven Teilarbeit: in kurzen Zeitabständen - in unserem Beispiel alle 45 Sek., also 80 mal in der Stunde - immer wieder die gleiche Arbeit ausführen, nur diese und immer diese ... ${ }^{66}(120)$ Die wissenschaftliche Organisation dieser Teilarbeit, von Taylor entwickelt, findet sich heute in der Arbeitswissenschaft ausgestaltet. Als kurze Anlerntätigkeit wird sie heute häufig von jungen Frauen und ausländischen Arbeitskräften (meist jungen) ausgeübt. „Das Tempo ist entscheidend. Wir haben schon versucht, ältere Kollegen an den Arbeitsplatz zu stellen, sie kamen mit dem Tempo eben nicht mit." (121) Man hat lediglich zu hoher Monotonieunempfindlichkeit und hoher Fingerfertigkeit ,befähigt" zu sein. Die Arbeit ist körperlich einseitig, verbunden mit durch Tempo und Monotonie entstehenden hohen nervlichen Belastungen. Es sind häufig Montagetätigkeiten, die in der Elektroindustrie z.B., im Fahrzeugbau, in der Verpackungsindustrie und in der Textilindustrie veeitverbreitet sind. Durch technische Veränderungen erhalten diese Formen der Arbeitabpressung einen zum Teil noch höheren Belastungsgrad. In einer Reihe von relativ typischen Umstellungsfällen wird zwar ein Teil der bisherigen Bandarbeitertätigkeiten auf maschinelle Anlagen übertragen, die verbleibenden Tätigkeiten sind dann aber noch einseitiger und wiederholen sich in noch kürzerer Taktfolge. (122) Vereinzelt wurde beobachtet, daß die Verkürzung der Taktzeit die Muskelbelastung insgesamt ansteigen ließ und mitunter zu einseitigen Belastungen führte; die weitere Arbeitsteilung führte zu noch stärkerer Dequalifizierung, die zur Ausübung erforderlichen Kenntnisse werden durch kurze Zweckanlernung er-

120) Bahrdt, H.P., Osterland, M., Schumann, M., Zwischen Drehbank und Computer, Hamburg 1970, S. 24

121) zit. ebd., S. 33

122) RKW-Projekt, Bd.6,a.a.O., S. 19 
worben. Der verkleinerte Einfluß und Beachtungsbereich erfordert weniger Nachdenken, Aufmerksamkeit und Verantwortung. Durch die ,wissenschaftliche Analyse" der Ermittlung der Arbeitsnormen über die Verfahren vorbestimmter Zeiten wird die Fließbandarbeit kostenoptimal organisiert. Trotz der Zunahme der unbeeinflußbaren Zeiten in diesen Tätigkeiten werden sie weitgehend im Akkord gelassen, da dies als das beste finanzielle Anreizverfahren erscheint. Allerdings dient hier der Akkord lediglich als flankierende Intensifikationsmaßnahme, da die Intensifikation weitgehend ohnehin durch die Maschine diktiert wird (deren Geschwindigkeit natürlich vom Kapitalisten bzw. seiner Agenten bestimmt wird!).

\subsection{Zu Kontrolltätigkeiten mit einfacher Qualifikation}

Die Automatenkontrolle stellt eine technisch fortgeschrittenere Form der totalen Unterordnung unter die Maschine als Kapital dar. Die Erweiterung des Arbeitsfeldes, nämlich die Kontrolle und Bedienung mehrerer Maschinen ist so scharf genormt, daß eine hohe Arbeitsgeschwindigkeit notwendig wird, um die jeweiligen Eingriffe bei Maschinenstörungen vornehmen bzw. ausüben zu können. Ähnlich wie bei dessen Geschwindigkeit, diktiert hier die jeweilige Störform der Maschine das Arbeitstempo; hohe nervliche Belastungen entstehen dadurch, daß solche Störungen nicht kalkulierbar sind und sogar oft gehäuft auftre ten können. In einer teilautomatischen Weberei etwa hat ein Arbeiter zwischen 20 und 45 Webstïhle zu betreuen (Mehrstellenarbeit); die Aufgabe der überwachenden Arbeiter liegt in der Früherkennung möglicher Fehlerquellen und Qualifikationsmängel der Maschinen sowie in der Beseitigung von Maschinenstillständen. ,Der Weber versucht diese Aufgabe durch optische und manuelle Kontrollen am Produkt gerecht $\mathrm{zu}$ werden. Er ist überdies bestrebt, vorbeugende Kontrollen durchzuführen, um break downs nach Möglichkeit gar nicht erst aufkommen zu lassen." (123) Aufgrund der großen Maschinenzahl sind meist einige Maschinen zugleich gestört, die die Arbeiter möglichst schnell wieder in Gang setzen müssen, um eine kontinuierliche Produktion zu gewährleisten; sonst geraten sie in einen Teufelskreis, nur noch die ausgefallenen Maschinen zu behandeln und die vorbeugenden Kontrollen vernachlässigen zu müssen und potenzieren damit die Störungen. Solche Arbeitsformen finden sich auch in metall- und kunststoffverarbeitenden Betrieben und in Stickereien. Wie bei der Bandarbeit sind auch bei diesen Tätigkeiten geringe Qualifikationen, kurze Anlernzeiten, hohe Fingerfertigkeiten und vor allem nervliche Belastbarkeit (angesichts des unregelmäßigen Arbeitsrhythmus) nötig.

Die RKW-Studie Bd. 6 erklärt dies als Folge technisch bedingter Veränderungen: „Nicht immer haben technisch modernere Anlagen die Arbeitsbedingungen verbessert. Die körperliche Schwerarbeit ist zwar in den meisten untersuchten Betrieben zurückgegangen, die psychischen Anforderungen sind jedoch erheb-

123) Kern, H., Schumann, M., Industriearbeit und Arbeiterbewußtsein, RKW-Forschungsprojekt, Bd. 8, Ffm 1970, S. 119 (in der Folge: K/S-Studie) 
lich gestiegen und haben vereinzelt die Grenzen der menschlichen Leistungsfähigkeit erreicht." (124) Entgegen den Annahmen der Verfasser ist es aber nicht die neue Maschinerie, sondern ihre kapitalistische Anwendung, die die Arbeiter zur Verausgabung ihrer letzten Reserven zwingt, mehr Arbeit, in derselben Zeit zu erpressen. Es geschieht dies in doppelter Weise: durch erhöhte Geschwindigkeit und erweiterten Umfang der von demselben Arbeiter zu überwachenden Maschinerie oder seines Arbeitsfeldes. ${ }^{6}$ (125)

Den technischen Veränderungen laufen Dequalifizierungsprozesse traditioneller Facharbeiter parallel, z.B. bei der Umstellung von Walzanlagen. Lassen sich diese Facharbeiter nicht umschulen, so wird ihre Arbeit ,abgewertet. (Was im Resultat der Senkung des Preises der Arbeitskraft entspricht). Bittel der ,Abwertung des Arbeiters resp. seiner Arbeit ist die oben beschriebene analytische Arbeitsplatzbewertung. Gehören die ehemaligen Facharbeiter zugleich zu denen uber 45 Jahren so sind sie häufig für die an den neuen Anlagen erforderte außerordentiche Intensität der Arbeit nicht mehr geeignet; sie müssen im Zeitlohn entgoltene Reinigungs-, Schreib- bzw. andere unter ihrem Qualifikationsniveau liegende Arbeiten durchfihren. (126)

Die über die Umwälzung der technologischen Basis der Produktion vermittelten Freisetzungen fühten zwar infolge noch prosperierender Kapitalakkumulation in anderen Bereichen bzw. Branchen nur zur,, fließenden Form ${ }^{66}$ der Überbevölkerung, das heißr, die freigesetzten Arbeiter konnten von anderen Kapitalen wieder absorbiert werden; ein Prozeß, der bei Marx wie folgt beschrieben ist: "Wachstum in der Anzahl der Fabrikarbeiter ist also bedingt durch proportional viel rascheres Wachstum des in den Fabriken angelegten Gesamtkapitalls. Dieser Prozeß vollzieht sich aber nur innerhalb der Ebbe- und Flutperioden des industriellen Zyklus. Er wird zudem stets unterbrochen durch den technischen Fortschritt, der Atbeiter als virtuell ersetz $t$, bald faktisch verdrängt. Dieser qualitative Wechsel im Maschinenbetrieb entfemt beständig Arbeiter aus der Fabrik oder verschließt ihr Tor den neuen Rekrutenstrom, während die bloß quantitative Ausdehnung der Fabriken neben den Herausgeworfenen frische Kontingente verschlingt. Die Arbeiter werden so fortwährend repelliert und attrahiert, hin und hergeschleudert, und dies bei beständigem Wechsel in Geschlecht, Alter und Geschick der Angeworbnen." (127) Den Freisetzungsprozessen folgt so ein Umschichtungsprozeßs innerhalb und $z$ wischen den Betrieben; zumindest die kurzfristig stärker belastbaren jüngeren Arbeitskräfte treten an die neuen Anlagen; häufig werden an diese Arbeitsplätze mit extrem hohen Belastbarkeitsanfordenugen auch ausländische Arbeitskräfte gestellt. Folgen der Einführung der neuen Maschinerie und ihrer kapitalisisischen Anwendung sind auch bei diesen Arbeitem Fireisetzungen, Dequalifikationsprozesse, stärkere Beldstung (insbesonders psychischer Art) und eine verschärgte Konkurrenz unter den Arbeitern.

\footnotetext{
124) RKW-Projekt, Bd.6, a.a.,, 3.161

125) MEW Bd. 23, S. 4.34

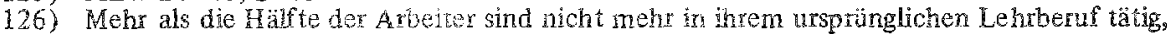
und besonders die ätemen werden un $\hat{1}_{2}$ - bis $1,50 \mathrm{DM}$ niedriger entohnt, wenn sie im Zeîlohn arbeiten. Daralis erklart sich auch das signifikante $A$ rsteigen der Zeitlöhner mit dem Aiter.
}

127) MEW 23, \$. 477 
Im Vergleich zu den bisher beschriebenen Arbeitsformen werden die Arbeiten an Einzelmaschinen (z.B. Fräsmaschinen) weniger durch die Maschine und ihr Tempo selbst diktiert. Hier bleibt vielmehr die traditionelle Akkordanreizfunktion wirksam (so in weiten Bereichen des Maschinenbaus, des Schiffbaus und insbes. in der Kleinstserienfertigung aller Branchen). Zwar werden auch für Dreher, Fräser, Schleifer etc. die Arbeitsabläufe im Zuge der technischen Entwicklung organisatorisch gestrafft, teilweise sogar über technische Apparaturen gelenkt; den Mechanisierungsmöglichkeiten sind jedoch engere Grenzen gesetzt. Dementsprechend werden gerade für diese Tätigkeiten die Systeme der Leistungsentlohnung nicht prinzipiell in Frage gestellt, sondern lediglich verfeinert. Die Einführung von Gruppenakkord fuihrt beispielsweise zur gegenseitigen Intensitätskontrolle der Arbeiter untereinander - anders als beim Einzelakkord. Die Langsamkeit des einen zwingt den anderen zur Pause oder muß je nach technischem Arbeitsprozeß yom anderen gar kompensiert werden. (128) Da der Proportionalakkord (Proportion zwischen Leistung und Lohn) bei technischen Veränderungen für die Unternehmen immer konfliktreicher wird und schleichende Rationalisierungen sowie Formen der Arbeitszurückhaltung dem Arbeiter seine Arbeit leichter machen, soll diese traditionelle Form des Akkords zurückgedrängt werden. Denn: „die technische Entwicklung begünstigt weiterhin die Anwendung von Entlohnungsmethoden, die nicht die mengenmäßige Mehrleistung schlechthin anreizen, sondern die Aufrechterhaltung eines im betrieblichen Sinne optimalen Leistungsniveaus zum Ziele haben. Dabei gewinnt die Prämienentlohnung in ihren vielfältigen Varianten zunehmend an Bedeutung. " (129) Darüberhinaus kann es ,an modernen Arbeitsplätzen nicht mehr genügen, den Lohn ausschließlich in seiner materiellen Ausprägung zu sehen. Während es frïher möglich war, durch einen rein materiellen Anreiz eine Erhöhung der mechanisch zu erbringenden Mengenleistung zu bewirken, kann eine derartige Leistungssteigerung heute nur noch durch Verbesserung der menschlichen Gesamteffizienz erzielt werden. Daraus leitet sich die Forderung $a b$, daß die moderne Leistungsgesellschaft nicht nur einen materiellen, sondern einen umfassenden, gleichermaßen materiell und ideell wirksamen Leistungsanreiz ausüben muß." (130) Die Intensität der Arbeit führt gerade unter diesen Formen des Akkords zu frühzeitigen Verschleißerscheinungen, die wiederum eine Rückstufung und/oder ${ }_{\text {,Abwertungen }}{ }^{66}$ zur Folge haben.

\subsection{Zu den Instandhaltungstätigkeiten}

Die Entwicklung im Instandhaltungssektor ist durch relativ hohe Qualifikationsanforderungen, wachsende Bedeutung bei inzwischen gleichzeitiger Rationalisierung und fortschreitender Arbeitsteilung gekennzeichnet, die zu Differenzierungen in höher qualifizierter Spezialarbeit und teilweise monotoner Routine-

128) Darin hattè der Streik der Vulkan-Werf t-Arbeiter (Bremen) seinen Grund

129) KKW-Projekt, Bd. 6, S. 209

130) Ebd., S. 131 
arbeiten führen. Hierzu schreibt Bahrdt: „Der Instandhaltungsarbeiter hat dafür zu sorgen, daß die technische Apparatur einwandfrei funktioniert und bei Störung umgehend wieder instand gesetzt wird." (131) Allerdings hat der Instandhaltungsarbeiter noch einen relativ großen Verhaltensspielraum, , ,der sich bisher aufgrund einer noch nicht durchrationalisierten Arbeitsorganisation zu halten vermochte." (132) Nimmt einerseits mit der fortschreitenden Umwälzung der technologischen Basis der Produktion der Prozentsatz der Instandhaltungsarbeiter zu, so setzen doch im verstärkten Maße Rationalisierungsmaßnahmen ein, bei denen u.a. auch MTM-Schnellverfahren eingesetzt werden. „Man systematisiert und schematisiert die Arbeitsgänge; man führt das schriftliche Auftragswesen und die Leistungsentlohnung nach Vorgabezeiten ein; man geht stärker zum Prinzip der vorbeugenden Instandhaltung über und strafft allgemein den Instandhaltungsbetrieb. ${ }^{6}$ (133) Die Arbeit des Instandhaltungsarbeiters ist geteilt in relativ einfache, sich wiederholende Tätigkeiten (z.B. das regelmäßige Auswechseln von Teilen, Kontrollgänge etc.), für die Zeitrichtwerte vorgegeben werden. Darauf basiert die Prämienentlohnung. „Beim Instandhaltungspersonal ist das Absinken der Muskelbelastung, der Belastung durch Umgebungseinflüsse und Unfallgefährdung weniger stark ausgeprägt. Eine Steigerung der psychischen Belastung entsteht vornehmlich durch Zunehmen der Arbeiten unter Zeitdruck (z.B. Störungsbehebung bei Produktionsunterbrechung). Die geistigen Anforderungen steigen infolge der Polarisierung (innerhalb des Instandhaltungspersonals, d. Verf.) nur bei einem Teil des Instandhaltungspersonals." (134) Man versucht teilweise sogar, ,in solchen Bereichen, für die reine Zeitentlohnung typisch ist, Leistungslohngerechtigkeit zu realisieren." (135) (Dies geschieht hier Z.T. in der Form von Gruppenprämien!)

Zusammenfassend müssen wir also bei technischen Veränderungen von erweiterten Möglichkeiten und Realisierungsschritten zur Steigerung der Belastung der Arbeiter ausgehen. Dabei verlagern sich die Formen der Belastungen von den körperlichen auf die psychisch-nervlichen. Die körperlich (muskulären) Belastungen sind teilweise zurückgegangen; insgesamt haben aber die technischen Umwälzungen der Produktion neue Mittel der Intensifikation der Arbeit aufgetan. Gleichzeitig hat das betriebliche Instrumentarium der Arbeitsablauforganisation einer starken kostenökonomischen Straffung der Arbeitsorganisation gedient. Ein stärker differenziertes und verfeinertes Lohnanreizsystem stopft die „Lücken“ der vom Arbeitsablauf noch nicht erzwungenen Intensifikation der Arbeit. Die Lohnformen werden flexibel und kombiniert eingesetzt. Zugleich zeigt unsere Beschreibung der Folgen der technologischen Umwälzung der Produktion, daß es nicht die neue Technik ist, die dem Arbeiter ste ts erhöhte Arbeitsanstrengung abpreßt, sondern die kapitalistisch angewandte Maschinerie: „Die von der kapitalistischen Anwendung der Maschinerie untrennbaren Widersprüche existieren nicht, weil sie nicht aus der Maschinerie selbst erwachsen, sondern aus ihrer kapitalistischen Anwendung. Da also die Maschinerie an sich betrachtet die Arbeitszeit verkürzt, während sie kapita-

131) Bahrdit u.a., a.a.O., S. 90

132) Ebd., S. 95

133) Ebd.. S. 102

134) RKW-Projekt, Bd 6, S. 108

135) Ebd., S. 154 
listisch angewandt den Arbeitstag verlängert, an sich die Arbeit erleichtert, kapitalistisch angewandt ihre Intensität steigert, an sich ein Sieg des Menschen über die Naturkraft ist, kapitalistisch angewandt den Menschen durch die Naturkraft unterjocht ..."(136) Dies soll im folgenden nochmals verdeutlicht werden.

Mit dem Übergang zu veränderten Formen der Profitproduktion in den 60er Jahren und den dabei erfolgenden technischen und arbeitsorganisatorischen Veränderungen wurden nur teilweise körperliche Belastungen abgebaut, umso stärker traten nervliche, psycho-physische und sensomotorische Belastungen in den Vordergrund. Wachsende Kostenplanung angesichts sinkender Ertragszuwächse führte zur optimalen arbeitstechnischen Ausnutzung der neuen Technologie, so daß Technik und arbeitstechnische Rationalisierung - wenn auch mit zeitlicher Verzögerung sich einander ergänzten. Die Krise wurde zur Personalreduzierung benutzt und ermöglichte erst recht die Durchsetzung der mit der neuen Technologie gegebenen Möglichkeiten der Ausschöpfung von Leistungsreserven. Dabei finden bedeutende Umschichtungen innerhalb der Lohnarbeiterklasse statt.

Die überdurchschnittlich hohen Freisetzungsraten in Industriezweigen mit hohen Rationalisierungsinvestitionen führen zum Verlust von Arbeitsplätzen, auf die die Arbeiter spezialisiert waren, und deswegen zur Abwertung bzw. geringeren Entlohnung. Davon sind besonders ältere Arbeiter betroffen, während für die neue Anlage vornehmlich jüngere, oft nur einseitig für diese Anlage spezialisierte Arbeitskräfte bevorzugt werden. Die typischen Fließbandarbeiten mit hoher Arbeitintensität werden zunehmend von Frauen und ausländischen Arbeitskräften ausgefuihrt, dafür rückt ein Teil der qualifizierten (oft jüngeren) Facharbeiter mit Erfahrung in die besseren Postitionen in der Hierarchie der Ärbeitsplätze herauf (z.B. Einrichter). Diese Umschichtungsprozesse werden durch die Anwendung eines differenzierten Leistungslohngefüges auf Basis der Grundlohnermittlung nach der analytischen Arbeitsplatzbewertung abgestützt. Gerade die A.A. setzt somit die auf dem Arbeitsmarkt erscheinende Vereinzelung der Arbeiter im Produktionsprozeß fort und führt so zu Formen der Verstärkung der Konkurrenz unter den Arbeitern um die jeweils besten Arbeitsplätze. Die traditionellen Akkordlohnformen werden zum Gruppenakkord bzw. Programmprämienlohn verfeinert, um zu einer höheren Anreizwirkung unter den gegebenen technologischen Bedingungen zu gelangen. Dort, wo der Arbeitsrythmus weitgehend durch den Rythmus der Maschine bestimmt ist, werden ebenfalls Prämienlohnverfahren zur Steigerung der Gesamteffizienz verwandt, um vor allem einen möglichst kontinuierlichen Produktionsausstoß in bestimmter Qualität zu erreichen. (Gerade deswegen werden häufig die Arbeitsprogramme bis ins einzelne kontraktlich festgelegt.)

EXKURS: Zu den Folgen der Intensifikation der Arbeit in der BRD

Die Folgen der Intensifikation der Arbeit lassen sich anhand einiger empirischer Untersuchungen andeuten. Zwar sind die negativen Auswirkungen der erhöhten Belastungen auf die Erhaltung einer normalen Lebensfähigkeit des Arbeiters weitgehend unerforscht, doch müssen zumindest einige Anhaltspunkte für das Ausmaß der gesundheitlichen Zerrüttung der Lohnarbeiter genannt werden, um auf die Bedeutung des Kampfes gegen den unmäßigen Gebrauch der Ware Arbeitskraft

136) MEW 23, S. 465 
im kapitalistischen Produktionsprozeß hinzuweisen. Die entsprechenden Wissenschaften, wie etwa die Arbeitsmedizin, haben sich sogar bisher weitgehend auf die Messung von Belastbarkeit zwecks optimaler Ausnutzung der Arbeitskraft im Produktionsprozeß konzentriert. Für die Gewerkschaften war dieses Problem lange Zeit ebenfalls zweitrangig.

a) Zur Belastung durch physische Schwerarbeit

Auch heute muß noch ein beträchtlicher Prozentsatz industrieller Arbeit als Schwerarbeit bezeichnet werden. Versucht man, ,einen entsprechenden Prozentsatz industrieller Arbeit fur die in der Gesamtindustrie Tätigen zu bilden, ist man im Hinblick auf die Arbeitsbelastung auf eine grobe Schätzung angewiesen. Nach den mir vorliegenden Unterlagen über die Beschäftigtenzahlen in den einzelnen Industriezweigen würde ich annehmen, daß von den in der Industrie Tätigen noch rund 18-20\% eine ausgesprochene Schwerarbeit ausfuhren müssen, d.h. mehr als 1,5 Mio. Werktätige in der Industrie. ${ }^{66}$ (137) Und: "Wach arbeitsmedizinischen Kriterien waren $44 \%$ der (in einer Studie uber physiologische Belastung bei Gießereiarbeiten, d. Verf.) untersuchten Arbeiten sowohl in energetischer Hinsicht als auch in Bezug auf den Kreislauf Belastungen ausgesetzt, welche die Dauerleistungsgrenze überschritten, d.h. das beinahe jeder 2. Gießereiarbeiter physisch überbelastet war. ${ }^{66}$ (138) Hinzu kamen ,starke Zusatzbelastungen durch negative Umgebungseinflusse in Form von Hitze und Lärm. " (139) Mögen die Muskelbelastungen auch zum Teil zurückgegangen sein, auch in Stufen der Hochmechanisiening und Teiloutomatisierung finden wir extreme Belastungen, so auch bei teilautomatisierten Anlagen in der Eisen- und Stahlindustrie. (140) Daher ist es nicht verwunderlich, daß, Arbeitsplätze mit maximalen Belastungen... Höchstbelastungen... naturgemäß nicht bis ins höhere Alter aufrechterhal-

137) Hettinger, T., Arbeitswissenschaftliche Aspekte des Arbeitsplatzes aus arbeitsmedizinischer Sicht, in: Arbeit und Leistung $11 / 1968$, S. 205 (zitiert nach Osterland, M. u.a., 2.a.O. O.)

138) Osterland, M., a.a.O., S. 55

139) Ebd.

140) Dazu R. Judith in: Der Gewerkschafter, Nr. 10/1972, S. 396: ,Die durch weitere Rationalisierungsbemühungen eintretenden Belastungen für die Beschäftigten (der Eisenund Stahlind., d. Verf.) sind nicht mehr zumutbar. Durch die personellen Einschränkungen in den ersten Monaten dieses Jahres ist die Belastung für den einzelnen Arbeitnehmer bei der derzeitigen Produktion erheblich gestiegen. Die Zahl der Überstunden hat aufgrund der knappen Belegschaften zugenommen. Die Lohn" und Gehaltserwartungen der Arbeitnehmer der Eisen- und Stahlindustrie werden sich an den Beanspruchungen und Belastungen orientieren, denen sie im Betrieb ausgesetzt sind. Der Anteil der nur einschichtig Beschäfigten nimmt durch die zunehmende Rationalisierung in der Eisen- und Stahlindustrie ständig $a b$. Die Wechselschicht im Dreischich try thmus oder die vierschichtige Konti-Arbeit, die das Wochenende voll Init in den Produktionszeitraum einbezieht, nimmt für die Arbeiterbelegschaft, aber auch für die Angestellten, zu .... Die Beschäftigten der Eisen- und Stahlindustrie haben unter äußerst schwierigen Bedingungen ihre A beit auszuführen. Dieser Tatbestand muß auch in der Entlohnung seinen Niederschlag finden. Die Umgebungseinflüsse, die durch Hitze und Staub auch bei hochmechanisierten Anlagen heute noch auftreten, missen in der Bezahlung ihren Niederschlag finden." 
ten werden (können). Physische Schwerarbeit fihhrt, wie Hettinger zeigen konnte, zu erhöhten Erkrankungszeiten, gehäuften Unfällen und u.U. auch zis einer vorzeitigen Invalidität." (141)

b) Relastungen bei repetitiven Tellarbeiten

Daß die nervliche Belastung bei repetitiven Teilarbeiten insbesonders bei sensorischen und motorischen Bandarbeiten sowie auch fü Automatenkontrolleure, außerordentlich hoch sind, wird durch einige empirische Untersuchungen drastisch belegt: „Nach Graf bilden die Abnahme der Reagibilität, die Ånderung der Handfertigkeit und Geschicklichkeit, die Verlangsamung der Denkvorgänge und Aufnahmefähigkeit insofern besondere Verhältnisse, als die Einfliisse des Altems am frihester und deutlichsten in Erscheinung treten .. Bei vielen Funktionen tritt schon relativ früh, im allgemeinen schon von etwa 30 Jahren an, ein, ,Knick ${ }^{6}$ auf. Die individuellen Unterschiede im Grade des Altems weisen dabei jedoch erhebliche Schwankugen auf. Ganz besonders früh jedoch machen sich Altersvorgänge bei allen Geschicklichkeitsleistungen bemerkbar, die unter Zeitdruck vor sich gehen müssen. Die Haupsussachen dafü: vermindere Reaktionsgeschwindigkeit, geringere Leistungsreserven, erschwerte Umstellfähigkeit. Weil. unter den heutigen industriellen Arbeitsformen die Arbeitsvorgänge unter Zeitdruck sichtlich zunehmen, insbesondere arbeitstaktmäßiger Zeitbindung bei Fließarbeit, wird dieses Problem immer wichtiger. Die Tatsache, daß mit zunehmenden Jahren die Fähigkeit nachläßt, leichte Arbeit mit großer Geschwindigkeit bei arbeitstaktmäßiger Zeitfindung zu verrichten, spielt bei Fließarbeit eine große Rolle; sie hat dazu gefuhrt, daß die taktgebundene Fließarbeit heute zu einer Domäne der Jugend geworden ist... Eine 21 Jahre alte Arbeiserin und eine 49 Jahre alte Arbeiterin hatten in einer 48 Stunden Schicht an einem Fließband bei einer Arbeitstaktzeit von $2,15 \mathrm{Min}$. den gleichen Lernvorgang auszuführen. Der jungen Arbeiterin war aufgrund ihrer besonderen Geschicklichkeit und Fingerfertigkeit möglich, insgesamt rund $30 \%$ der Schichtzeit für, ,Wartezeit ${ }^{66}$ durch Unterschreiten der Taktzeit zu verwenden, während es die ältere Arbeiterin nur auf etwa $7 \%$ der Schichtzeit brachte. "(142)

c) Belastungen durch Nacht- und Schichtarbeit

Die Belastungen werden durch Überstunden bzw. Nacht-und Schichtarbeit potenziert. Von 12 Mio. Arbeitem übten 1965 13,5\% Nacht- und Schichtarbeic aus (143); die Prozentzahlen steigen an. N/SArbeit konzentrieren sich zum groben Teil aut Industriebereiche mit ohnehin hoher Belastung, also auf Bergbau, Eisen und Stahlindustrie (vgl. dazu FN 140), Chemie sowie auf Verkehrsberufe. ,Da eine vollständige sehr stabile 24-stïndige Rythmik vieler arbeitsphysiologischer und einiger psychischer Rrozesse als gesichert gelten kann (144), führt Nacht- und Schichtarbeit zu potenzicrter Leistungsan-

141) Hentuger, T., steimhausen, W., Bosse, D., Die physische Belastung an Arbeitsplätzen der E-S Industrie, in: Arbeit und Leistung, $11 / 1969$, zit. nach Osterland, $u . a$.

142 aus: Arbeits- und betriebsundliche Eeihe, 1 , Alter und Leistung, $0.0 .0 .1 .9 .24 / 25$, vgl. Osterland u.a, a. a.O., $\$ .56 \mathrm{ff}$.

143) Vgl. die Tabellen $20 / 2.1$ bei Osterland u. a., a. a. 0.

144) Miehe, J. Schichtarbeit, in: Thomas, K. Analyse der Arbeit, Stutetgart 1969, S. 244 
spannung gegen das als normal empfundene Ruhe- und Erholungsbedürnis. So kommt es zu Schlafstörungen mit erhöhter Nervosität und Appetitstörungen Verdauungsstörungen und Magenerkrankungen. Untersuchungen ergaben eine dreifach höhere Zahl von Magenbeschwerden bei Wechselschichtarbeitern gegenüber normal arbeitenden, nämlich bei einem Drittel aller Wechselschichtarbeiter. (145) Langfristig führen die negativen gesundheitlichen Auswirkungen unweigerlich zu frühzeitigem Verschleiß. Arbeitsmediziner sind veranlaßt zu erklären, daß Schichtarbeit lediglich zum Zwecke der Gewinnsteigerung daher grundsätzlich abzulehnen sei - nur: die Bemühungen der Kapitalisten, das vorhandene (angewachsene) fixe Kapital möglichst schnell umschlagen zu lassen (unter Voraussetzung profitablen Warenabsatzes!) lassen die Prozentsätze von N/SArbeit gerade in einer Phase, in der jeder Einzelkapitalist über die Einführung der neuesten Technik die Produktivkraft der Arbeit zu steigern versucht, enorm anschwellen.

d) Zum Zusammenhang von Belastungen und Unfällen

Neben Utberstunden und Schichtarbeit, arbeitsplatzbedingten psychischen und nervlichen Belastungen treten Unfälle, Berufskrankheiten und Erwerbsunfähigkeit in hohem Maße auf; sie bedingen sich gegenseitig und haben einen kumulativen Effekt. Sie werden hier eigens aufgeführt, um zumindest einen ungefähren Hinweis auf das ganze Ausmaß der Entwicklung der Intensifikation der Arbeit zu geben. Im Vergleich zu 1950 nimmt die in Versicherungsstatistiken ausgewiesene Unfallquote beträchtlich zu, sie liegt im Jahre 1970 97,4 pro Tausend Versicherte; die reale Unfallentwicklung und Gefährdung liegt weit höher, da viele Unfälle verschwiegen werden können. Da die Quote der tödlichen Unfälle nicht verschwiegen werden kann, gibt ihre Steigerungsrate in den letzten Jahren auch während der Krise eher einen realen Überblick über die Entwicklung der Arbeitsindtensitätals die gleichzeitig (nämlich in der Krise) fallende allgemeine Unfallquote in den Betrieben. Untersuchungen (146)konstatieren den Zusammenhang von hoher Belastung, Ermüdung und wachsender Unfallgefährdung (dies insbes. auch bei Uberstunden- bzw. N/SArbeitern).

Arbeiter insbesonders mit manuellen Tätigkeiten sind extrem gefährdet, mittlere oder höhere Angestellte dagegen weniger betroffen. Als besonders unfallintensiv gelten deswegen neben dem Bergbau die Bereiche Steine, Erden, Eisen, Metall und Holz, in denen jeder 6.Beschäftigte pro Jahr einen Unfall erleidet. Wie bei Arbeitsunfällen sind auch bei Berufskrankheiten die Arbeiter besonders betroffen, die manuelle Tätigkeiten ausüben; ihre jeweilige Krankheitsdauer ist höher und nimmt mit dem Alter zu, was auf zunehmend schwerere Krankheiten schließen läßt. $\mathrm{Zu}$ berücksichtigen ist dabei, daß die Statistik einen großen Teil der psychischen Krankheit gar nicht enthält, sofern sie sich nicht psychosomatisch äußern oder zu manifester Arbeitsunfähigkeit führen. Das ganze erschreckende Ausmaß unmenschlicher gesundheitlicher Schädigungen und Verschleißerscheinungen der Arbeiter durch ihre Arbeitsbelastung wird deutlich, wenn man sieht, daß wegen Frühinvalidität

145) Vgl. Osterland, u.a., S. 60ff.

146) Vgl. ebd., S. 60ff. 
mehr als die Hälfte aller Arbeiter aus dem Erwerbsleben vorzeitig ausscheiden müssen: Wegen Berufsunfähigkeit allein 13,6\% aller Zugänge zur Rentenversicherung und wegen Erwerbsunfähigkeit 38,9\% im Jahre 1970. Die Zahlen lägen noch bedeutend höher, gäbe es nicht derart große Schwierigkeiten, überhaupt zu einer Rente zu kommen. Manche Berechnungen sprechen von einer Frühinvalidität von bis zu zwei Dritteln aller Arbeiter. (147) Die „flexible Altersgrenze" ist so längst von der Praxis der kapitalistischen Produktionsweise vorweggenommen worden.

Die hier aufgezeigte Lage der einzelnen Arbeiter oder Arbeiterschichten in den Großbetrieben ist aber noch unvollständig für eine Analyse der Lage der Arbeiter als Klasse, wird nicht die Veränderung ihrer gesellschaftlichen Stellung im historischen Kontext als Klasse im Gegensatz zum Kapital mit einbezogen. Dazu ist aber eine kurzgefaßte Skizzierung von allgemeinen Resultaten des Akkumulationsprozesses des westdeutschen Kapitals notwendig.

\section{Schlußfolgerungen}

Wenn wir im ersten Teil des vorliegenden Aufsatzes (in PROKLA 4/72) aus der Analyse von Tendenzen im Akkumulationsprozeß des westdeutschen Kapitals und auf dem Weltmarkt die forcierte Steigenung der Produktivkraft der Arbeit über die Umwälzung der technologischen Basis der Produktion und die Intensifikation der Arbeit ableiten konnten, so soll dieser Zusammenhang an dieser Stelle wieder aufgenommen werden und a) allgemeinere Ergebnisse für die Lage der Arbeiterklasse (insbesonders in den großen Betrieben) entwickelt, b) die Ausgangspunkte des Kampfes der Arbeiter gegen die Intensifiaktion der Arbeit genauer bestimmt und c) die Stellung der Gewerkschaften darin skizziert werden. Aus diesem Grund wollen wir zunächst allgemeine Resultate des Akkumulationsprozesses des Kapitals in der BRD und sich darin andeutende weitergehende Tendenzen festhalten.

Für den Reproduktions- und Wachstumsprozeß des westdeutschen Kapitals in den 60er Jahren war - wie schon ausgeführt - entscheidend, daß Ende der 50er/Anfang der 60er Jahre auf Basis prosperierender Kapitalakkumulation die Nachfrage nach brachliegender Arbeitskraft enorm ausgeweitet und die industrielle Reservearmee absorbiert wurde (ein Prozeß, der wesentlich über die Srellung des westdeutschen Kapitals auf dem Weltmarkt vermittelt wurde!). Die Beschränkung der Möglichkeit, die Mehrwertmasse mittels der Steigerung der im Produktionsproze $B$ angewandten absoluten Masse von Arbeitskräften zu erhöhen (eine Schranke, die auch nicht allein über den Import von Arbeitskräften aus dem Ausland kompensiert werden konnte) führte dazu, daß die Einzelkapitale über die

147) Die Sachverständigenkommission der Weltgesundheitsorganisation (WHO) errechnete, daß zwei Drittel aller Arbeitnehmer in der BRD wegen Frühinvalidität vorzeitig aus dem Berufsleben ausscheiden müssen. (Vgl. Frankf. Rundschau vom 29.11.1971) Und nicht nur das: Laut Zeitungsmeldungen von Anfang August 1972 hat die Bundesversicherung für Angestellte ermittelt, daß erwerbtätig gewesene Frauen eine um mehr als sieben Jahre geringere Lebenserwartung besitzen als nichterwerbstätige Frauen. Die Aufschlüsselung dieser bisher nicht zugänglichen Zahlen wird zeigen, welche Schichten der Lohnabhängigen von der Verkürzung ihrer Lebenszeit, gleichsam dem Mord auf Raten in der kapitalistischen Produktion, besonders betroffen sind. 
Steigerung der Produktivkraft der Arbeit die Erhöhung der Mehrwertrate und damit der Profitmasse forcierten. Insofern aber die Arbeiterklasse, sei es als Resultat von gewerkschaftlichen Kämpfen, sei es aufgrund der, ,uberhöhten ${ }^{66}$ Nachfrage nach. bzw. mangelnder $\mathbb{Z}$ ufuhr von Arbeitskräften auf dem Arbeitsmarkt, die Höhe des Reallohns zu steigern vermochte, konnte sie sich einen Anteil an der Steigenung der Froduktivkraft der Arbeit verschaffen und ihr Reproduktionsniveau insgesamt erhöhen (wenngleich hervorgehoben werden muß, daß derselbe Prozeß den Exploitationsgrad der Arbeit erhöhte!). Diese Beschränkung des akkumulierbaren Mehrprodukts über die Erhöhung der Lohnquote (vgl. dazu auch die von uns in der PROKLA 3/72 entwickelten Thesen zur Bewegung und Aussagekraft der Lohnquote) geht aber in den $60 \mathrm{er}$ Jahren einher mit einer wachsenden organischen Zusammensetzung des Kapitals als Resultat der erfolgten und erfolgenden Umwällzung der technologischen Basis der Produktion (dies in den einzelnen Branchen durchaus unterschiedlich und uber den $Z$ Zyklus vermittelt). Mit dem Wachstum an Kapital und damit dem Wachstum der organischen Zusammensetzung vermindert sich aber (relativ zur Zunahme an Kapital) die Zunahme in der Nachfrage nach Arbeit durch das Kapital bei gleichzeitig vergrößertern Unfang der Freisetzung durch Umwälzung der technologischen Basis der Originalkapitale und Zentralisation der Einzelkapitale. Denn: Die „Prozeduren zur Erzeugung von telativen Mehrwert (laufen) im ganzen und großen darauf ... (hinaus): einerseits von einer gegebenen Masse Arbeit möglichst viel in Mehrwert zu verwandeln, andererw seits im Verhältnis zum vorgeschossenen Kapital möglichst wenig Arbeit überhaupt anzuwenden; so daß dieselben Grinde, welche erlauben, den Exploitationsgrad der Arbeit zu erhöhen, es verbieten, mit demselben Kapital ebensoviel Arbeit zu exploitieren." (148) Wenn sich dieser Prozeß gerade in den Wachstumsindustrien (etwa der Chemie- und Elektrobranche) in den 60er Jahren (beschleunigt in der

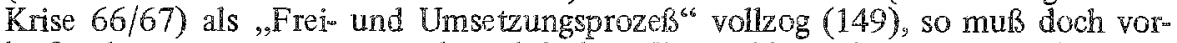
läufig davon ausgegangeri werden, daß diese Entwicklung der Widerspriche noch über die beschleunigte Größenausdehnung des Kapiăls (die eben in der BRD bes. durch die besondere Stellung auf dem Weltmarkt ermöghich $i$ wurde) vermittelt werden konnte; die industrielle Reservearmee blieb insgesamt gering (auch in „Fließender Form ${ }^{6}$ ). Ist aber die dazu notwendige beschleunigte Akkumulation des Kapitals und damit die Absorption einer Überflußarbeitsbevölkerung durch das Zusatzkapital aufgnund eines über die steigende organische Zusammensetzung vermittelten abnehmenden Verwertungsgrades nicht mehr gewährleistet (wie schon jetzt zeitweise in den USA und GroBbriannien), dann ist mit von ständiger Unterbeschâfligung begleiteten Stagnationsphasen zu rechnen; dies unso mehr, wenn die freigesetzten Arbeiter nicht mehr durch unproduktive Bereiche absobiert werden können und die Staatseingriffe an Grenzen stoßen, wie es sich jetzt schon oberflächlich als Dölemma von Vollbeschäftigungspolitik und Preisstabilität andeutet. (150)

Dies ist aber der historische Zusammenhang, in dem sich die zukünftigen Probleme der Arbeiterklasse in der BRD und ihrer Organisationen (sei es Partei oder Gewerkschaft) entfalten werden. War die prosperierende Kapitalakkumulation in der BRD Vorqussetzung der relativen Steigerung des Reproduktionsniveaus der

148) MEW 25, S. 243

149) Vgl. dazu RKW-Projekt, Bd. 2, Ffm 1971, S. 69ff. und Bd.3, a.a.O., S. $373 \mathrm{ff}$.

150) siehe nächste Seite 
Arbeiterklasse (und der Erfolge des gewerkschaftlichen Kampfes), so wird mit den oben angedeuteten entwickelten Konflikten im Reproduktions- und Wachstumsprozeß des Kapitals der Spielraum herkömmlicher Tarifpolitik in wachsendem Maße eingeschränkt denn der Arbeitslohn kann nur in dem Maße steigen, wie sein Steigen noch genügend unbezahlte Arbeit für die Akkumulationsbedürfnisse des Kapitals beläßt. Die Folge der oben skizzierten Entwicklung wird aber nicht nur ein wachsender Druck auf die Lohnrate sein (wie er sich schon Ende der 60er Jahre in der Form der staatlichen Einkommenspolitik - ,Konzertierte Aktion ${ }^{66}$ - andeutete und wie er, angesichts stagnativer Tendenzen bei gleichzeitiger Preisinstabilität, immer offener von den Ideologen des Kapitals gefordert wird); darüberhinaus wird - auch bei Unterbeschäftigung eines Teils der Lohnabeiter - die Erhöhung der Mehrarbeit des beschäftigten Teils über die Steigerung der Produktivkraft der Arbeit (einschließlich ihrer Intensifikation) für das Kapital ein wichtiger Hebel sein, den Exploitationsgrad der Arbeit und damit die Mehrwertmasse insgesamt zu erhöhen. (150a) Werden so gesamtgesellschaftlich der Druck auf den Arbeitstohn und drohende Überschußarbeiterbevölkenung (also Arbeitslosigkeit als Resultat der verminderten Zunahme in der Nachfrage nach Arbeit bei gleichzeitiger Freisetzung von Arbeitskraft aufgrund technologischer Unwälzungen) für die Lage der Arbeiterklasse und ihre gesellschaftliche Stellung bestimmend, so geht diese Entwicklung infolge des oben skizierten Umschlags in den Methoden der Proditproduktion einher mit sich verschärfenden Arbeitsbedingungen in den Betrieben, wie es von uns ausschnitthaft dargestellt wride.

Dieser hier entwickelte historische Zusammenhang zeigt uns, daß sich Strategien gesellschaftlicher Veränderung, die nicht, die gesellschaftlichen Bedingungen der Reproduktion, sondern die Erfahrungen am Arbeitsplatz, hier nun bereinigt um die gesellschaftliche Stellung der Arbeiter ${ }^{\text {ch }}$ (151), zum Ausgangspunkt haben, in

150) Vgl. zum allgemeinen Zusammenhang; Semmler/Hoffmann, Kapitalakkumulation Staatseingtiffe und Lohnbewegung in PROKLA 2/72; zu den Tendenzen auf dem Weltmarkt Neusïß, Blanke, Altvater, Kapitalistischer Weltmarkt und Weltwährungskrise, in PROKLA 1/71 und Busch/Schöller/Seelow, Weltmarkt und Weltwährungskrise, Bremen 1971. Es muß an dieser Stelle hervorgehoben werden, daß die hier skizzierten sich andeutenden Tendenzen keinesfalls mit der Konstatierung einer Tendenz zum $\mathrm{Z}$. sammenbruch der kapitalistischen Wirtschaft gleichzusetzen sind. Wichtig fur uns sind hier die veränderten formen der Vermittlung der Gegensätze und Konflikte im Kapitalismus der siebziger Jahre, deren Bedeutung für die Lage der Arbeiterklasse, die Politik der Gewerkschaften und die Taktik der kommunistischen Parteien.

150a) Es zeigt sich in den neueren Disskussionen der bürgerlichen ôkonomen, daß angesichts der veränderten Bedingungen des Wirtschaftswachstums und der Profitproduk tion nicht nur eine staatliche Beschränkung der Lohnzunahme gefordert wird (vgl. die aktuellen Disk ussionen in der , Wirtschaftswoche"), sondern daruberhinaus sollen die ,klassischen ${ }^{6}$ Mittel der Exploitation wieder stärker reaktiviert werden: Durch die Beschränkung des (privaten) Verbrauchs sollen die Investitionquoten erhöht werden, die Arbeitszeit soll verlängert und die Intensität der Arbeit gesteigert werchen: ,Ein ganz ungewöhnlich erscheinender Weg, an den anscheinend heute schon keiner mehr denkt, wäre die Möglichkeit, einmal wieder etwas länger zu arbeiten ... Eine vermutlich rech erhebliche Steigerung des Sozialproduk ts düifte sich aber auch bei unveränderter Arbeitszeit durch eine Enthemmung der Arbeitsleisiung(?) erreichen lassen." (C. Fönl, Wieweit ist Wirtschaftswachstum machbas? in: Fohl/Oppeniänder, ders. Titel, Berlin-Müchen 1968) Selbstverständlich ist für Fönl eines der besten Mittel des Anreizes zur Profitproduktion die ,massive Steuerbegünstigung der Kapitalisten (vgl. ebd. S. 18)

151) Herkommer, a.a.0., S. 78 
dem Maße sich historisch als falsch erweisen, wie sich der Gegensatz der Lohnarbeiter gegen das Kapital (zunächst als Kampf um die Lohnrate und bessere Arbeitsbedingungen) entfaltet. War die Tatsache, daß in den 50er und 60er Jahren vermittelt über das stetige Ansteigen des Reproduktionsniveaus der Arbeiterklasse - der Gegensatz zwischen Kapital und Arbeit sich nur in unterentwickelten Formen äußerte (und schon gar nicht als Kampf um bessere Arbeitsbedingungen) rückführbar auf die besonderen historischen Bedingungen der Akkumulation des westdeutschen Kapitals (in die natürlich die politischen Bedingungen wie Zerschlagung der Organisationen der Arbeiterklasse, Antikommunismus etc. mit einzubeziehen sind), so werden Theorien von der Integration der Arbeiterklasse (resp. der Gewerkschaften) in die bürgerliche Gesellschaft, vom Zerfall der Arbeiterklasse bzw. ihrer Polarisierung im Zuge des technischen Wandels in dem Maße obsolet, wie die entwickelten Konflikte im Reproduktions- und Wachstumsprozeß $B$ die gemeinsame Aktion der Lohnarbeiter gegen das Kapital erzwingt! Genauer: In dem oben abgeleiteten Zusammenhang von gesellschaftlicher Stellung der Lohnarbeiter und ihrer betrieblichen Lage liegt mit der Entfaltung dieser Konflikte auch die Möglichkeit begründet, daß sukzessive die Schranken fallen, die (gerade in den 60er Jahren) gemeinsame Abwehraktionen der Arbeiter verhinderten. Wurde oben entwickelt, daß die Umschichtungs- und Dequalifikationsprozesse (entsprechend der zunehmenden Differenzierung der - konkreten - Arbeit) eine Polarisierung innerhalb der Arbeiterklasse zur Folge haben, so macht sich - gerade im Gegensatz zu den etwa von Kern und Schumann im RKW-Forschungsprojekt gemachten Annahmen - im Zuge der hervortretenden Gegensätzlichkeit von Kapital und Arbeit die Einheit von gesellschaftlichen Bedingungen der Reproduktion und betrieblicher Arbeitssituation den Arbeitern gegenüber geltend. Dies findet zunächst seinen Ausdruck darin, daß der über die Intensifikation der Arbeit erhöhte Verschleiß der Arbeitskraft nicht mehr im „genügenden“ Maße über die Lohnhöhe kompensiert werden kann; den Arbeitern also der ,gerechte Lohn" für die erbrachte Leistung verweigert wird. Ist der Fehler etwa der Kern/Schumannschen Argumentation schon in dem Ansatz aufzusuchen, die typischen Erscheinungsformen industrieller Arbeit unter dem Einfluß des technischen Wandels zu untersuchen, „ohne im spezifisch gesellschaftlichen Charakter der Arbeit in ihrer ökonomischen Form als Lohnarbeit deren . . . inneren Kern entdecken zu können,“ (152) so gelingt es ihnen auch nicht, die ökonomische Bestimmtheit der von ihnen beschriebenen Prozesse wie Dequalifikation, Belastungsprogression (bei inadäquater Belohnung) und wachsende Gleichgültigkeit des Arbeiters gegenüber den Inhalten seiner Arbeit (153) aufzuzeigen. (Diese Borniertheit gegenüber dem Stoff, die Arbeit unter rein technologischen Bedingungen $\mathrm{zu}$ fassen, also lediglich den einfachen Arbeitsprozeß getrennt vom Verwertungsprozeß $\mathrm{zu}$ untersuchen, wirkt allerdings bei $\mathrm{K} / \mathrm{S}$ umso paradoxer, als die ökonomische Form der Arbeit sich bei ihnen unter der Hand wieder einschleicht wenn sie zu dem Ergebnis kommen, daß ,das Urteil über die Arbeit bei allen Lohnarbeiten stark von den betrieblichen Rahmenbedingungen der Tätigkeit, vor allem von der Höhe der Entlohnung und der Arbeitsplatzsicherheit, abhängt." (154)) Ferner: K/S stützen die These von der Polarisierung innerhalb der Arbeiter-

152) Ehd.s. S. 80

153) Vgl. K/S-Studie, S. 197ff., bes. S. 203, 206f., 21 2, 214, $216-220$

154) Ebd. S. 219 (Wir gehen im folgenden exemplarisch auf Kern/Schumann ein) 
klasse auf ihr Untersuchungsergebnis, daß die qualifizierten Automatenarbeiter (insbes. Meßwertenarbeiter) gegenüber den körperlich und/oder sinnlicn-nervlich stark belasteten repetitiven Teilarbeitern aufgrund ihrer Arbeitssituation und betrieblicher Position privilegiert seien (als Folge technischer Umstellungen). Demgegenüber kann jedoch davon ausgegangen werden, daß die von $\mathrm{K} / \mathrm{S}$ als privilegiert bezeichnete Schicht der Automatenarbeiter, die nach den erfolgten technischen Umstellungen den restriktiven Bedingungen der Lohnarbeit weitgehend entziehen konnten, neuerdings - wie von uns im Teil 3 entwickelt - in zunehmendern Maße über den Einsatz der neueren Entlohnungsmethoden in den allgemeinen Prozeß der Intensifikation mit einbezogen werden, was mit entsprechender Belastungsprogression bei den Automatenarbeitern offenbar einhergeht. Auch wird das Ausmaß der Dequalifikationsprozesse von dem Arbeiter nur bedingt sinnlich erfahren, solange der gcsunkene Wert der Arbeitskraft noch nicht im Preis (in der Lohnhohe) seinen Niederschlag findet (sei es, daß die Arbeitsmarktsituation eine Senkung nicht zuläßt, sei es, daß der Arbeitsplatz noch nicht neu, ,bewertet ${ }^{66}$ ist, sei es, daß uber Utberstundenarbeit die absolute Lohnhöhe noch gehalten werden kann).

Wenn daher die Beschränkung der Lohnrate, die Arbeitsplatzunsicherheit und die wachsende Arbeitsbelastung als allgemeine Probleme der Arbeiterklasse in der BRD in stärkerem Maße sich geltend machen, so ergibł sich daraus zunächst die Möglichkeit von Konflikten, die selbst wieder die mögliche Grundlage der Bildung von Klassenbewußtsein und damit der Vereinheitlichung der Arbeiter als Klasse gegenüber dem Kapital bilden. Damit sind die zukünftigen Probleme für die gewerk. schaftliche Interessenvertretung der Arbeiter gestellt, die zugleich die politische Artikulierung der Arbeiterklasse gegenüber dem Kapital und dem Staat beforderr werden.

Der ASTA an der Uni Erlangen-Nürnberg hat in Verbindung mit den BASISGRUPPEN Und der SOZNATEK eine Broschüre zum Bayeri schen Hochschulgeset $z^{:}$herausgegeben:

\section{DOKUMENTATION ZUM BHG}

(Das Wichtigste vom BHG/Kampf dem BHG/Kapitalistische Hochschulreform/SHB-KaUGerwelsch/Maier und Dohnany/SFD-Leitlinien eśc,)

Die Broschüre ist erschienen im Selbstverlag der Herausgeber, sie hat 64 Setren, kostet 1,50 DM und wird vertrieben vom POLITLADEN ERLANGEN, 852 Erlangen, Hincenburgst 17 


\section{KAMPF DER ARBEITER GEGEN INTENSIVIERUNG UND GEWERKSCHAFTEN}

„Läßt eine fortschreitende Arbeitszeitverkürzung nicht die Produktivität unserer Wirtschaft sinken? Das Gegenteil ist der Fall!

Während von 1955 bis 1964 die Zahl der Beschäftigten um etwa 23\% zunahm, erhöhte sich die Industrieproduktion im gleichen Zeitraum um das Doppelte. Dieser Anstieg der Produktivität ging Hand in Hand mit erheblichen Arbeitszeitverkürzungen in allen Branchen .... Im übrigen nehmen die Gewerkschaften ja Rücksicht auf die angespannte Arbeitsmarktlage und stellen das Tempo der Arbeitszeitverkürzungen danach ein. Sie achten darauf, daß planvoll und in Stufen verkürzt wird und nicht ruckweise und überstürt. So gewinnen die Unternehmer mehrere Jahre Zeit, sich durch Rationalisierung auf die neue Situation einzustellen. Arbeitszeitverkürzungen dieser Art fördern das Tempo, in dem sich die Betriebe rationalisieren und modernisieren. Sie bewirken einen vernünftigen und durchdachten Arbeitsablauf und steigende Produktionszahlen. Denn schließlich ist nicht entscheidend, wie lange sich jemand am Arbeitsplatz aufhält, sondern seine tatsächliche Arbeitsleistung. In diesem Punkt schneiden wir beim Vergleich mit anderen Industrieländern keineswegs schlecht ab: Im Rahmen der Europäischen Gemeinschaft liegt die Arbeitsintensität in der Bundesrepublik um 14\% höher als in den Nachbarländern! ${ }^{65}$

(aus: Kraftfelder, Herausgb. DGB, o.0. o.J., ca. 1970) 


\subsection{Kampf gegen Intensivierung und Kampf gegen das Lohnsystem}

In seinem Aufsatz „Die Massen, die Gewerkschaften und die politischen Avantgarden “ (155) hat Peter Schneider die Frage formuliert, welche sich ihm im Zusammenhang der Darstellung der Klassenkämpfe bei Fiat für die Analyse der Arbeiterklasse in der BRD als entscheidende Frage darstellt: ,Die Hauptstoßkraft der technologischen Transformation richtet sich also auf die Neuorganisation des Arbeitsablaufs. Das bedeutet: Einführung neuer Arbeitsbewertungssysteme, Vereinfachung und Dequalifizierung der Arbeit, Erhöhung der Anzahl der zu bedienenden Maschinen pro Arbeiter, Erhöhung des Arbeitstempos, Verlängerung der Arbeitszeit durch Überstunden und zusätzliche Schichten. Die zahlreichen Befragungen der italienischen Arbeiter, vor allem aber die Kämpfe von 1968-1971 beweisen, daß diese Veränderungen nicht nur stattgefunden haben, sondern auch wahrgenommen werden. Selbstverständlich genügt es nicht, vor allem nicht in der $\mathrm{BRD}$, die neuen Ausbeutungsmethoden zu analysieren. Ebenso wichtig ist es, $\mathrm{zu}$ untersuchen, was von ihnen wahrgenommen wird. Wenn die Arbeiter auf diesen Transformationsprozeß vorwiegend noch mit traditionellen Lohnforderungen antworten, so ist nichts damit getan, wenn die Anallyse ihnen nachweist, daß mit ihren Lohnforderungen eigentlich politische Forderungen gemeint sind. Es kommt dann gerade darauf an, die Widerstände zu untersuchen, die das Arbeiterbewußtsein daran hindern, die neuen Bedingungen wahrzunehmen und zu bekämpfen." (156)

Diese Frage trifft in der Tat ein entscheidendes Moment der Entstehung von Klassenbewußtsein als Bedingung des Kampfs gegen das System der Lohnarbeit. Was Marx in „Lohn, Preis und Profit“ als abstraktes Postulat aufstellt, daß nämlich die täglichen Kämpfe der Arbeiter um höhere Löhne und bessere Lebens- und Arbeitsbedingungen umgewandelt werden müssen in einen Kampf gegen das Lohnsystem, dies ist in Ansätzen in den großen Betrieben Norditaliens in der Tat geschehen, und zwar zunächst unmittelbar entspringend aus dem Widerspruch zwischen den praktischen Lebensbedürfnissen der Arbeiter und dem Verwertungstrieb des Kapitals. „Was das Proletariat zu tun hat, ist den gegenwärtigen kapitalistischen Charakter dieser organisierten Arbeit und dieser zentralisierten Arbeitsmittel umzuwandeln, sie aus Werkzeugen der Klassenherrschaft und der Klassenausbeutung in Formen der freien assoziierten Arbeit und in gesellschaftliche Produktionsmittel zu verwandeln." (157) Den ersten Schritt zur Erkenntnis dieser Aufgabe hat das italienische Proletariat in seinem Widerstand gegen das kapitalistische System der Organisation der Arbeit getan. Die Forderungen nach Abschaffung des Akkords, Abschaffung der Nachtschichten, Kontrolle der Bandgeschwindigkeiten, Abschaffung der Lohnstufen und damit Milderung der durch das Kapital unter den Arbeitern gesetzten Konkurrenz, Abschaffung der betrieblichen Hierarchie, Kontrolle über die Produktionstechniken richten sich nicht einfach nur auf die Verbesserung dor Lebens- und Arbeitsbedingungen, sondern in ihrem Zusammenhang frontal gegen das gesamte System kapitalistischer Form und Organisation des Produktionsprozesses, die Unterwerfung der Arbeit unter die Herrschaft des Kapitals. Denn sic

155) Peter Schneider, in: Die Klassenkämpfe in Italien, Kursbuch 26/1971, S. 135 - 163

156) Eloda., S. 140

157) Karl Marx, Erstor Entwurf zum Burgerkrieg in Frankreich, MEW 17, S. 551 
setzen diesem eine reale Vorstellung von der Organisation des Produktions- und Arbeitsprozesses entgegen, in welchem sich die Arbeit die Produktionsbedingungen unterordnet und nicht umgekehrt, das tote Kapital die lebendige Arbeit, eine Vorstellung, welche nicht bloß abstrakte Negation der bestehenden Verhältnisse, sondern aus der praktisch erfahrenen und praktisch bekämpften Unerträglichkeit der Arbeits- und Lebensbedingungen entstanden ist.

Daß die Verwirklichung dieser Forderungen nicht innerhalb der kapitalistischen Produktionsweise erreicht werden kann, sondern die revolutionäre UmwandIung der Gesellschaft erfordert, daß hier also nicht reformistische Illusionen über die Möglichkeiten der Verbesserung der Lebenssituation innerhalb des Kapitalismus entstehen, formulieren die Arbeiter in ihren Straßenkämpfen gegen die Polizei mit der Parole: ,Was sagen wir: Schluß jetzt! Was wollen wir: Alles!"Daß allerdings die Revolutionierung der Gesellschaft noch nicht mit der Revolutionierung des Bewußtseins von Arbeiteravantgarden geleistet ist, zeigt die gegenwärtige Situation in Italien.

Immerhin ist es jedoch gelungen, die zunächst von den Arbeitern in ihren spontanen Kämpfen z.T. gegen die Beschränkung der gewerkschaftlichen Kampfziele auf Lohnerhöhungen erhobenen Forderungen zu Kampfzielen der Gewerkschaften selbst zu machen. So berichtet die ,Wirtschaftswoche“ (vormals ,Volks" wirt ${ }^{66}$ ) in ihrer Ausgabe vom 18. August 1972 über die kommenden Tarifauseinandersetzungen: „Europas Gewerkschaften suchen neue Strategien für den - Arbeitskampf. Würde das italienische Beispiel Schule machen, hätte das unübersehbare negative Folgen. ,Wir wollen', sagt Luciano Lama, Chef der größten Arbeitnehmerorganisation des Landes, der kommunistischen CGIL, ,den ausbeuterischen Unternehmen ein sozialistisches Fegefeuer anzünden. Die ,Brandstiftung ist für den Herbst vorgesehen ... Die ersten Forderungen (in der Chemie, der Metallindustrie, im Bauhauptgewerbe) zeigen bereits: Es geht den Sindicati diesmal weniger um direkte Lohn- als um Nebenforderungen: 40-Stundenwoche, Gleichbehandlung von Arbeitern und Angestellten, Überwindung des Akkordsystems, Abbau der Leistungsgruppen mit gleichzeitiger Anhebung des Mindestlohnes, vier Wochen Urlaub fiir alle.6"

Die Kämpfe in Italien machen deutlich, was wesentliche Entwicklungsmomente eines Klassenbewußtseins, welches nicht von außen in die Arbeiterklasse hineingetragen werden kann, sein können: Die Weigerung der Arbeiter, weiterhin einen Trennungsstrich zwischen der Reproduktion der Arbeitskraft und ihrer Anwendung durch den Kapitalisten, zwischen dem Verkauf und dem Gebrauch der Arbeit durch das Kapital zu ziehen. Die Frage, welche Peter Schneider stellt, ist diejenige nach den Widerständen, welche bisher die deutsche Arbeiterklasse daran hindern, diese Trennung im Bewußtsein und im Klassenkampf aufzuheben. Es käme in der BRD darauf an, nicht nur die verschärften Arbeitsbedingungen zu untersuchen, sondern sich die Frage zu stellen, ob sie auch wahrgenommen und bekämpft werden. Und wenn nicht, aus welchen Gründen.

Wir glauben, daß in dieser Form die Frage selbst nicht ganz richtig gestellt ist. Als Beweis dafür, daß die italienischen Arbeiter die Unmenschlichkeit ihrer Arbeit im Betrieb wahrnahmen, fuhrt er zum einen die Befragungen an, welche bei Fiat vor dem Ausbruch der Kämpfe stattfanden, zum andern die Kämpfe selbst. In der Tat sind in der BRD Widerstandsaktionen gegen die Arbeitsbedingungen, abgesehen vom täglichen Kleinkrieg zwischen Lohnarbeit und Kapital, noch kaum entwickelt. 
Doch stellen wir einige Aussagen von deutschen und italienischen Arbeitern über das, was sie von ihrer Arbeit denken, gegenüber, so wird es schwer sein, die Behauptung, đaß der Unterschied im Nichtwahrnehmen veränderter Arbeitsbedingungen besteht, aufrechtzuerhalten: "Vor ein paar Jahren brachte es hier noch Spaß zu arbeiten, aber die letzten paar Jahre ekelt es einen förmlich an. Das Akkordsystem, daß alles auf Minuten und Sekunden ausgearbeitet ist, das Gleichmäßige, man hat ja keine Zeit, sich mal mit den Kollegen zu unterhalten, denn dann kriegt man nichts mehr raus. Und dazu: immer dasselbe, immer dasselbe ... Wenn man was verdienen will, dann muß man jede Minute ausnutzen." (158) ,Jetzt mit den 26 Stiuhlen bin ich nicht zufrieden ${ }^{66}$ (Die Frage lautete nach der Arbeitszufriedenheit). ${ }^{66}$ Das ist eine große Nervenbelastung, die Nerven gehen dabei in Stücken kaputt. Marn ist, wenn man 2 bis 3 Stunden gearbeitet hat, einfach kaputt. Wir sind im Akkord tåtig und die Akkordsätze sind so niedrig, daß man gezwungen ist, eine hohe Leistung zu erbringen. Man ist auch noch für die Ware verantwortlich, für die fehlerhafte Ware. Man hat 20 Stühle und schlechtes Material gibt es immer wieder, und dann fängt es da an, schiefzugehen und dann da, und man läuft hin und her und schwitzt und kocht über und vibriert am ganzen Körper... das ist heute eine kolossale Belastung, ein Gesundheitsverschleiß ist das allemal.“ (159) ,Ich arbeite an den Fließbändern, es ist ekelhaft, weil die Arbeit ständig zunimmt und unsere Gesundheit aushöhlt, und was noch schlimmer ist, daß der Lohn immer gleich bleibt oder auch sinkt, wenn man an die geleistete Arbeit denkt.“ (160) ,Arbeit würde ich das nicht nennen, eine rhythmische Bewegung der Arme, die acht Stunden dauert. ${ }^{\text {.6 (161) }}$ „.. .das ist keine Arbeit mehr, das ist Abhetzerei, die wir da haben. ${ }^{66}$ (162) ,Meine Arbeit macht einen Menschen zum Tier. Sie wird immer größer aber die Bezahlung bleibt immer die gleiche oder wird sogar schlechter." (163) „Eine übergroße Anstrengung für schäbigen Lohn." (164)

Vergleichen wir die Aussagen der deutschen und italienischen Arbeiter, so wird klar, daß die Verschärfung der Arbeitsbedingungen dort, wo sie stattfindet, gleichermaßen wahrgenommen wird. Der entscheidende Unterschied liegt darin, daß in den Aussagen der deutschen Arbeiter deutlich wird, daß 3 die erschwerten Arbeitsbedingungen noch objektiv kompensiert werden durch das Reproduktionsniveau während die italienischen Arbeiter die Erfahrung gemacht haben, daß die außerordentliche Arbeitsanspannung nicht einmal durch einen Lohn abgegolten wird, der zum Leben einigermaßen hinreicht. So schreibt auch Schneider richtig:" ,Der qualitative Sprung im Arbeiterbewußtsein besteht in der Erkenntnis, daß die relativ sinkenden Löhne nicht zu trennen sind von der Veränderung der Arbeitsbedingungen." (165) Und Kern/Schumann stellen fest: ,Die repetetiven Teilarbeiter und Automatenkontrolleure konzentrieren ihre Kritik auf jene Bedingungen ihrer Tätigkeit, die die gesellschaftlichen Reproduktionsmöglichkeiten des Arbeiters grund-

158) Horst Kem/Michael Schumann, Industriearbeit und Arbeiterbewuß tsein, a.a.O., S. 202

159) Ebda., S. 207

160) Fiat-Streiks, Schriften zum Klassenkampf, Nr. 16, München 1970, S. 11

161) Ebda., S. 9

162) Kern/Schumann, a.a.O., S. 189

163) Fiat-Streiks, a.a.O., S. 8

164) Ebda, S. 10

165) Peter Schneider, a.a.O., S. 141 
sätzlich gefährden: die frühzeitige Zerstörung seiner Arbeitskraft durch große Belastungen. In das Urteil über die Arbeit gehen dabei die Betriebsbedingungen und hier insbesondre die finanzielle Entschädigung entweder in kompensatorischer Funktion ein, aussöhnend gleichsam mit der Tätigkeit selbst - negativ eingeschätzt verschärfen sie die Ablehnung der Arbeit." (166)

Es kann sich also beim Unterschied zwischen deutschen und italienischen Arbeitern nicht nur um einen Unterschied des Bewußtseins, der Traditionen der Arbeiterbewegung, der Wahrnehmung der gleichen objektiven Tatbestände, der gleichen Bedingungen der Arbeit und der Reproduktionsmöglichkeiten der Arbeitskraft handeln. Die deutschen Arbeiter sagen: Man muß schuften wie ein Tier, um leben zu können; die italienischen sagen: wir schuften wie die Tiere und können nicht einmal leben. Die Unterschiede in der Wahrnehmung sind hier Unterschiede in der wirklichen Lebenssituation, Unterschiede in der Höhe der Löhne, der Höhe der Mieten, in der Art der Wohnverhältnisse aber auch noch in der Schärfe des Arbeitsdrucks im Produktionsprozeß. Kern/Schumann finden heraus, daß die Ablehnung der Arbeitsbedingungen, bzw. die Erfahrung von deren Unerträglichkeit sich in dem Maße verschärft, wie die Lohnhöhe nicht mehr als Kompensation des Arbeitsleids angesehen werden kann, wo also trotz der Schufterei im Betrieb die Löhne kaum zum Leben hinreichen. (167)

So ist auch z.B. für den Ausbruch der großen Kämpfe bei Fiat im Herbst 1969 kennzeichnend, daß es sich hier nicht um den isolierten Widerstand einzelner Arbeitergruppen gegen die Arbeitsbedingungen handelt, sondern um die Zusammenfassung der Arbeiter unter gemeinsamen Forderungen, welche die Lohnhöhe, die Intensität der Arbeit und die von den Kapitalisten gesetzte Konkurrenz der Arbeiter untereinander zum Gegenstand haben: Die Forderungen lauten: „Höheren Lohn, weniger Arbeit, Lösung der Lohnhöhe von der Arbeitsproduktivität, Lösung der Löhne von der Arbeit überhaupt. Zusammen mit diesen Forderungen wurde immer die Forderung nach besseren Arbeitsbedingungen erhoben ... Die Lösung der Lohnhöhe von der Produktivität (168) faßt die Forderungen, die gegen die gegenwärtigen Arbeitsbedingungen gerichtet sind, zusammen und gibt die politischen Ziele an, um die sich die Organisationsarbeit zu zentrieren hat. ${ }^{60}$ (169)

Was die Lohnerhöhungen in den vorangegangenen Jahren anging, so war es Fiat immer wieder gelungen, sie durch außerordentliche Verschärfungen des Arbeitstempos und des Arbeitsdrucks zu kompensieren. Die Höhe der Mieten und sonstige Preiserhöhungen hatten das ihrige dazu getan, die reale Lage der Arbeiter $\mathrm{zu}$ verschlechtern und die Lohnerhöhungen wegzufressen. Gerade der unzureichende Lohn war selbst wiederum Hebel in der Hand des Kapitals, die Ausbeutung voranzutreiben und den Arbeiter an seiner eignen Ausbeutung zu interessieren. So wird eine der fortgeschrittensten Forderungen in der Form einer Lohnforderung gestellt, nämlich Lösung der Lohnhöhe von der Produktivität. In dieser Fordenung

166) Kern/Schumann, a.a.O., S. 195 (Hervorhebung von uns). K/S stellen weiterhin fest, daß dort, wo die höhere Árbeitsbelastung deutlich wahrgenommen wird, gleichbleibender Lohn als nicht mehr adäquater Preis der Arbeit begriffen wird. (vgl. S. 199, 202, 207).

167) Vgl. dazu den Aufsatz von M. Salvati in Nr. 4 der PROKLA

168) Gemeint ist die Loslösung des Lohns von der individuellen Produktivität.

169) Bericht über Potere Operario, in: Sozialistische Korrespondenz, 18.11.70, S. 4 
ist folgendes einbegriffen: 1. Sie zielt auf die Durchbrechung des Ausbeutungsmechanismus' hin, welcher den Arbeiter durch die Bindung seines individuellen Lohns an die Höhe seiner Produktivität, und dies liegt allen Formen des Stïcklohnsystems und des Stundenlohns (Zwang zu Überstunden) zugrunde, zur äußersten Anspannung seiner Kräfte zwingt. 2. Durch die Ausrichtung der Löhne nach der Produktivität der einzelnen Arbeiter oder einzelner Arbeitergruppen wird die Konkurrenz unter den Arbeitern forciert, was für den Kapitalisten dann wieder die Grundlage zur Lohnsenkung durch Erhöhung der Akkordrichtsätze abgibt. Es wird also mit dieser Forderung, welche die Form einer Lohnforderung hat, begriffen, daß die Konkurrenz der Arbeiter untereinander, forciert durch die Bindung der Lohnhöhe an die Produktivität, ein wesentliches Mittel des Kapitalisten zur Ausbeutung darstellt. Aufhebung der Konkurrenz ist demnach als Ziel in dieser konkreten Lohnforderung enthalten und damit Entschärfung eines Mittels der Ausbeutung. Wenn neben dieser Forderung noch andere wichtig werden, welche die Aufhebung oder zumindest Einschränkung der Lohngruppendifferenzierung zum Gegenstand haben und damit auf die Milderung der Konkurrenz unter den Arbeitern zielen, so zeigt sich darin, wieweit hier der ökonomische Kampf um die Reproduktionsbedingun. gen der Ware Arbeitskraft selbst den Erkenntnisprozeß über die Herrschaft des Kapitals und die Knechtungsbedingungen der Lohnarbeiter vorangetrieben hat.

Die Klassenkämpfe bei Fiat zeigen demnach, daß die Intensität und Breite der Kämpfe sich nicht allein aus dem Kampf um Kontrolle der Arbeitsbedingungen, aus welchem dann auch die Institution der Fabrikräte entsteht, erklären läßt. Wichtig für die Möglichkeit der Verallgemeinerung der Kämpfe ist der unmittelbare Zusam. menhang von Lohnforderungen und Forderungen, welche sich gegen die Herrschaft des Kapitals über den Produktionsprozeß richten. (170) Denn da die Arbeitsbedingungen selbst die verschiedenen Arbeitergruppen und Schichten, je nach ihrer Situation im differenzierten Arbeitsprozeß, zunächst in unterschiedlicher Form treffen, wie in den vorangehenden Teilen des Aufsatzes gezeigt wurde, so trägt hier der Abwehrkampf zunächst die Gefahr der Beschränkung auf Einzel- oder Gruppenwiderstand in sich, solange nicht eine Abstraktion von der unmittelbaren Besonderheit der Belastung aufgrund umfassender Kampfziele möglich wird. Dies gilt umsomehr, je weniger der Arbeitsprozeß selbst für die Massen der Arbeiter vereinheitlicht ist, je stärker also die Unterschiede der konkreten Arbeiten als trennendes Moment noch wirksam sind. So läßt sich die These aufstellen, daß noch einigermaßen zum Leben hinreichende Löhne ein Grund für die bisher in der BRD noch nicht stattgefundene Aufnahme kollektiver Kämpfe gegen die Herrschaft des Kapitals über den Produktionsprozeß ist.

170) Bemerkt sei hier noch, daß sich die Vehemenz und auch bestimmte Formen der Kämpfe bei Fiat gegen die Intensifikation der Arbeit natürlich auch aus der Tatsache erklärt, daß3 in den Turiner Betrieben ein der kapitalistischen Arbeitsdisziplin noch nicht unferworfenes Prole tariat konzentriert war. 


\subsection{Lohnfetisch und Ausgangsbedingungen des Lohnkampfes}

Doch diese Erklärung allein reicht nicht hin. Sehen wir doch z.B. in Großsbritannien, daß der Kampf um Arbeiterkontrolle gerade während einer Prosperitätsphase des Kapitals in dessen Wachstumsbranchen, wo vergleichsweise hohe Löhne gezahit wurden, mit großer Militanz und zunächst auch mit Erfolg geführt wird. Für die Beantwortung der anfangs formulierten Frage von Peter Schneider sind demnach noch weitere Argumentationsschritte notwendig. Soweit sich diese Frage auf die Widerstände im Bewußtsein der Arbeiter, den Kampf um die Lohnhöhe zlim Kampf um Kontrolle der Arbeitsbedingungen auszudehnen, bezieht, wäre an sich an dieset Stelle eine Auseinandersetzung mit dem Problem des Lohnfetischs notwendig. Doch können hier nur einige Anmerkungen gemacht werden, welche vor allem die Schwierigkeiten aufzeigen sollen, in diesem Punkt gegenwärtig zu Ergebnissen zu kommen. Mit dem Begriff des Lohnfetischs bezeichnet Marx die Erscheinungsform des. Lohns als Preis der Arbeit und damit die Verhüllung der Ausbeutung durch die Form des Arbeitslohns selbst. (171) Die Verfügungsgewalt des Kapitalisten über die Anwendung der vom Arbeiter verkauften Arbeitskraft in der Produktion ist in der Form des Lohnarbeitsverhältnisses selbst enthalten. Der Arbeiter verksurt eine Ware, nämlich seine Arbeitskraft (im Bewußtsein der Tauschagenten als Verkanf der Arbeit erscheinend) und der Käufer dieser Ware kann, wie in jedem anderen Fall, die Ware gebrauchen wie er will. Der Tausch der Ware Arbeitskraft gegen Lohn schließt zunächst im Bewußtsein der Tauschagenten die Verfügungsgewait des Kapitalisten über die Arbeiter im Produktionsprozeß als Konsequenz des Austauschprozesses ein. Auf dem Markt treten Kapitalist und Arbeiter ,in ein

171) Her noch einmal das einschlägige Zitat: ,Man begreift daher die entscheidende Wichtigkett oler in Wert und Preis der Arbeit selbst. Aus dieser Erscheinungsform, die das wirkliche Verhalltnis unsichtbar macht und gerade das Gegenteil zeigt, beruhn alle Rechtsvorstellungen des Arteiters wie des Kapitalisten, alle Mystifikationen der kapitalistischen Froduxtonsweise, alle inre Freiheitsillusionen, alle apologetischen Flausen der Bulgärokononie." (AEW 23, 5. 562) Hier muß allerdings festgehaiten wercien, daß die Mystifi. kationen des Kapitalverhälnisses die Arbeiter niemals in der Weise beherrschen könen, wie die Kapitalisten sowie Vulgärökonomen jeglicher Provenienz, da nämlich der Verkauf der Arbeit auf dem Markt gegen Lonn nur die eine Seite der Erfahrung der Arbeiter bidet, wie Gerberei inrer eigenen Haut im Produktionsprozeß jedoch die andere. , Die Konsumition der hubeitskraft, gleich der Konsumtion jeder anderen Ware, vollzieht Sch außurhalb des Markts oder der Zirkulationssghäre ... Hier wird sich zeigen, nicht Intr wie das Kapital produziert, sondern auch, wie man es selbst produziert, das Kapical.

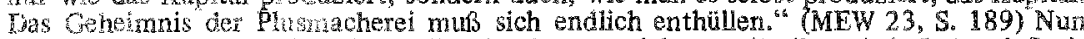
enthuilt sich der srbeitar dieses Gehemnis zwar nicht unmittelbar, da ja Lohn als reis der Arbeit erschent, doch die Erfahrung der Ausbeutung, Unterdrickung, Hersichaft des Kapitals in unmitteibaren Produktionsprozes steht in Widerspruch zur Erfahnug des Warenbesitzers, der einen siguivalententausch vollzieht, und biden neben der allgemeinen Unsicherheit der Arbeiterexistenz eine wesentliche Grundlage firi die Entwick. lung von Kiassenbewuß tsein. Beruhen zwar alle lllusionen und Rechtsvorstellungen aut der Eorm des Arbeitslohns, so darf das Bewußtsein der Arbeiter doch auch nicht einfacts iäntisch mit diesen Illusionen gesetzt werden. Zur Frage des Lohnfetischs vgl. noch $T_{\text {. }}$ Damrn, a.a.O., sowie Bierbaum/Bischoff/Krätke/Menard, Zur Aktualität der Leninschen Partei, in: SOPO Nr. 10/1971, insbesondere S. 64-71. Beide Aufsätze stellen allerdings unserer Ansicht nach keine befriedigende Entwicklung des Problems dar. 
Verhältnis zueinander, als ebenbürtige Warenbesitzer, nur dadurch unterschieden, daß3 der eine Käufer, der andre Verkäufer, beide also juristisch gleiche Personen sind. ${ }^{66}$ (172) Vom Standpunkt des Kapitalisten ist folgerichtig der Gebrauch der gekauften Ware seine Sache: „Der Arbeitsprozeß, wie er als Konsumtionsprozeß der Arbeitskraft durch den Kapitalisten vorgeht, zeigt nun zwei eigentümliche Phänom mene. Der Arbeiter arbeitet unter der Kontrolle des Kapitalisten, dem seine Arbeit gehört. Er paßt auf, daß die Arbeit ordentlich vonstatten geht und die Produktionsmittel zweckmäßig verwandt werden ... Zweitens aber: Das Produkt ist Eigentum des Kapitalisten, nicht des unmittelbaren Produzenten, des Arbeiters. Der Kapitalist zahlt Z.B. den Tageswert der Arbeitskraft. Thr Gebrauch, wie der jeder andren Ware, Z.B. eines Toferdes, das er für einen Tag gemietet, gehört ihm also für den Tag. Dem Käufer der Ware gehört der Gebrauch der Ware ... Von seinem Standpunkt ist der Arbeitsproze? nur die Konsumtion der von ihm gekauften Ware Arbeitskraft... Der Arbeitsprozen ist ein Prozeß zwischen Dingen, die der Kapitalist gekauft hat, zwischen ihm gehörigen Dingen。" (173) Die bürgerliche Rechtsauffassung sanktionient genau in dieser Form das Verhältnis zwischen Kapital und Arbeit. Frank Deppe kennzeichnet diese Auffassung kurz gefaßt folgendermaßen: „Wesentlicher Thalt des bürgerichen Arbeitsrech is ist ein individuelles Gläubiger-Schuldner Verhältnis: Der Arbeiter ist Gläubiger der Lohnforderung und Schuldner der Arbeits Ieistung. Damit verzichtet der Arbeiter darauf, Einfluß auf den Inhalt der Nutzung seiner Arbeitskraft durch den. Unternehmer zu nehmen, denn er stellt diesem seine Arbeitskraft zur $\vee$ erfügung, ,damit dieser von seiner Arbeitskraft in den gesetzlich, tariflich, betrieblich oder einzelvertraglich gesetzten Grenzen Gebrauch machen kann". (Nikisch) Aus dieser rechtlich begriindeter Verfügung uber den Gebrauchswert Ger Ware Arbeitskraft resultiert - nach den Vorstellungen des bürgerlichen Arbeitsrechts - notwendig die kapitalistische Leitungs- und Direktionsfunktion, ,weil sich das Direktionsrecht aus dem Wesen des abhängigen Arbeitsverhältnisses ergibt." (Nikisch) (174) Doch Nikischs Hinweis auf die, gesetzlich, tariflich etc. gesetzten Grenzen " des Gebrauchs der Ware Arbeitskraft durch den Kapitalisten gestent seibsi $z u$, Gaib in den Klassenkämpfen diese Hertschaftsfunktion des Kapitals Ficht widerspruchslos hingenommen, sondern im Ergebnis eingegrenzt wurde. (175)

Laibt sich nun der historische Tatbestand, daß bisher in der BRD ein allgemeiner Kampi der Arbeiter gegen den unmäßigen Gebrauch der Ware Arbeitskraft in Produktionsorozeß noch kaum entwickelt ist, aus der allgemeinen Wirkung des

17) MEV 23, 3,182

$173)$ Ebda.s $\$ .199 / 200$

174) Trank Deppe, Das Bewabisein der Arbeiter, Studien zur politischen Soziologie des Axbeiterbewußtseins, Köh 1971, S. 123/12\%. Deppe nennt diese Rechtsauffassung ideologisch urd begrimdet dies damit, daß , hier ein Rechtsverhältnis yon formal gleichgestedten Vertagspartnem als die auf rationalem Konsens beruhende Ursache der tber. wnd Unteroramungwerhältnisse in der Produktion alsgegeben wird." (ebda.s. S. 124) Doch kann hier von Ideologit nur im Sinne des notwerdig falschen Bewußtseins aufgrumd der verkelyreter Form, in welcher die kapitalistischen Ausbeutungsverhältnisse ihren Agenter erscheinen müssen, gesprochen werden.

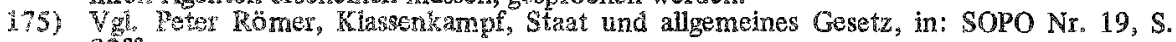
$82 \mathrm{ff}$. 
Lohnfetischs erklären? (176) Die Logik der Lohnform als Preis der Arbeit impliziert, daß, wenn der Kapitalist den Arbeiter zur Verausgabung von mehr Arbeit zwingt, dies zunächst nichts anderes bedeutet, als daß er ihm diese erhöhte Arbeitsleistung in der Form einer Lohnerhöhung bezahlen muß (Lohn-Leistungsäquivalenz). Konflikte entstehen danach zunächst unter der Bedingung, daß der Kapitalist diese Bezahlung der Mehrleistung nicht vornimmt, also selbst dem Gesetz des Äquivalententauschs entgegenhandelt, oder daß eine Lohnerhöhung nicht als adäquat von den Arbeitern begriffen wird. Sie würden von Seiten der Arbeiter formuliert als Konflikte um den ,gerechten Preis ${ }^{6}$ der Arbeit. (177) Ausbeutung würde begriffen als Prellerei um diesen gerechten Arbeitspreis. Es handelte sich dabei um Konflikte zwischen Tauschagenten um den Warenpreis, was implizierte, daß in ihnen genausoviel und genausowenig weitertreibende Momente des Klassenkampfes hin zu einer Infragestellung des gesamten Kapitalverhältnisses enthalten wären, wie im Lohnkampf. Auf der andren Seite geht Marx im Kapitel über den Arbeitstag davon aus, und stellt dies auch historisch dar, daß von Beginn des Kapitalverhältnisses an sich der Kampf auch gegen den unmäßigen Gebrauch der Arbeitskraft richtet. Marx läßt seinen in den Kategorien des Warentauschs argumentierenden Arbeiter gegenüber dem Kapitalisten sprechen: „Du und ich kennen auf dem Marktplatz nur ein Gesetz, das des Warentausches. Und der Konsum der Ware gehört nicht dem Verkäufer, der sie veräußert, sondern dem Käufer, der sie erwirbt. Dir gehört daher der Gebrauch meiner täglichen Arbeitskraft. Aber vermittelst ihres täglichen Verkaufspreises muß ich sie täglich reproduzieren und daher von neuem verkaufen können. Abgesehen von dem natürlichen Verschleiß durch Alter usw. muß ich fähig sein, morgen mit demselben Normalzustand von Kraft, Gesundheit und Frische zu arbeiten, wie heute. Du predigst mir ständig das Evangelium der ,Sparsamkeit ' und der ,Enthaltung'. Nun gut! Ich will wie ein vernünftiger, sparsamer Wirt mein einziges Vermögen, die Arbeitskraft, haushalten und mich jeder tollen Verschwendung derselben enthalten. Ich will täglich nur soviel von ihr flüssig machen, in Bewegung, in Arbeit umsetzen, als sich mit ihrer Normaldauer und gesunden Entwicklung verträgt. Durch maßlose Verlängerung des Arbeitstags kannst du in einem Tag ein größeres Quantum meiner Arbeitskraft flüssig machen, als ich in drei Tagen ersetzen kann. Was du so an Arbeit gewinnst, verliere ich an Arbeitssubstanz. Die Benutzung meiner Arbeitskraft und die Beraubung derselben sind ganz verschiedene Dinge ... Du zahlst mir eintägige Arbeitskraft wo du dreitägige verbrauchst. Das ist wider unseren Vertrag und das Gesetz des Warenaustausches . . Ich verlange den Normalarbeitstag, weil ich den Wert meiner Ware verlange, wie jeder andere Verkäufer.“" (178) Der Arbeiter besteht hier also gerade aufgrund der Gesetze des Warentauschs auf seinem Recht, sich gegen den unmäßigen Gebrauch seiner Arbeitskraft zur Wehr zu setzen. Dieser unmäßige Gebrauch ist vom Standpunkt des Arbeiters als Warenbesitzer und Warenverkäufer gegen den mit dem Kapitalisten geschlossenen Vertrag. Die an anderer Stelle von Marx dargestellte Wirkung des Lohnfetischs, welche die Anerkennung des Verhältnisses von Kapitalist

176) (entfällt)

177) Vgl. Anm. 166)

178) MEW 23, S. 248/49 
und Arbeiter als Träger eines Äquivalententauschverhältnisses impliziert (die Teilung des Arbeitstags in bezahlte und unbezahlte Arbeit ist in der Lohnform verhüllt und damit das Ausbeutungsverhältnis) bedeutet demnach nicht, daß für den Arbeiter im Tauschakt selbst das Recht des Käufers der Arbeit zur uneingeschränkten Vernutzung der Arbeitskraft gesetzt ist. (179) Lohnkampf und Kampf gegen die Beraubung der Arbeitskraft im Produktionsprozeß liegen zunächst gleichermaßen auf der Ebene der Auseinandersetzung zwischen Warenbesitzern, deren Rechte, wie Marx im Kapitel über den Arbeitstag expliziert, in antagonistischem Verhältnis zueinander stehen, so daß zwischen den gleichen Rechten nur die Gewalt, d.h. die je erreichten Machtverhältnisse zwischen den Klassen entscheiden. (180) Es ist demnach nicht möglich, prinzipiell den Kampf gegen Arbeitsbedingungen, welche zu den praktischen Lebensbedürfnissen der Arbeiter in unerträglichem Widerspruch stehen, als per se revolutionärer im Gegensatz zum Kampf um Lohnerhöhungen zu betrachten.

Trotzdem bleibt die Frage, ob ein militanter von unten getragener Kampf der Arbeiter gegen den Anspruch des Kapitals, die Arbeitskraft nach seinem Belieben im Produktionsprozeß zu vernutzen, insbesondere wenn er sich zur Forderung nach Kontrolle der Produktionsbedingungen durch die Arbeiter verallgemeinert, die Dimension zur Einsicht in das Verhältnis von Lohnarbeit und Kapital als Herrschafts- und Knechtungsverhältnis und zum Kampf gegen das so begriffene Verhältnis nicht doch eher eröffnet, als ein Kampf, der sich auf die scheinbare Kompensation der Beraubung der Lebenskraft der Arbeiter durch Lohnerhöhungen beschränkt. Dabei ist es jedoch wichtig, zu sehen, daß das Kapital in seinem Akkumulationsproze $B$ die Lohnarbeiterklasse alls in verschiedene Schichten differenzierte produziert, deren Lage und deren erfahrener Widerspruch zum Kapital selbst unterschiedlich ist. Unterschiedlich in Bezug auf den konkreten Charakter des Arbeitsprozesses, das Maß des Arbeitsdrucks und der Intensität der Arbeit, die Bedrohung durch Arbeitslosigkeit und die Lohnhöhe. Dies bedeutet aber auch, daß für diese verschiedenen Schichten sowohl innerhalb der Betriebe als auch innerhalb der verschiedenen Branchen die Angriffspunkte des Kapitals auf die Lebensbedürfnisse in unterschiedlicher Intensität ausgeprägt sind. Mag sich den Arbeitern einiger Großbetriebe die Forderung nach Kontrolle der Arbeitsbedingungen als Notwendigkeit aufzwingen, so wird in anderen Branchen die Forderung nach Erhaltung der Arbeitsplätze oder nach Erhöhung der Löhne Hauptgegenstand der Kämpfe sein. Eine Vereinheitlichung der Kämpfe der Arbeiter kann demnach niemals unter einem beschränkten Kampfinhalt stattfinden. (181) Erst im organisierten $\mathrm{Zu}$ -

179) Nach Aussagen eines englischen Genossen impliziert bei aen englischen Arbeitern traditionell gerade das Verständnis des Arbeitslohns als Preis der Arbeit, welcher vom Kapitalisten nach geleisteter Arbeit bezahlt wird, den Anspruch der Arbeiter auf Kontrolle der Arbeitsbedingungen.

180) Vgl dazu Müller/NeusitB, Die Sozialstaatsillusion und der Widerspruch von Lohnarbeit und Kapital in: SOPO 6/7, Juni 1970 und in PROKLA, Sonderheft 1. Juni 1971

181) Exemplarisch für solche Mißverständnisse ist aber der Standpunkt von solchen linken Gruppen in Italien und Frankreich, die - jetzt einmal grob vereinfacht - den ,bloß quantitativen ${ }^{6}$ Lohnforderungen der Gewerkschaften die, qualitativen' Forderungen der Arbeiter entgegenhalten, wobei sie davon ausgehen, daßs quantitative Forderungen der Tendenz nach die Arbeiter ins kapitalistische System integrieren, während qualitative Forderungen, Forderungen also um die Arbeitsbedingungen, potentiell revolutionär seien. 
sammenhang des Widerstands gegen die Angriffe des Kapitals und des bürgerlichen Staates an allen Punkten, bilden sich Kampfforderungen und Klassenbewußtsein heraus, welche der Tendenz nach auf die Revolutionierung der Gesamtgesellschaft hinauslaufen.

\subsection{Zur gewerkschaftlichen Betriebspolitik in der BRD}

Doch gehen wir wieder auf die Situation in der BRD zurück, welche durch eine weitgehende Beschränkung der Kampfinhalte auf Lohnforderungen gekennzeichnet ist. Wir kommen damit zur Frage nach den Gründen, welche dazu führen, daß bis jetzt die Intensifikation der Arbeit nicht nur keine spontanen Aufstände der Arbeiter erzengt hat, wie in Italien, sondern auch aus der gewerkschaftlichen Interessenvertretung herausfiel. Denn im Gegensatz zu Italien, wo es in der Restaurationsphase gelungen war, die Gewerkschaften aus den Großbetrieben zu verdrängen oder gar nicht erst hineinzulassen, (182) waren sie in der Institution der Vertrauensleute zumindest in den Metallbetrieben präsent. Gerade die Existenz einer funktionierenden Vertretung der Arbeiter auf Betriebsebene, nämlich der shopstewards, war in Großbritannien eine entscheidende Grundlage für die Möglichkeit militanter Kämpfe um Kontrolle des Arbeitsprozesses, welche die Entwicklung der Klassenauseinandersetzungen in den 60er Jahren kennzeichnet. (183) Dabei verdankt sich allerdings die Stärke dieser betrieblichen Gewerkschaftsorgane besonderen Umständen, welche in der Zersplitterung der Gewerkschaften in Berufsgewerkschaften zu suchen sind. Aufgrund dieser Zersplitterung war die Herausbildung einheitlicher betrieblicher Vertretungsorgane selbst im Interesse des Kapitals, weil ihm nur so die Möglichkeit, einen einheitlichen Verhandlungspartner sich gegenüber zu haben, gegeben. (184) Die Stärke der betrieblichen Gewerkschaftsorgane ist so nicht einfach das Produkt eines per se entwickelteren Klassenbewußtseins der englischen Arbeiter, sondern sie bildet sich im Zusammenhang der in England nicht stattgefundenen Transformation der naturwüchsig zunächst entstehenden Berufsgewerkschaften in Industriegewerkschaften heraus. Sie entspringt also einer Schwäche zentraler Gewerkschaftsorganisationen, bildet sich selbst aufgrund des Widerspruchs zwischen der Konzentration der Arbeiter in den großen Betrieben und der Organisation der Arbeiter in berufsständischen Vertretungsorganen.

Dieser Widerspruch existierte demgegenüber in der BRD von Beginn an nicht. Mit der Organisation der Arbeiter in starken und einheitlichen Industriegewerkschaften war zunächst wenigstens der Form der Organisation nach die berufsständische und damit auf spezifische Schichteninteressen hin orientierte Gewerkschaft aufgehoben. Nun sind zwar einheitliche Gewerkschaftsorganisationen als einheitliche Verhandlungspartner für das Kapital von Interesse, doch bilden sie auf der anderen Seito ihrer organisatorischen Form nach auch ein mächtiges Kampfinstru* renent der Arbeiter. Dem deutschen Kapital mußte es demnach darauf ankommen,

182) Vgl. dazu den Aufsatz von Salvati in Nr. 4 der PROKLA

183) Vgl: Albers/Goldschmidt/Oehlke, Klassenkämpfe in Westeuropa, Hamburg 1971, S. 215 fí.

184) Vgl.: Neue Zürcher Zeitung, 3.11.71; 5.11.71; 13.11.71; Die Machtstrukturen bei den britischen Sozialpartnern, Artikelserie. 
eine weitere organisatorische Stärkung der Gewerkschaften durch eine Verbindung zwischen betrieblicher und zentraler Organisation der Arbeiter zu verhindern, was ihm offensichtlich gelungen ist.

Nach der Zerschlagung der gewerkschaftlichen Basisinitiativen, welche unmittelbar nach Kriegsende in eine betriebliche Vertretungsbewegung eingemündet waren, durch die Besatzungsmächte, (185) bildete das Betriebsverfassungsgesetz zunächst den endgültigen Sieg der Bourgeoisieklasse bei der Schwächung der zentralen Gewerkschaftsorganisationen. Dieser Schwächung war allerdings von den reformistischen Gewerkschaftsführungen selbst vorgearbeitet worden: Indem diese aktiv den Versuch der Besatzungsmächte und später der BRD-Regierung, den Einfluß der Kommunisten zurïckzudrängen, unterstützten, nahmen sie selbst an der Liquidation einer starken betrieblichen Interessenvertretung der Arbeiter innerhalb der Gewerkschaften teil. So wurde $z_{\text {.B. }}$. die Betriebsrätebewegung nach Kriegsende von den Gewerkschaftsführungen selbst geschwächt, indem zum Zwecke der Einschränkung kommunistischen Einflusses die Basisorganisationen auf Stadtteilanstelle von Betriebsgruppen umgestellt wurden, Der Höhepunkt dieser Politik war der Beschluß zur Unvereinbarkeit von KP-und Gewerkschaftszugehörigkeit 1953; wetcher aufgrund der fälschen KP-Politik zur Entfernung der Kommunisten aus den Gewerkschaften führte. (185a)

Doch gehen wir auf das BVG zurück. Mit ihm wurde den Gewerkschaften eine rechtlich anerkannte Vertretung innerhalb der Betriebe aberkannt. Der Betriebsrat wurde andererseits als Interessenvermittlungsorgan zwischen Kapital tind Arbeit im Betrieb, "nicht jedoch als Kampforgan der Arbeiter institutionalisiert. Dagmar Pfeiffer und Reinhard Krusche schreiben in ihrer Arbeit: „Das Verhältnis von betrieblichem und zentralen ökonomischen Kampf als Problem der Gewerkschaftsbewegung": „Die Verabschiedung des Betriebsverfassungsgesetzes 1952 bedeutete für die Gewerkschaften die Gefahr, ihren Einfluß auf die Belegschaften zu verlieren. Das Instrument des betrieblichen Kampfes war den Gewerkschaften aus der Hand geschlagen, und die betriebliche Auseinandersetzung zum Gegenstand der ,vertrauensvollen Zusammenarbeit ${ }^{6}$ von Betriebsrat und Unternehmer gemacht. Dies bedeutete der Tendenz nach die Isolierung der Gewerkschaftsorganisationen von den Problemen der Mitglieder im Betrieb, und damit des Schwundes der Mitgliederbasis, der Schwächung des Organisationsgrades und der Schwierigkeit, die Belegschaften zum Zwecke des zentralen ökonomischen Kampfes zu mobilisieren und zu organisieren“. (186) „Ein entscheidender Bereich der gewerkschaftlichen Tätigkeit wurde illegalisiert. Der Kampf um die betriebsspezifische Durchsetzung und Modifi.zierung der gewerkschaftlichen politischen Zielsetzungen sowie die Aufnahme der

185) Reinhard Krusche/Dagmar Pfeiffer, Das Verhältnis von betrieblichem und zentralem ökonomischen Kampf als Problem der Gewerkschaftsbewegung, Diplomarbeit am soziologischen Institut der FU-Berlin 19\%2, unveröffentlichtes Manuskript, S. 142, vgl. dazu auch Eberhard Schmidt, Die verhinderte Neuordnung, Frankfurt/Main 1971

185a) Die KPD bestand ihrerseits auf der formellen Beibehaltung der KP-Mitgliedschaft.

186) Krusche/Pfeiffer, a.a.O., S. 145; ,Die Gewerkscharten wurden durch die Errichtung des Interessenvertretungsorgans BR praktisch aus dem Betrieb verdrängt." (ebda., S.118) 
besonderen betrieblichen Probleme in die zentrale Politik wurde somit bedeutend erschwert, wenn nicht unmöglich gemacht." (187)

Der Versuch zur Stärkung und zum forcierten Aufbau der Vertrauenskörper als betrieblicher Vertretungen der Gewerkschaft war die Antwort der IG-Metall auf die Gesetzgebung. (188) Es stellt sich nun die Frage, ob die heute immer noch schwache Position der betrieblichen Vertrauenskörper, ihre Unfähigkeit, den Kampf auf betrieblicher Ebene zu organisieren, sich ausschließlich auf ein organisatorisches und politisches Versagen der Gewerkschaftsapparate zurückführen läßt - dies ist sicherlich ein wesentliches Moment - oder ob dieses Versagen selbst in der Entwicklung der Lage der Arbeiterklasse noch eine Begründung fïndet. Nur wenn dies der Fall ist, ließe sich die Möglichkeit einer Verändenung der gegenwärtigen Situation, daß nämlich den Arbeitern auf Betriebsebene im großen und ganzen keine funktionsfähigen Kampfinstrumente zum Widerstand gegen die Intensifikation der Arbeit zur Verfügung stehen, ausmachen. Denn mit einer voluntaristisch initierten Selbstveränderung des Gewerkschaftsapparats ist nicht zu rechnen.

Trifft die im ersten Abschnitt der Arbeit vorgenommene Analyse über das Verhältnis von Arbeitslohn, Arbeitszeit und Arbeitsintensität für die fünfziger Jahre zu, so läßt sich damit zunächst ein Erklärungsgrund dafür finden, wieso eine wirkliche Verankerung der Gewerkschaften in den Betrieben durch die Vertrauenskörper nicht gelang. Geht man davon aus, daß die allgemeine Niedrigkeit des Lohns und die außerordentliche Länge des Arbeitstags in den 50er Jahren Hauptangriffspunkte des Kapitals waren, welche der normalen Reproduktion der Ware Arbeitskraft entgegenstanden und die Inhalte des Konflikts zwischen Lohnarbeit und Kapital konstituierten, so kann darin ein Grund dafür gesehen werden, daß die Strategie der Gewerkschaften, sich auf Betriebsebene durch Vertrauensleute zu verankern und auf diese Weise eine Verbindung zwischen zentraler und betrieblicher Organisation der Arbeiter entgegen den Bestimmungen des Betriebsverfassungsgesetzes herzustellen, unter den damals gegebenen Umständen scheitern mußte. Krusche und Pfeiffer stellen fest: „Ein wesentliches Moment für das Mißlingen der gewerkschaftlichen Initiatjven, den Einfluß auf der betrieblichen Ebene vermittels der umfassenden Aufstellung von Vertrauenskörpern auszubauen, muß in dem hauptsächlich formal- organisatorischen Charakter der gewerkschaftlichen Aktivi-

187) Ebda., S. 142; Entscheidend ist hier noch die weitere Einschränkung der gewerkschattlichen Tätigkeit im Betrieb durch die Arbeitsrechtsprechung. Krusche und Pfeiffer verweisen darauf, daß 1 .) ein BAG-Urteil vom 2.5.1955, jede Werbung für Gewerkschaften und jegliche Diskussion gewerkschaftlicher Fragen in Betriebsversammlungen untersagt, denn die Betriebsversammlung habe dem betrieblichen Frieden $z u$ dienen und dazu gehöre auch strik te gewerkschaftliche Neutralität." (ebda., S. 120/21); 2.) Es folgt ein BAG-Urtell von 195\%, welches jede Möglichkait der Gewerkschaften, betriebliche Streiks für übertarifliche Arbeitsbedingungen zu organisieren oder zu unterstïtzen, ausschaltet." Im dem Urteil heißt es: ,Ein Streik verstổt auch dann gegen die tarifliche Friedenspflicht, wenn er übertarifliche Arbeitsbedingungen, sei es durch Betriebsvereinbarung oder Einzelarbeitsverträge geregelt, erkämpfen soll." (vgl. ebda., S. 121/122) 3.) 1963 wird vom $\mathrm{BAG}$ der "organisatorische Schutz für an spontanen Streiks beteiligte Gewerk. schaftsmitglieder durch Gemaßregelten"Unterstitzung untersagt." Bei Zahlung ist die Gewerkschaft zu Schadensersatz furr den gesamten Streikschaden verantwortlich. (ebda, S. 123)

188) Vigl. ebda., S. $157-70$ 
täten gesucht werden. In einer Situation der relativen Loslösung der gewerkschaftlichen Politik vom betrieblichen Bereich werden z.B. Zielsetzungen der ,Aktion Vertrauenskörper (189) im wesentlichen nur als organisatorische Majnahmen formuliert: Schwerpunkt der Aktion sollte der Aufbau von Vertrauenskörpern sein, weitere Zielsetzungen das gute Zusammenwirken von VK, Betriebsrat und Ortsverwaltung, regelmäßige Betriebsbesprechungen der VK, örtliche Zusammenkünfte der Vertrauensleute usw. Im Verlauf der Aktion gelingt es der IG-Metall nicht, diese organisatorischen Initiativen inhaltlich zu füllen, d.h. eine Vermittlung der zentralen gewerkschaftlichen Politik mit den betrieblichen Bedingungen zu leisten." (190) Doch geben auch Krusche und Pfeiffer nicht an, wie eine solche inhaltliche Auffüllung der organisatorischen Initiativen hätte aussehen müssen. Denn eine inhaltliche Alternative zur im BVG angelegten betriebsegoistisch orientierten Politik der Betriebsräte hätte nur dann erfolgreich sein können, nur unter der Bedingung den Vertrauenskörper zum ,Kontrollorgan der Belegschaft gegenüber dem Betriebsrat ${ }^{66}$ funktionalisieren können, (191) wenn tatsächlich entscheidende Konflikte auf Betriebsebene aufgetreten wären, bei welchen die Arbeiter auf die zentrale Machtorganisation der Gewerkschaften zur Austragung ihrer Kämpfe verwiesen worden wären. Die Situation war aber dadurch gekennzeichnet, daß Lohnerhöhungen, Arbeitszeitverkürzung, und, wie im Fall des Streiks in Schleswig-Holstein von 1957, Lohnfortzahlung im Krankheitsfall in der Tat Inhalte des Interessenwiderspruchs zwischen Lohnarbeit und Kapital waren, welche nicht als besondere Forderungen auf Betriebsebene als betriebsspezifische Forderungen formuliert werden konnten, sondern alle Arbeiter unabhängig von den Betriebsbedingungen betrafen. So konnten auch in dieser Situation keine inhaltlichen Perspektiven der Politik der Vertrauensleute entwickelt werden, aufgrund derer eine Alternative bzw. Kontrolle der Betriebsratspolitik hätte erfolgreich durchgeführt werden können. Denn Ergebnis der weiteren ökonomischen Entwicklung war gegen Ende der 50er und zu Beginn der 60er Jahre mit der Attraktion der industriellen Reservearmee und der Prosperität des Kapitals eine Bereitschaft der Einzelunternehmen, auf betrieblicher Ebene Zugeständnisse an die Arbeiter zu machen. Dieser Bereitschaft entsprach aber durchaus die Institution des Betriebsrats, welche darauf angelegt ist, auftretende Konflikte auf ,friedlichem Verhandlungswege ${ }^{6} \mathrm{zu}$ bereinigen. Die Zugeständnisse selbst bezogen sich inhaltlich auf die Zahlung übertariflicher Löhne, z.T. ausgezahlt in allen möglichen Formen sogenannter betrieblicher Sozialleistungen. Doch die entstehende Spanne zwischen Tarif- und Effektivlöhnen erklärt sich nur z.T. aus solchen aus der Konkurrenz um die knapp werdende Ware Arbeitskraft hervorgehenden ,freiwilligen" Leistungen. Zum anderen Teil hat sie ihre Ursache in Uberstunden, Utbererfüllung von Akkord und auch in den Veränderungen in den Lohn strukturen und Lohnformen - hier zunächst immer nur auf der Ebene von Einzel-

189) Die Aktion wurde 1955 vom Vorstand der IG-Metall eingeleitet (vgl. ebda., S. 158ff.)

190) Ebda., S. 168

191) Ebda, S. 161/62; vgl. auch Günter Friedrichs, Technischer Fortschritt und Beschaftigung in Deutschland, in: Automation und technischer Fortschritt in Deutschland und den USA, Ffm 1963, S. $118 / 119$ 
betrieben. (192) Die Spanne zwischen Tarif- und Effektivlohn hat in der Mehrarbeit demnach u.a. ihre Begründung. Das bei der Darstellung neverer Methoden der Lohnzahlung aufgezeigte Obsoletwerden der traditionellen Lohngruppeneinteilungen, die Umwälzung der betrieblichen Qualifikationsstruktur und - früher oder später auch der Lohnstruktur durch die Einführung von Verfahren vorbestimmter Zeiten,

- die Ablösung des Akkordlohns durch den Prämienlohn, die Enführung der analy tischen Arbeitsplatzbewertung etc. führen dazu, daß die zentralen tarifvertraglichen Instrumente und Formen zur Erkämpfung und Absicherung eines einheitlichen Lohnniveaus nicht mehr reichen. Die zentralen Lohnverhandhungen verlieren an Bedeutung fur den tatsächlich ausgezahlten Lohn, was u.a. am Abbau übertariflich bezahlter Löhne vor oder nach den Tarifverhandlungen deutlich wird. Die Festsetzung des Lohns verlagert sich im Zuge der oben beschriebenen Veränderungen in der stofflichen Gestalt des Produktionsprozesses und in der Verwertungssituation des Kapitals zunächst zunehmend auf die Betriebsebene. Zwar wird in den 60er Jahren die analytische Arbeitsplatzbewertung innerhalb der regionalen Manteltarifverträge progressive als Grundlage der Lohneinstufung anerkannt, doch bedetztet dies bei der außerordentlichen Vielfalt der Arbeitsbewertungssysteme (insgesamt mindestens 60!), die sich zudem noch dauemd verändern, was die Gewichtung von Einzelmerkmalen angeht, faktisch die Anerkennung eines betrieblichen Freiraums der Lohnfestsetzung durch die Kapitalisten und damit zunächst den Verzicht auf das gewerkschaftliche Monopol der Aushandlung des Preises der Arbeit. Das gleiche gilt für die neuen Prämienlohnformen. Zwar wird ihre tarifliche Absicherung programmatisch angestrebt, doch kommen weitgehend - und dies ist durchaus der Form des Prämienlohns adäquat - vor allem Betriebsvereinbarungen zustande, die sich won zentralen Tarifverhandlungen dadurch entscheidend abheben, daß sie kurzfristig kündbar und-rechtlich-nicht mittels Streik erzwungen werden können. Die Streichung der Prämien kann gegebenenfalls nur durch Kampfaktionen der Beleg. schaft, die dann als wilde Streiks gelten, verhindert werden.

$\mathrm{Zu}$ dieser Verlagerung der Lohnfestsetzung auf die Betriebsebene im Prozeß der Veränderung traditioneller Formen der Lohnzahlung kommt hinzu, dab die zentrale Tarifpolitik der Gewerkschaften sich in der Aushandlung der Lohnhöe und der Arbeitsbedingungen nicht an den prosperierendsten Betrieben der jeweiligen Branchen orientierte, sondern nur die Untergrenze der Lohnerhöhung in den. jeweiligen Tarifgebieten festsetzt. (193) Doch die damit angestrebte Vereinheitlichung des Lohnniveaus wird aufgrund der 0 .a. entgegenwirkenden Tendenzen nicht erreicht. So war auch die Gewerkschaft - mit Ausnahme des Síreiks in Baden-Württemberg im Jahre 1963 - nicht zur $A$ ustragung größerer Streiktewegun-

192) An Eckart Teschners Auisatz, Zentraisierte Lohpolitk und betrichliche Lohntindmg, in: Kritisches Jahrbuch 72, a.a.O., S. 123, ist zu kritisieren, dar er sich bel der Aufzäh lung der Grüde fü die Spanne zwischen Tanfo und Effektivbhnen unefektiert aur die bürgerliche Literatur bezieht und dadurch die Mehrarbeit als eine wesentiche Grindlage dieser Spanne ibersieht.

193) Vgl. Pfeiffer/Krusche, S. 125/126; vgl. auch zum Gesantproblen: Institut für Sozialforschung, $Z$ wischenbericht iber den Stand der Arbeiten zum Forschungsprojekt: Die Funktion der Gewerkschaften im Prozeß der gesellschaftichen Eatwicklung in West. deutschland, Ffm 1969 
gen und damit der dazu erforderlichen Mobilisierung ihrer Mitglieder gezwungen. Wenn aber ein wichtiger Teil des Lohns vom Einzelunternehmer festgelegt wird, wenn seine Absicherung allenfalls aufgrund einer Abmachung zwischen Betriebsrat und Unternehmensleitung vorübergehend möglich wird, wird auch das Interesse der Arbeiter an gewerkschaftlicher Organisierung zunächst geringer. Der gewerkschaft.m liche Schutz der Arbeitsbedingungen und der Lohnhöhe erscheint unter diesen Bedingungen als nicht notwendig, insofern dieser Schutz in der Tat nur partiell besteht, (194) und der Betriebsrat wird im Bewußtsein der Arbeiter zu der entscheidenden - wenn auch nur betrieblichen - Interessenvertretung. (Hier soll noch einmal darauf hingewiesen werden, daß es sich hier nur um die Darstellung von Entwicklungstendenzen in den beginnenden 60er Jahren handelt. Es wird noch z zeigen sein, unter welchen Bedingungen der gewerkschaftliche Kampf um die Loinrate wieder notwendig an Bedeutung gewinnt.)

Das Konzept der betriebsnahen Tarifpolitik, das von der Gewerkschaftslinken in der IG-Metall und der IG-Chemie zu Ende der 50er Jahre proklamiert wurde, ist eine Antwort auf diese Verhältnisse. „Die Strategie der betriebsnahen Tarifpolitik knüpft an die beiden geschilderten Momente an: an der Spanne zwischen Tarif- und Effektivverdiensten, sowie an der mangelnden Mitwirkungsmöglichkeit der Basis an den Entscheidungen der Tarifverhandlungen." (195) Dabei wird nicht reflektient, daß eine solche Strategie nur dann überhaupt Aussicht auf Erfolg haben könnte, wenn sie auf Widerspruchserfahrungen bei den Arbeitern antworten würde. Nur unter der Bedingung, daß die Arbeiter und Angestellten ihre mangelnde Mitwirkung als Grund für die von ihnen als zu gering eingeschätzten Lohnerhöhungen begreifen (wie dies dann später in den Septemberstreiks der Fall war), und nur, wenn sie die Erfahrung machen, daß die Spanne zwischen Tarif- und Effektivlöhnen tatsächlich vom Unternehmer als Mittel der Lohnsenkung eingesetzt wird (wie in der Krise 1966/67 geschehen), können solche Konzepte überhaupt Gegenstand der Auseinandersetzung bei Gewerkschaftsmitgliedern und unteren Gewerkschaftskadem werden. Da jedoch weder grundsätzliche Widersprüche zwischen der Politik der Betriebsräte und der der Gewerkschaften vorhanden waren, (196) auf der anderen Seite von den Arbeitern selbst kein Widerstand gegen die offizielle Politik vorgetragen wurde, mußte das Konzept der betriebsnahen Tarifpolitik aufgrund seines formal-organisatorischeh Charakters erfolglos bleiben, wenn zudem, wie Preiffer

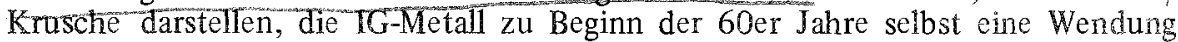
ihrer Politik in Richtung auf eine stärkere Unterstützung der Betriebsräte vollzog. (197) Sie paßte sich den vom BVG gesetzten Grenzen an, was darauf hinauslief, die Vertrauensleute als verlängerten Arm von Betriebsrat und Ortsverwaltung zur Effektivierung der Politik von Betriebsrat und Gewerkschaftsapparat zu betrachten. (198) Denn an den Punkten, an denen nun tatsächlich im Gefolge u.a. der Arbeits-

194) Krusche/Pfeiffer, vgl. S. 129. Das Absinken des gewerkschaftlichen Organisationsgrads findet in den 60 er Jahren hierin eine wichtige Begründung.

195) Autorenkollek tiv: express in ternational, Gewerkschaftliche Vertrauensleute fur eine amikapitalistische Betriebsstrategie, Offenbach o.J. (1972), S. 23

196) Vgl. dazu Zwischenbericht, Die Funktion ..., a.a.O., S. 177 und 185, vor allem aber Anhang II

197) Krusche/Pfeiffer, vgl. S. $175 f$.

198) Vgl. ebda., S. $183 \mathrm{ff}$. 
zeitverkürzungen der Angriff des Kapitals auf die Lebensbedingungen der Arbeiter cinsetzte, gab es keine prinzipiellen Unterschiede zwischen der Politik der Gewerkschaften und der der Betriebsräte. (199)

Zwar wird Anfang der 60er Jahre von gewerkschaftlicher Seite sehr wohl gesehen, daß mit dem ,technischen Wandel ${ }^{6}$ sich zunehmend die Arbeitsplatzanforderungen verändern, psychische Belastungen sich verstärken, monotone Arbeitsformen zunehmen und daß eine beträch tliche ,Lohnunsicherheit ${ }^{6}$ existiert. (200) Doch läuft die reale Politik in den Betrieben vor allem den Vorstellungen solcher Gewerkschaftsvertreter parallel, welche primär in einer dem technischen Wandel entsprechenden Differenzierung und Neubegründung der Löhne eine Möglichkeit sehen, die negativen Folgen, die vor allem in der entstehenden Lohnunsicherheit gesehen werden, zu mildern. Die Wiederherstellung der Lohn-Le istungsäquivalenz und ihre tarifvertragliche Absicherung, also die Wiederherstellung einer so verstandenen Lohnsicherheit, wird zu einem Hauptpunkt der Diskussion und Auseinandersetzung zwischen Gewerkschaften und Betriebsräten auf der einen, Kapitalisten auf der anderen Seite. Deutlich vertritt Hans K. Weng, Refa-Experte der IG-Metall in seinem Beitrag zum ersten Automationskongreß der Gewerkschaften 1963 diese Position: ,Wie also der technische Fortschritt die Betriebe gezwungen hat, die Fertigungsvorgänge den neuen Erkenntnissen anzupassen, so sind auch die Gewerkschaften gezwungen, den Tarifvertragstext im Bereich der Lohnfindung oder Lohnbegrïndung anzupassen. “ (201) Die Anpassung wird in einer möglichst differenzierten Betrachtung der Anforderungen des Arbeitsplatzes nach der analytischen Arbeitsplatzbewertung gesehen, die sich ohnehin durchsetze; die Entlohnung nach dem Ausbildungsprinzip sei historisch überholt, denn , je mehr die technische Entwicklung ... zur Hochmechanisierung drängt, desto lauter wird der Ruf nach einer genaueren Betrachtungsmöglichkeit der Arbeitsschwierigkeit." (202) Die Vorstellung von der individuellen Lohn-Leistungsäquivalenz wird von Weng ungebrochen propagiert. ,Die Auffassung von dem Wert, den ein Arbeitsplatz im Verhältnis zu einem anderen hat, wird durch ... Komponenten bestimmt, die sich mit der analytischen Arbeitsplatzbewertung erfassen lassen." (203) Das Problem der

199) Dies unsere These. Es fehlt hier allerdings noch an eingehenderen empirischen Untersuchungen.

200) Vgl. dazu vor allem: 3.-5.7.1963, Erste internationale Arbeitstagung der IG-Metall zu Fragen der Automation und des technischen Fortschritts in Frankfurt/Main, wo u.a. die Notwendigkeit sozialer Kämpfe festgestellt wird, damit auch dic Werktätigen in den Vorteil der großen Möglichkeiten der Automatisierung gelangen. Am 16.-19.3.1965 fïndet die zweite Internationale Arbeitstagung der IG-Metall, Automation-Risiko und Chance" in Oberhausen statt. Im Mittelpunkt steht dic Auswirkung der Automation auf die Arbeiter. Weitere Daten zur Diskussion dieser Zusammenhänge innerhalb des DGB und der Einzelgewerkschaften vgl: Autorenkollektiv, Dic westdeutschen Gewerkschaften und das staatsmonopolistische Herrschaftssystem 1945-1966, Ostberlin 1968, Chronologie (S. 544ff.), Gewerkschaften und wissenschaftlich-technische Revolution (S. 190-209), Dokument Nr. 23, S. 664ff.

201) Hans $\mathrm{K}$. Weng, Lohnfindung an modernen Arbeitsplätzen in Deutschland, in: Automation und technischer Fortschritt in Deutschland und den USA, Ftm 1963, S. $199 \mathrm{ff}$.

202) Ebda., vgl. auch Anhang II, vor allem aber auch dic WWI-Studie von Gerhard Leminsky und Mario Helfert, Der Wandel der Arbeitsanforderungen bei technologischen und organisatorischen Änderungen, WWI-Studien Nr. 19, Köln 1970.

203) Ebda. 
Lohnunsicherheit stellt sich für den Refa- Experten der IG-Metall vor allem ais ein Problem der Verunsicherung des Gefühls der Arbeiter für individuelle Lohngerechtigkeit dar, das durch den Widerspruch zwischen der neuen Gestalt des Arbeitsprozesses und den alten Formen der Lohnfestsetzung zustande kommt. Daß die Arbeitsbewertung, wie ausgeführt, über ihre Differenzierung zur Steigerang der Arbeitsintensität beiträgt, die Konkurrenz unter den Arbeitern im Betrieb verstärks, und über die Neubewertung von Arbeitsplätzen zur Herabstufung (Dequalifizienung) von Arbeitern fihrt, wird dabei von Weng überhaupt nicht reflektiert. (204)

Allerdings ist hier die Position der Lohnexperten der Gewerkschaften nicht einheitlich. So wird z.B. von Pornschlegel durchaus das Rroblem gesehen, dak bei Anwendung der analytischen Arbeitsplatzbewertung und ihrer tarifvertraglichen Anerkennung als System der Bestimmung von Lohngruppen ,eine weitgehende Unsicherheit der Arbeitenden hinsichtlich ihres Einkommens oder ihrer Verdienstchancen" entstehe, ,wobei lediglich die Arbeitsmarktlage augenblicklich noch cinen

204) Zwar muß betonî werden, daß die Probleme gerade der Arbeitsbelastung durchaus immer wieder gesehen werden: So schreibt Otto Brenner, Die Tarifpolitik der IG-Metall, in: werden, Jahrbuch fiir die deutschen Gewerkschaften, S. 37-42: ,In einzelnen Betrieben mit überwiegend klassischer Fertigungsweise sind etwa 50-60\% aller Arbeitsplätze Facharbeits- oder qualifizierte Facharbeitsplätze... Durch die Vereinfachung der Arbeitsar-forderungen als Ergebnis der Rationalisierung und Automatisierung sink $\mathrm{t}$ der Anteî der Facharbeit oder qualifizierten Facharbeitsplätze in vielen Betrieben au $10-15 \%$ allez Arbeitsplätze ab. Eine bedeutende Erhöhung des Facharbeiteriohns bleibt in diesen Betrieben für die Mehrheit der Arbeitnehmer uninteressant. Hinzu kornmen die Methoden moderner Betriebsorganisation, die - wie es beispieisweise in der Elektroindustrie typisch ist - die Arbeit in kleiriste Teloperationcn zerlegt... Die dadurch erzielte Erhöhung der Produktivitat pro Kopf der Arbeitnehmer wird exkauft auf Kosten der Würde des Arbeitnchmers... Dieser Arbeitsteilung steht auf der Lohnseite ein Akkordsystem gegeniber, das den Arbeitnehmer zusätzlieh einem Zeitdruck auslievert. Die bei längerer Übung der vereinfachten Arbeiten erzieiten Lcistungssteigerungen werden durch Kürzung der Akkordzeiten entwertet. Der Arbeitnetmer emält trotz gestiegener Leisturg keinen proportional gestiegenen Verdienst, sondern nur einer verkürten." (ebda., S. 38) Doch bleiben solehe Feststellungen weitgehend korisequenzenlos fir die reale Taktik der Gewerkschaften. Z,war spricht hier Bronner weder von der Notwendigkeit betriebsnaher Tarifpolitik, doch bejaht der gleiche Brenner zwei Jahro später die Verfestigung der sehon herausgebildeten Zentralisierung der Tarîpolitik in der konzerticrten Aktion. 
gewissen Schutz bietet". (205) Es gäbe deshalb Versuche in den Gewerkschaften, Einstufungen wenigstens für die Laufzeit der jeweiligen Tarifverträge zu sichern. „,Damit werden natürlich die sogenannten ,arbeitswissenschaftlichen "Prinzipien dieser Methode zugunsten sozialökonomischer Überlegungen zurïckgedrängt.“6 (206) Pornschlegel geht sogar soweit, einen hohen Zeitlohn in der Form von Monats- oder Jahreslöhnen als Ziel gewerkschaftlicher Lohnpolitik anzugeben. (207) Doch die von Pornschlegel unter dem Gesichtspunkt, daß es Aufgabe der Gewerkschaften sei, den ,sozialen Besitzstand ${ }^{6}$ der Arbeiter zu sichern, angestellten Überlegungen zu den Zielsetzungen einer gewerkschaftlichen Lohnpolitik haben in der tatsächlich eingeschlagenen lohnpolitischen Linie der Gewerkschaften - Orientierung am Prinzip der individuellen Lohn-Leistungsäquivalenz - kaum einen Niederschlag gefunden. (208) In der tarifvertraglichen Praxis wird die Anpassung an die analy tische Arbeitsplatzbewertung ebenso wie an die Verfahren vorbestimmter Zeiten vollzogen. (209) Die Versuche, eine Höherbewertung von nervlicher Belastung und Monotonie bei sogenannten, einfachen ${ }^{6}$ Arbeiten zu erreichen, blieben bisher weitgehend erfolglos. (210) So stehen sich heute, wie Eckart Teschner schreibt, die Ratifikation der lohntechnischen Entwicklungen durch die Gewerkschaften und das Mißtrauen der Belegschaften bei der Einführung neuer Entlohnungsmethoden innerhalb der Betriebe gegenüber. (211)

205) Hans Pornschlegel, Sicherung des sozialen Besitzstands bei technischem Fortschritt in Deutschland, in: Automation und technischer Fortschritt, a.a.O., S. 248.

Die von den technologischen Veränderungen her zu angelernten dequalifizierten traditionellen Facharbeiter erlitten durch Riickstufung in niedrigere Lohngruppen mittels der analytischen Arbeitsplatzbewertung beträchtliche Lohneinbußen. So sank z.B. nach Einführung der Arbeitsplatzbewertung der Facharbeiteranteil in einem untersuchten Apparatebaubetrieb von ursprünglich $41.8 \%$ auf $15 \%$; damit war gleichzeitig Herabstufung in den Lohngruppen und d.h. langfristig Lohnsenkung verbunden. (Vgl. Geschäftsbericht der IG-Metall 1962-1964, S. 62f., Ffm 1965)

Dic Arbeiter an Steuer- und Überwachungsapparaturen werden je nach Arbeitsschwierigkeit per AA entlohnt und kommen so z.T. auf relativ hohe Löhne bei qualifizierten Tätigkeiten wie Einrichter, sind aber permanent der Gefahr von Lohnminderungen bei of t nur geringfügigen Arbeitserleichterungen durch Rationalisierungsmaßnahmen ausgesetzt.

Im Instandhaltungssektor treten aufgrund der beschriebenen Rationalisierungsbemühungen gerade in letzter Zeit beträchtliche Konflikte um die Verschärfung des Arbeitstempos und um die Lohnhöhe auf. (z.B. Streik der Handwerker bei Continental im letzten Jahr gegen das dort 1963 eingeführte UMS-Akkordsystem.)

206) Pornschlegel, a.a.O., S. 248

207) Ebda., S. 258

208) Vgl. Teschner, a.a.O., S. 143: Zu Pornschlegel sei allerdings noch bemerkt, daß es ihm keinesfalls um die Aufhebung der innerbetrieblichen Lohndifferenzierung geht. Ihm schweben einfachere Methoden der Lohngruppierung vor, „die auf summarische sozioökonomische Wertung der Tätigkeiten zurückgreifen", wie z.B. Lage am Arbeitsmarkt, Verhandlungsstärke der Tarifvertragsparteien, betriebswirtschaftliche Bedeutung der Arbeit splätze, notwendige soziale Hierarchie. (vgl. ebda. S. 258)

209) Vgl. dazu Anhang II; Die Etablierung der AA findet etwa u.a. in den Lohnrahmentarifverträgen 1966 für Nordrhein-Westfalen oder 1968 für Baden-Württemberg statt;

210) siehe nächste Seite

211) siehe nächste Seite 
Erzeugte das Obsoletwerden alter Lohnformen und damit auch der tarifvertraglichen Absicherung der betrieblich gezahlten Löhne zusammen mit der allgemeinen Arbeitskräfteknappheit in den beginnenden 60er Jahren zunächst einen Verhandlungsspielraum für die Betriebsräte, so macht Teschner heute die wichtige Feststellung, daß die Ratifikation der vom Kapital initiierten neueren Entlohnungsmethoden durch die Gewerkschaften auch zunehmend den Handlungsspielraum der Betriebsräte in Bezug auf den bisher noch bestehenden Einfluß auf die betriebliche Lohnfindung einengt. Nach Teschner sind AA, VvZ und die Spielarten der Festlohnformen (bei uns unter Prämienlöhnen angeführt) Instrumente der Unternehmen, , den jenseits des Tarifvertrags vorhandenen lohnpölitischen Spielraum der Belegschaften und Betriebsräte einzudämmen und die Prozesse betrieblicher Lohnpolitik unter die Kontrolle des Managements zu bringen" (212) Hinzuzusetzen wäre, daßs dieser Verhandlungsspielraum des Betriebsrats zusätzlich durch eine - mit stagnativen Tendenzen der Akkumulation einsetzende - ,Entspannung des Arbeitsmarkts eingeengt wird. Von da aus würde aber auch - und dies wäre zu untersuchen - einem passiven Verhalten der Arbeiter, gekennzeichnet durch die Delegation ihrer Interessen an den Betriebsrat und die mangelnde unmittelbare Einsicht in die Notwendigke it gewerkschaftlicher Organisation als Form der Organisation der eigenen Kämpfe gegen das Kapital, die Basis entzogen. In diesem Zusammenhang müssen

210) Nach wie vor haben Fließbandarbeiterinnen bzw. -arbeiter zwar einerseits die stärksten Belastungen, werden aber gleichzeitig auch angesichts ihrer geringen Ausbildung über die AA in den untersten Lohngruppen gehalten. Trotz formalen Gleichheitsgrundsatzes zwischen Männern und Frauen im Arbeitsprozeß werden den Lohngruppen sogenannte Leichtlohngruppen ,vorgeschuht', was eine Minderentlohnung um über $1 / 3$ erlaubt.

Einen groben Ưberblick, an welchen Punkten vor allem die Betriebsräte das Interesse der Arbeiter bei der Einführung neuer Lohnsysteme wahren sollen, gibt u.a. der Arbeitsmittelkatalog der IG-Metall für die BRD, Nr. 5, 1967, wo die zur Verfügung stehenden Tonbildschauen, Filme und Arbeitsmittel für die Schulung der Betriebsräte und Vertrauensleute jeweils mit kurzen Erläuterungen versehen sind. Dort heißt es u.a.: „Immer mehr breitet sich die Prämienarbeit aus. Auch hier müssen Erholungszeiten als bezahlte Pausen gewährt werden. Häufig genug versuchen die Arbeitgeber, beim Prämienlohn an den Erholungszeiten vorbeizukommen. Das sollte kein BR zulassen. Immer mehr Arbeiter arbeiten unter Zeitdruck ..." (S. 101)

„Betrachtet man die Geschichte des Arbeitsstudiums, so stellt man mit Erstaunen fest, die einfachsten Erkenntnisse der Arbeitsphysiologie und der Arbeitspsychologie sind bei der Entwicklung in gröblicher Weise vernachlässigt worden. Hier liegt ein großer Nachholbedarf zum Wohle der arbeitenden Menschen." (S. 99)

Einer der wichtigsten Autoren der IG-Metall in Fragen Arbeitsorganisation, Hans Pornsehlegel, hat mehrere Arbeitshefte, u.a. zusammen mit anderen verfaßt. Bei der Einführung von Verfahren vorbestimmter Zeiten sollen nach ihm Betriebsräte und VK auf folgendes achten: , 1. Die Handlungs- und Verhandlungsfreiheit über die Regelung des Verhältnisses Geld- Leistung-örtliche Arbeitsbedingungen muß gewahrt bleiben. 2. Eine der jewciligen Situation angemessene Höhe der Mindestverdienste ist sicherzustellen. 3. Das Verfahren zur Festlegung der Zeitvorgaben, der Prämiennormen ... etc. ist genau zu regeln. Die Mitbestimmung des BR muß garanticrt sein. 4. Die für die Situation am Arbeitsplatz maßgeblichen Sonderbedingungen müssen in jedem Einzelfall besonders geregelt werden können. 5. Die Ermittlung der gezahlten Verdienste und der erbrachten oder abgeforderten Leistung muß für die betroffenen Arbeitnehmer verständlich sein. (S. 180)

211) Vgl. Teschner, a.a.O., S. 143

212) Fibda. 
sowohl die Betriebsrätewahlen 1972 als auch die Entwicklung einer Vertrauensleuteopposition etwa in der IG-Metall und der IG-Chemie untersucht werden.

Kennzeichnend für die Automationskongresse der IG-Metall war, daß von Gewerkschaftsseite Technik als Sachzwang, dem man sich anpassen müsse, begriffen wurde. Zwar werden gründlich die Gefahren, die in der ,technischen Entwicklung ${ }^{6}$ liegen, reflektiert, vor allem das Problem möglicher allgemeiner Verunsicherung der Arbeiterexistenz in der Form von Dequalifikation und Arbeitsiosigkeit, doch wird davon ausgegangen, daß es Aufgabe und Möglichkeit gewerkschaftlicher Politik sei, die technischen Errungenschaften zum Vorteil für die ,arbeitenden Menschen ${ }^{6} \mathrm{zu}$ wenden. Die mit der Entwicklung des gesellschaftlichen Reichtums als Tendenz gesetzte Verschlechterung und Verunsicherung der Lage der Arbeiter wird nicht als notwendige Folge der kapitalistischen Form der Entwicklung dieses Reichtums begriffen. Doch die Entwicklung der wirklichen Verhältnisse läßt solche naiven Re. forme und Fortschrittsvorstellungen zunehmend obsolet werden. Sie werden zur bloßen, den Erfahrungen der Arbeiter widersprechenden Ideologie und dienen dann nur noch der Legitimation der Anpassung gewerkschaftlicher Politik an die Bedürfnisse der Kapitalakkumulation, wenn die Gewerkschaften nicht dazu bereit und in der Lage sind, alle Möglichkeiten zur Initiierung von Kämpfen der Arbeiter gegen Intensifikation der Arbeit, Lohnherabstufung, Betriebsstillegungen etc. wahrzunehmen ohne Rücksich $t$ auf die Bedürfnisse des Kapitals.

Zwar kann man zumindest für die beginnenden 60er Jahre feststellen, daß sich die Politik von Gewerkschaftsapparat und Betriebsräten im Zusammenhang mit dem Verhalien der Arbeiter selbst erklären läßt, doch diese Erklärung zeigt, daß die Gewerkschaft als Organisation sich nicht die Aufgabe stellt, die Widerstandskraft der Arbeiter gegen die Angriffe des Kapitals zu entwickeln. Die mangelnde Mobilisierung der Arbeiter zu Streiks, die Zentralisierung der Lohnverhandlungen und die damit verbundene mangelnde Beteiligung der Gewerkschaftsbasis an den Auseinandersetzungen mußte selbst wieder das Bewußtsein der Arbeiter verstärken, daß sie dem Kapital als einzelne gegenüberstehen, wenn sie um den Preis ihrer Arbeit markten und untereinander sich im Zustand der Konkurrenz befinden, so daß sich die Ansprüche gegen das Kapital auf den Anspruch des gerechten Preises für die geleistete Arbeit reduzieren. Finden keine kollektiven Kämpfe statt, bestehen andererseits auf betrieblicher Ebene keine Institutionen, die auch von sich aus in einer Phase der relativen Prosperität der Arbeiterklasse zu kämpfen in der Lage sind, so kann sich auch kein Klassenbewußtsein entwickeln. Die Konflikte werden als individuelle, allenfalls Guppenkonflikte formuliert und an den Betriebsrat herangetragen, welcher sich wiederum durch Einfihhrung von - den Schein des individuell gerechten Lohns bestärkenden - wissenschaftlichen Entlohnungsmethoden eine Konfliktlösung erwarten muß. Indem nun aber die Gewerkschaft selbst keine alternative Strategic zur indiviauellen Konfliktösung des Betriebsrats im Falle von "Lohnungerechtigkeiten" entwickelte, konnten dic Vertrauenskörper als Gewerkschaftsorgane auch nicht vons sich aus einen allgemeine ren Kampf um Kontrolle der Arbeitsbedingungen entwickeln.

Hier scheint jedoch noch ein anderes Moment eine wesentliche Rolle zu spielen: Die großen Umschichtungen in der Arbeiterklasse und ihre Auswirkungen auf die gewerkschaftliche Organisation. Die Neuzusammensetzung der Arbeiterklasse in der BRD, die sich in den 50 er Jahren andeutet und in den 60er Jahren voll sichtbar wird, lauft, wie in 2. Abschintt des vorliegenden Aufsatzes gezeigh, zu- 
nächst darauf hinaus, daß Teile der westdeutschen Arbeiter in Facharbeiter- und bestimmte Angestelltenschichten aufsteigen, während die Schichten der ungelernten und angelernten Arbeiter (z.B. mit Montagetätigkeiten), die zunächst am stärksten von der Intensifikation der Arbeit betroffen sind, inzwischen vor allem aus Frauen und Arbeitsemigranten bestehen. Dabei ist kennzeichnend, daß die Vertrauenskörper primär von Facharbeitern gestellt werden, während die Frauen und die ausländischen Arbeiter vergleichsweise gering in den betrieblichen Vertretungsorganen (also im Betriebsrat und in den Vertrauenskörpern) repräsentiert sind. Dies scheint ein wesentlicher Grund dafür zu sein, daß die Vertrauenskörper selbst bisher noch kaum ein Organ des Kampfes gegen die unmäßige Vernutzung der Ârbeitskraft geworden sind. Zwar ist in den besonderen Lebensverhältnissen dieser Lohnarbeiter selbst ein Grund zu suchen, warum bisher nicht von ihnen aus ein kollektiver Widerstand entwickelt wurde. Das Dasein als Lohnabhängiger wird hier z.T. als vorübergehendes begriffen. Weil das proletarische Lebensschicksal nicht als Lebensperspektive erfahren wird, erscheint auch die unmäßige Vernutzung der Arbeitskraft durch das Kapital als ein vorübergehender Zustand. Besonders den Arbeitsemigranten, die nur einige Jahre in der BRD arbeiten wollen und sich dann den Aufbau einer kleinbürgerlichen Existenz in ihrem Heimatland erhoffen, kommt es darauf an, möglichst viel Geld in möglichst geringer Zeit zu verdienen, was sie selbst an einer außerordentlichen Verausgabung ihrer Arbeitskraft interessiert, wenn diese mit Lohnerhöhungen verknüpft ist. Hinzu kommen die quasi rechtlose Position dieser Arbeiterschichten und die Sprachschwierigkeiten. Alle Momente zusammengenommen, die Ohnmachtsituation, das Fehlen einer proletarischen Lebensperspektive und die mangelnde Repräsentation dieser Arbeiterschichten in den VK und BR bilden die Grundlage dafür, daß von diesen Schichten der Arbeiter bisher kein wesentlicher Widerstand gegen die Ausraubung der Arbeitskraft entwickelt wurde.

Wenn jedoch die Illusionen, die das proletarische Schicksal als ein vorïbergehendes erscheinen lassen, ihre Wirksamkeit verlieren, wenn der Druck des Kapitals den Widerstand dieser Arbeiterschichten erzwingt, so kann die Tatsache, daß die Gewerkschaften selbst institutionell als Vertrauenskörper nicht in diesen Schichten verankert sind, dazu führen, daß der Widerstand außerhalb und z.T. - dies hängt von den örtlichen Verhältnissen ab - gegen die offizielle Gewerkschaftspolitik entwickelt werden muß. Eine Reaktualisienung der Gewerkschaften zum Kampfinstrument gegen die unmäßige Vernutzung der Arbeitskraft verläuft nicht als widerspruchsloser Prozeß, in dem sich die Gewerkschaften kontinuierlich und bruchlos transformieren. Dabei vernachlässigen u.E. sowohl die DKP als auch antigewerkschaftliche Gruppen wie die BMW-Gruppe in München (Arbeitersache) und die Gruppe Revolutionärer Kampf bei Opel-Rüsselsheim, bestimmte Punkte der Entwicklung von Kapital, Lage der Arbeiterklasse und gewerkschaftlichem Kampf. Während die DKP nur bedingt anzuerkennen scheint, daß die historische Entwicklung der Gewerkschaften als zentrale Institution und in den Betrieben dazu geführt hat, daß bestimmte Gegensätze der Arbeiter gegen das Kapital von ihnen nicht formuliert und zum Kampfinhalt gemacht werden (vgl. z.B. das weitgehende Versagen der IG-Metall, was den Kampf für die Interessen der ausländischen Arbeiter angeht, weshalb der Gegensatz der unteren Arbeiterschichten gegen das Kapital sich z.T. auch gegen die offizielle Gewerkschaftspolitik formulieren muß), sind auf der anderen Seite Gruppen wie die BMW-Gruppe undRevolutionärer Kampf nicht in der Lage, zu begreifen, daß es besondere historische, also veränder- 
bare Bedingungen sind, die die Gewerkschaften unfähig machen, ein bestimmtes Moment des ökonomischen Gegensatzes der Arbeiter gegen das Kapital zu formulieren und in ihre Auseinandersetzung mit dem Kapital einzubeziehen. Die antigewerkschaftliche Politik dieser Gruppen, die auf die Propagierung qualitativ neuer Formen der Organisierung hinausläuft, ist blind für die Tatsache, daß der Kampf gegen die unmäßige Vernutzung der Arbeitskraft durch das Kapital durchaus in den Rereich gewerkschaftlichen Kampfes gehört, also nur eine Seite des Interessenwiderspruchs zwischen Kapital und Ärbe it darstellt und demgemäß jede Politik es sich zum Ziel setzen muß, die Gewerkschaften zü befähigen, diesen Kampf wieder auf. zunehmen.

\subsection{Perspektiven innergewerkschaftlicher Opposition}

In den Thesen zur Gewerkschaftsanalyse sind wir davon ausgegangen, daß die Entwicklung und die konkrete Gestalt der gewerkschaftlichen Organisationen der Arbeiter nicht unabhängig von dem historischen Entwicklungsstand der Kapitalakkimulation und der daraus resultierenden Lage der Arbeiter untersucht werden kann. Dies gilt insbesondere dann, wenn es um die Herausarbeitung von Strategien zur Organisation des Kampfes der Arbeiter gegen das Kapital geht. Es zeigt sich aber, daßs auch interne Auseinandersetzungen in der Gewerkschaft, vorgetragen von der Gewerkschäftslinken, immer wieder von der unbefragten Voraussetzung ausgehen, als sei die Reorganisation der Gewerkschaften zu Kampfinstrumenten der Arbeiterklasse vor allem Resultat der Willensanstrengung und der Schaffung verbesserter organisatorischer Formen. Wir fuihren dies an, weil in Bezug auf unsere Frage nach dem Zusammenhang von Kapitalakkumulation, Intensifikation der Arbeit, Lage der Arbeiter und Organisationsformen des Klassenkampfes die jüngst von ,express-international" herausgegebene Broschüre "Gewerkschaftliche Verirauensleute - für einc antikapitalistische Betriebsstrategie" (213) relevant ist. Dort heißt es: „Der traditionelle Lohnkampf hat zwar nicht an Aktualität verloren, es zeigt sich aber, daß er längst nicht mehr hinreicht, die Auswirkungen der kapitaIistischen Produktionsweise auf den Einzelnen im Betrieb zu mildern. Gewerkschaftlicher Kampf muß also entschiedener als bisher auch Kampf um dic Arbeitsbedingungen werden." (214) Die Forderung nach Stärkung des Vertrauenskörpers und seiner organisatorischen Stellung, gegenüber den Betriebsräten und übergeordneten Gewerkschaftsgremien" (215) basiert wesentlich auf der Erfahrung, daß unter den gegenwärtigen Bedingungen die Gewerkschaften nicht in der Lage sind, selbst den Abwehrkampf gegen die täglichen Angriffe des Kapitals auf die Lage der Arbeiter im Betrieb zu organisieren. Zur Durchsetzung der Forderung wird an die Vertrauensleute der Appell gerichtet, sich „neue Aktions- und Organisationsmöglichkeiten" $\mathrm{zu}$,erkämpfen, und dies teilweise gegen dic lokalen Gewerkschaftsorganisationen und teilweise gegen die Betriebsräte." (216) Dabei wird zwar ge-

213) Autorenkoilektiv, ,express-international", a.a.O.

214) Ebda., S. 11

215) Ebda, S. 17, vgl auch S. 19

216) Ebdan, S. 43 
sehen, daß eine solche Veränderung der Kräfteverhältnisse und eine Stärkung der gewerkschaftlichen Basis nur unter dem Druck der Arbeiter selbst erfolgen kann, doch wird dieser wieder davon abhängig gemacht, wieweit es den Vertrauensleuten gelingt, die „Mitglieder für ihre Politik zu gewinnen." (217) Ansatz der politischen Strategie bleibt also die Vorstellung von einer Selbsttransformation der Vertrauenskörper in ein gewerkschaftliches Kampforgan, welches die auf Betriebsebene auftretenden Widerspriiche der Arbeiter gegen das Kapital formuliert und organisiert, was in dieser Form auf einen mehr oder weniger voluntaristischen Appell an das Klassenbewußtsein dieser Gewerkschaftsorgane hinausläuft: Voluntaristisch deshalb, weil nicht gezeigt wird, wie es zur gegenwärtigen Situation der Verkümmerung der betrieblichen Gewerkschaftsorgane kommen konnte und welche Momente in der Lage der Arbeiterklasse ihre Aktualisierung als Organisatoren des betrieblichen Kampfes überhaupt ermöglichen, welche ihr entgegenstehen.

Dabei wird die mangelnde Reflexion auf die Genese der gegenwärtigen Situation, nämlich die Unfähigkeit der Gewerkschaften, den Kampf gegen die maßlose Vernutzung der Arbeitskraft im Produktionsprozeß zu tragen und vorwärtszutreiben, unter anderem auch daran deutlich, daß ein wichtiger konkreter Organisationsvorschlag von einer Einschätzung der Lage der Arbeiter im Produktionsprozeß ausgeht, die nicht als realistisch angesehen werden kann. Es handelt sich um das Konzept der Mitbestimmung am Arbeitsplatz ,Die Mitbestimmungsrechte der Arbeitsgruppe hätten sich auf alle den Arbeitsplatz betreffenden Fragen zu erstrecken.“ (218) Dieses Konzept wird deshalb für „,realitätsnah" gehalten, weil das „Produktionsinteresse der Geschäftsleitung ... vorerst nicht berïhrt" werde. „Im Gegenteil: die relative Unabhängigkeit der Gruppe wird oft steigende Arbeitsleistungen zur Folge haben. “ (219) Die Realitätsnähe des Konzepts geht demnach davon aus, daß die formale Despotie des Kapitals zunächst wesentlicher von den Arbeitern erfahrener Inhalt des Widerspruchs zwischen Arbeit und Kapital im Betrieb sei, und nicht etwa der Trieb des Kapitals, ohne Rücksicht auf die praktischen Lebensbedürfnisse der Arbeiter Mehrarbeit aus ihnen herauszupressen. Denn wie sollten sonst die Arbeiter und die Kapitalisteñ für ein solches Konzept interessiert werden können.

Nach dem im ersten und zweiten Abschnitt des Aufsatzes Entwickelten, kann eine solche Vorstellung jedoch sich entweder nur auf eine Phase der Kapitalentwicklung in der BRD beziehen, wo das Kapital aufgrund der Kürzung der Arbeitszeit auf der einen, Einführung technischer Neuerungen und gleichzeitiger Prosperität des Kapitals auf der anderen Seite (Ende der 50er bis Mitte der 60er Jahre) noch keine strenge "Kostenplanung" und Rationalisierung des gesamten Produktionsprozesses durchgeführt hatte, sodaß seine Despotie z.T. wirklich formalen Charakter haben mochte, weil nicht voll identisch mit ihrem Inhalt, der Steigerung der Produktivkraft der Arbeit ohne Rücksicht auf den Arbeiter. Denn eine Steigerung der Arbeitsleistung bei Kontrollrechten der Arbeitsgruppen am Arbeitsplatz kann nur dann vorausgesetzt werden, wenn den Gruppen vorher ,Freiräume` zur Zurück-

217) Ebda.

218) Ebda., S. 32

219) Ebda., S. 33 
haltung von Arbeitsleistung gegeben waren und insgesamt der Produktionsprozeß noch nicht unter dem Druck sinkender Profite vollends durchorganisiert war. Oder das Arbeitsgruppenkonzept bezieht sich von vornherein nur auf solche Facharbeiterschichten, welche vom besonderen Charakter ihres Arbeitsprozesses her noch nicht der totalen Kontrolle der Arbeitsleistung unterzogen werden können. Wahrscheinlich spielen beide Momente eine Rolle beim Zustandekommen des Konzepts. Wichtig ist jedoch, daß die Propagierung dieses Konzepts als ,realitätsnah', weil nicht unmittelbar dem Interesse des Kapitals widersprechend, notwendigerweise die Bedingungen unter den Tisch fallen lassen muß, unter welchen allein ein Druck der Basis zur Aktualisierung der Vertrauenskörper als betrieblichen Kampforganen erfolgen könnte: Nämlich Widerstand gegen die Unerträglichkeit des Arbeitsleids, und nicht ein demokratisches Bedürfnis der Arbeiter zur Selbstbestimmung an sich. Entspringt aber die Bewegung der Arbeiter dem Widerstand gegen den maßlosen Gebrauch der Arbeitskraft, so ist völlig illusorisch, daß das Kapital hier selbst ein Interesse hätte, Arbeiterkontrolle einzuführen. Es gesteht sie allenfalls zeitweise im Gefolge und der immer erneuten Androhung harter Kämpfe zu, wie dies gegenwärtig in Italien der Fall ist. Wobei solche Zugeständnisse selbst wieder Momente der Krise des Kapitals werden können, d.h. aber auch der Verunsicherung der Lage der Arbeiterklasse.

In der vorgetragenen Form weist die in der o.a. Broschüre enthaltene Konzeption einer Vertrauensleutestrategie voluntaristische Momente auf. Doch läßt sich andererseits aus den entwickelten Tendenzen zunehmender Intensifikation der Arbeit, wachsender Belastung der Arbeiter, Dequalifikationsprozessen bis in die Schichten ehemals privilegierter Facharbeiter hinein, aus der allgemeinen Verunsicherung der Arbeiterexistenz aufgrund von Betriebsstillegungen und Freisetzungen und den daraus den Arbeitern aufgezwungenen Konflikten eine reale Grundlage dafür ableiten, weshalb eine antikapitalistische Vertrauensleutestrategie an Bedeutung gewinnen kann. Wir waren davon ausgegangen, daß die realen Tendenzen des Akkumulationsprozesses des Kapitals in der BRD der 70er Jahre überhaupt erst die Grundlage bilden, auf der sich vereinheitlichende Kämpfe der Arbeiter entfalten können. Dabei bleibt bis jetzt die Frage ungelöst, in welcher Weise die organisatorische und politische Vermittlung dieser Widersprüche unter den gegebenen Bedingungen in der BRD erfolgen kann. Unter gegebenen Bedingungen sind hier die organisatorischen Formen der Arbeiterklasse gemeint. Sic lassen sich - grob umrissen - folgendermaßen kennzeichnen. Im Gegensatz etwa zu England aber auch bis jetzt noch zu Italien und Frankreich bestehen in der BRD der Form nach stark zentralisierte und funktionsfähige Industriegewerkschaften, die eben dieser Form nach ein mächtiges Kampfinstrument der Arbeiterklasse gegen das Kapital sein könnten. Doch diese Zentralisierung ist ihrem jetzigen Inhalt nach nicht Produkt der Klassenkämpfe des Proletariats, sondern historisches Ergebnis des Klassenkampfs von oben. Drei Momente sind historisch hicr wirksam geworden: 1. Die Politik der Alliierten, welche auf eine Stabilisierung der reformistischen Gewerkschaftsführungen gegenüber der unter dem Einfluß der Kommunisten stehenden Organisation der Arbeiter in den Betrieben hinauslief. 2. Die Organisation des Kapitals in den Tarifverhandlungen übte in der Entwicklung der BRD einen starken Druck in Richtung der Zentralisierung vor altem der Tarifverhandlungen aus. 3. Dic Aktionen des Staates zur Begrenzung der Lohnrate erzwangen eine weitere Stärkung der Macht der zentralen Gewerkschaftsapparate im Zuge der 
konzertierten Aktion. Zusammengefaßt ergibt sich also: Zwar existieren zentral geführte und einheitliche Gewerkschaftsapparate, aber der Inhalt dieser Einheit ist nicht die Kampfkraft der Arbeiterklasse gegen das Kapital, sondern die versuchte Festlegung der Arbeiterklasse auf eine systemerhaltende, allenfalls reformistische Politik innerhalb der kapitalistischen Gesellschaft. Politischer Transmissionsriemen dieser Politik ist die Bindung der Gewerkschaften an die SPD, die bisher in ihrer Reformpolitik eine Seite der dem Kapitalinteresse selbst immanenten Widersprüche darstellt, aber keinesfalls die politische Organisation des Gegensatzes der Arbeiterklasse zum Kapital ist. Die DKP als eine Form der politischen Organisierung der Arbeiterklasse ist vergleichsweise schwach. In diesen Zusammenhang muß nun die Konzeption einer antikapitalistischen Vertrauensleutestrategie, deren politische Parole Demokratisiemung der Gewerkschaften lautet, eingeordnet werden. Denn diese Farole implizert in der Tat unter den gekennzeichneten Bedingungen eine Konfliktstrategie, welche auf dem sich entwickelnden Widerspruch zwischen dem historisch entstandenen reformistischen und systemimmanenten Charakter der Gewerkschaften und den tatsächlich erfahrenen und erfahrbaren Widersprüchen zwischen den Lebensbedürnissen der Arbeiterklasse und dem Kapitalverhältnis beruht. (Daher sei hier, um Mißverständnisse von vornherein auszuschließen, darauf verwiesen, daß es sich formell nicht einfach nur um einen Widerspruch zwischen Basis und Apparat, zwischen Mitgliedern und Bürokratie handeli, sondern dałs zum einen der Charakter der gegenwärtigen Politik des Gewerkschaftsapparats mit Sicherheit durchaus dem Bewußtsein eines Teils der Arbeiterklasse entspricht, deren Lage ja nicht einfach von vornherein einheitlich ist, deren Bewußtsein aufgrund mangelnder Klassenkampferfahrung noch viel weniger, und daß zum anderen Widerstand sich durchaus bis hinein in Teile des Apparats formulieren kann.) Doch kommen wir auf die oben genannte Konfliktstrategie zurück. Ist ihr übergeordneter Inhalt auch die Formulierung der dem Kapitalinteresse entgegenstehenden Lebensbedürfnisse der Arbeiter, so sind ihr Ziel- und Angriffspunkt doch zunächst die systemstabilisierenden Momente in der Politik der Gewerkschaften, organisatorisch durchgeseizt durch die Machtberugnisse der Gewerkschaftsführungsgremien gegeniiber der Gewerkschaftsbasis und ihren wichtigsten Organisationsformen, den Vertrauensleuten, Z.T. aber auch den Betriebsräten. (220) Betrachten wir die wirkliche Entwicklung der Forderung nach Demokratisierung der Gewerkschaften, so zeigt sich, daß sich ihr Inhalt gar nicht so sehr auf die Ergänzung der zentral gefuhrten Lobnkämpfe durch betrieblich zu führende Kämpfe um die Verbessenung der Arbeitsbedingungen beschränkt, sondern vielmehr durch den politischen Widerspruch bestimmt ist zwischen einer Gewerkschaftsfuihrung, welche den Versuch macht, die Interessen der Arbeiter nur soweit zu formulieren, wie sie nicht in unvereinbaren Widerspruch mit der gesamtwirtschaftlichen Entwicklung, sprich den Notwendigkeiten der Kapitalakkumulation, geraten, und einer im Ansatz unmittelbar an den Bedürfnissen der Arbeiter orientierten Politik. (Daß eine so umschriebene Politik der Gewerkschaftsführungen selbst wieder u.a. eine reale Basis in der Tatsache hat, daß die Ware Arbeitskraft nur solange vom Kapital gekauft wird, als ihre Anwendung eine für die Akkumulation genügende Profitrate abwirft, braucht

220) Vgl. dazu die Position der Betriebsräte in Baden-Würtemberg, wie sie in dem Film, der Kampf um 11\% deutlich wird. 
hier nich noch einmal ausgeführt werden.) So wird in der Chemietarifrunde 1971 die Forderung nach Demokratisierung unmittelbar in gewerkschaftlichen Massenversammlungen gegen das Einschwenken der zentralen Verhandlungskommission auf die einkommenspolitischen Orientierungsdaten der konzertierten Aktion vehement formuliert und auf der Grundlage dieser Erfahrungen wird auf dem Gewerkschaftstag 1972 der IG-Chemie eine institutionelle Stärkung der Stellung der Vertrauenskörper innerhalb der IG-Chemie durchgesetzt. In der IG-Metall formiert sich der Widerstand an der Frage der konzertierten Aktion, die größte Stimmenzahl gegen den Vorstand kommt auf dem IG-Metalltag 1971 gegen die Manipulationsversuche des Vorstands zustande. (221)

Die Frage, wie sich die als Resultat der Kapitalbewegung für die Arbeiterklasse gesetzten Widersprüche als Konflikte in den Gewerkschaften entwickeln, müßte die Untersuchung der bisher stattgefundenen Konflikte unter den dårgelegten Gesichtspunkten zum Gegenstand haben: 1. Die Konflikte zwischen den Gewerkschaftszentralen, soweit ihre Lohnforderungen sich an einkommenspolitischen Gesichtspunkten orientieren und Vertrauensleutekörpern bis hin zu Betriebsräten, soweit Höhe und Form (lineare Lohnerhöhung) ihrer Forderungen von den Reproduktionsbedürfnissen der Arbeiter ausgehen. (Hier wäre auch die Bedeutung der Tatsache, daß 1972 die IG-Metall auf der einen Seite erstmals lineare Forderungen stellt, auf der anderen Seite aber die Höhe der Forderung letztlich auf die Akzeptierung einer Reallohnsenkung hinausläuft, zu untersuchen.) 2. Konflikte, welche sich auf der Grundlage entwickeln (wo und in welcher Form?), daß weithin die Politik von Gewerkschaften und Betriebsräten hinsichtlich der Einführung neuer Lohnformen noch am Schein der Lohn-Leistungsäquivalenz orientiert ist, diese neuen Formen aber von den Arbeitern andererseits als Mittel der Intensivierung der Arbeit und damit der Steigerung der Arbeitsbelastung z.T. bis zur Unerträglichkeit erfahren werden. Wie entfaltet sich also der Widerspruch zwischen der Ideologie der Lohn-Leistungsäquivalenz und der Ausraubung der Arbeitskraft als Konflikt in den Gewerkschaften? 3. Konflikte zwischen Inhalt und Stoßrichtung von Kämpfen gegen Betriebsstillegungen und der Politik örtlicher und zentraler Gewerkschaftsstellen. Diese Konflikte müssen unter dem Gesichtspunkt untersucht werden, wieweit sie den von den Arbeitern erfahrenen Widerspruch ihrer Interessen zum Kapital und zu einer historisch herausgebildeten und eingefahrenen systemimmanenten Politik der Gewerkschaftszentralen organisatorisch als Konflikt in den Gewerkschaften selbst entwickeln.

Insgesamt kann davon ausgegangen werden, daß es gegenwärtig die primäre Aufgabe ist, diesen Widerspruch in den Gewerkschaften zu entwickeln. (222) Dabei

221) Vgl. auch die Metalltaritrunde 1971, in der es zu scharfer Kritik an der IGM-Führung kam und die ,Order' Funktion der Gewerkschaftsbasis in Streikversammlungen und Basisgremien gegenübur der Gewerkschaftsspitze gefordert wurde.

Sehr deutlich zeigt sich diese Tendenz im Film ,Der Kampf um 11\%" von Busse, A., Mitscherlich, Th. und Peters, Jï., - z.B. dann, wenn die in Mannheim versammelten Streikhelfer den Einigungsvorschlag von $7,5 \%$ diskutieren: "Wir, die versammelten Streikhelfer, lehnen den Vorschlag der Arbeitgeber ab und beordern unsere Mitglieder aus Mannheim, in der großsen Tarifkommission dagegen Stellung zu nehmen und ebenfalls eine ablehnende Haltung zu boziehen."

222) Vgl. dazu z.B. auch die Diskussionen um ,innergewerkschaftliche Demokratic", "proletarische Demokratie in den Gewerkschaften' sowie dic Konzeptionen innergewerkschaftlicher Opposition. Vgl. die Ausgaben des Gewerk schaftsspiegels von 1972. 
stehen sich nicht einfach Mitglieder und Apparat konfligierend gegenüber, sondern der Konflikt entwickelt sich an einzelnen Punkten, formuliert von Arbeiteravantgarden in einzelnen Betrieben; Vereinheitlichung kann unter diesen Bedingungen zunächst nur heißen: Bildung einer Machtposition von solchen Arbeiteravantgarden innerhalb der Gewerkschaften, die es gewerkschaftlichen Machtträgern, die unter dem politischen Einfluß der SPD stehen, verbietet, sei es auf zentraler, sei es auf lokaler Ebene, diesen Widerstand unter dem Schlagwort der Kommunistenbekämpfung zu zerschlagen. Ein solcher Widerstand hat seine materielle Grundlage in den als Resultat der Kapitalbewegung sich entwickelnden Widersprüchen in der Lage der Arbeiterklasse: Denn die materielle Bewegung entzieht selber progressive den reformistischen und systemintegrationistischen Vorstellungen und Ideologien ihre Basis. Heute kann nicht mehr die wirkliche Erfahrung der Arbeiter bestätigt werden, wenn die Gewerkschaft, wie dies auf den Automationskongressen in den beginnenden $60 \mathrm{er}$ Jahren der IG-Metall geschah, propagiert, es käme nur noch darauf an, den technischen Fortschritt zugunsten der Verbesserung der Arbeiter auszunutzen. Arbeitszeitverkürzung und Lohnerhöhung seien mögliche Früchte der Entwicklung des gesellschaftlichen Reichtums (in der Form des Kapitals), die es nun im Interesse des Kapitals selbst (Vergrößerung des Absatzmarktes) durchzusetzen gälte.

Damit soll nun keineswegs der Vorstellung einer automatischen Entwicklung von Klassenbewußtsein mit der Herausbildung von Tendenzen zur Verschlechterung in der Lage der Arbeiterklasse das Wort geredet werden. Es kommt vielmehr darauf an, zu zeigen, wo überhaupt die möglichen Ausgangspunkte zur Entwicklung von Klassenbewußtsein liegen, indem die Ausgangspunkte von Kämpfen in ihrem Zusammenhang mit der historischen Entwicklung des Kapitals in der BRD betrachtet werden. Schließlich entwickeln sich ja auch Konflikte in den Gewerkschaften keineswegs einfach als unmittelbares Resultat der Klassenlage der Arbeiter etwa in dem Sinne, daß die zunächst am schwersten betroffenen Arbeiterschichten oder auch Betriebe gleichzeitig Avantgarden der Arbeiterklasse wären. Besondere Momente, z.B. das Vorhandensein von bewußten Arbeiterkadern in einzelnen Betrieben, die besondere Kampftradition eines Betriebs, oder die besondere Entwicklung und die besonderen Erscheinungsformen der allgemeinen Widersprüche in einzelnen Betrieben oder Branchen sind u.a. der Ausgangspunkt zur Bildung von Arbeiteravantgarden. Je nach der örtlichen Verfassung des Gewerkschaftsapparats, so z.B. dem Grad seiner Verflechtung mit der SPD, entwickelt sich der Widerstand zunächst entweder gegen die offizielle örtliche und betriebliche Gewerkschaftspolitik, oder in Übereinstimmung mit ihr. Es ist ein großer Fehler der DKP, wenn sie die Notwendigkeit dieser widersprüchlichen Bewcgung nicht erkennt, wenn sie die Einheit der A rbeiterklasse im Kampf gegen das Kapital in der Einheit des Gewerkschaftsapparats repräsentiert sieht, wie dies beispielhaft in der Diffamierung der ,Plakat'-Gruppe Stuttgart durch die DKP geschchen ist. Auch wenn eine solche Politik aufgrund der Traumata der falschen RGO-Politik der KP in der Weimarer Republik und den Fehlem von 1953 crklärlich ist, so ist sic nichtsdestoweniger unter den gegebenen organisatorischen Verhältnissen falsch. Dic Entwicklung einer Machtposition von Arbeiterkadern in den Gewerkschaften auf der Grundlage der Existenz von Arbeiteravantgarden in den Betrieben kann nur durch eine immer wieder gemcinsame Politik dieser Kader erreicht werden, dic basieren muß auf der Formulierung des von den Arbeitern erfahrenen Gegensatzes zum Kapital. Wesent- 
lich ist dabei die Möglichkeit der Entwicklung eines Klassenbewußtseins bei den Arbeitern. Liegt die Möglichkeit der Entwicklung eines Klassenbewußtseins in der oben entwickelten Erfahrungsbasis der Arbeiter, so muß gerade aus diesem Zusammenhang heraus festgehalten werden, daß in der gegenwärtigen Situation noch nicht die Einsicht der Notwendigkeit einer politischen Massenorganisation den Arbeitem massenhaft vermittelt werden kann, sondern es vielmehr vor allem darauf ankommt, die vorhandenen Konfliktpunkte aufzugreifen und über die Austragung dieser Konflikte in den Gewerkschaften und gegen das Kapital das Bewußtsein von der Notwendigkeit der Klassenorganisation überhaupt erst zu entwickeln. Auch die gegenwärtige Situation der DKP ist hierfür ein sprechender Beweis, insofern die Kader der DKP in den Betrieben erfolgreich sind, wenn sie als Gewerkschafter die Interessen der Arbeiter gegenüber dem Kapital fomulieren, andererseits die DKP ihre unmittelbaren politischen Zielsetzungen nur schwer vermitteln kann, insofern sie nicht die Klassenkampferfahrungen selbst interpretieren. Die Entwicklungsmomente eines solchen Klassenbewußtseins haben wir ansatzweise an der Entwicklung und dem Inhalt der Kämpfe in Italien zu zeigen versucht. Der Inkalt muß nicht der gleiche sein. Die allgemeine Verunsicherung, Betriebsstillegungen etc. können ebenso Ausgangspunkt für die Einsicht der Arbeiter in ihre wirkliche Lage sein, wie Kämpfe für Lohnerhöhung und gegen die Ausraubung der Arbeitskraft im Produktionsprozeß. Der exemplarische Charakter solcher Kampfaktionen ist unter den gegebenen Bedingungen entscheidend. Diese Entwicklung von Klassenbewußtsein selbst ist aber kein einheitlicher, die Arbeiterklasse insgesamt und von vornherein umfassender Prozeß. Doch wesentliches Moment der Entwicklung eines solchen Bewußtseins ist die Einsicht der Arbeiter, daß nur der gemeinsame und organisierte Kampf gegen das Kapital die Grundlage einer wirklichen Machtposition der Arbeiterklasse bildet. Von da aus lassen sich auch die Fehler einer antigewerkschaftlichen Politik bestimmen, da diese einem schon entwickelten Bewußtsein dei Arbeiter, nur gemeinsam und organisiert eine Macht gegenüber dem Kapital darzustellen, entgegenwirkt. 

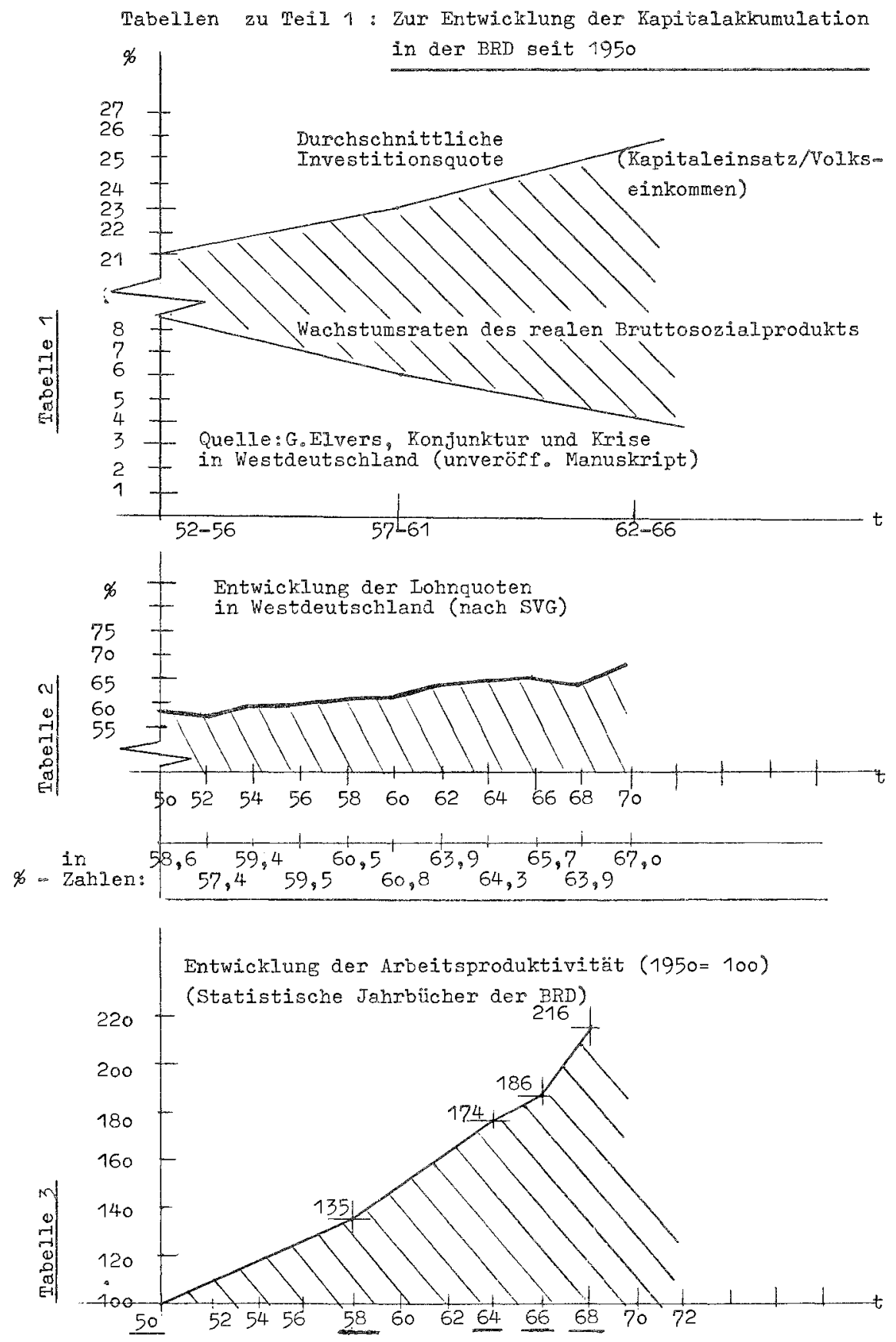

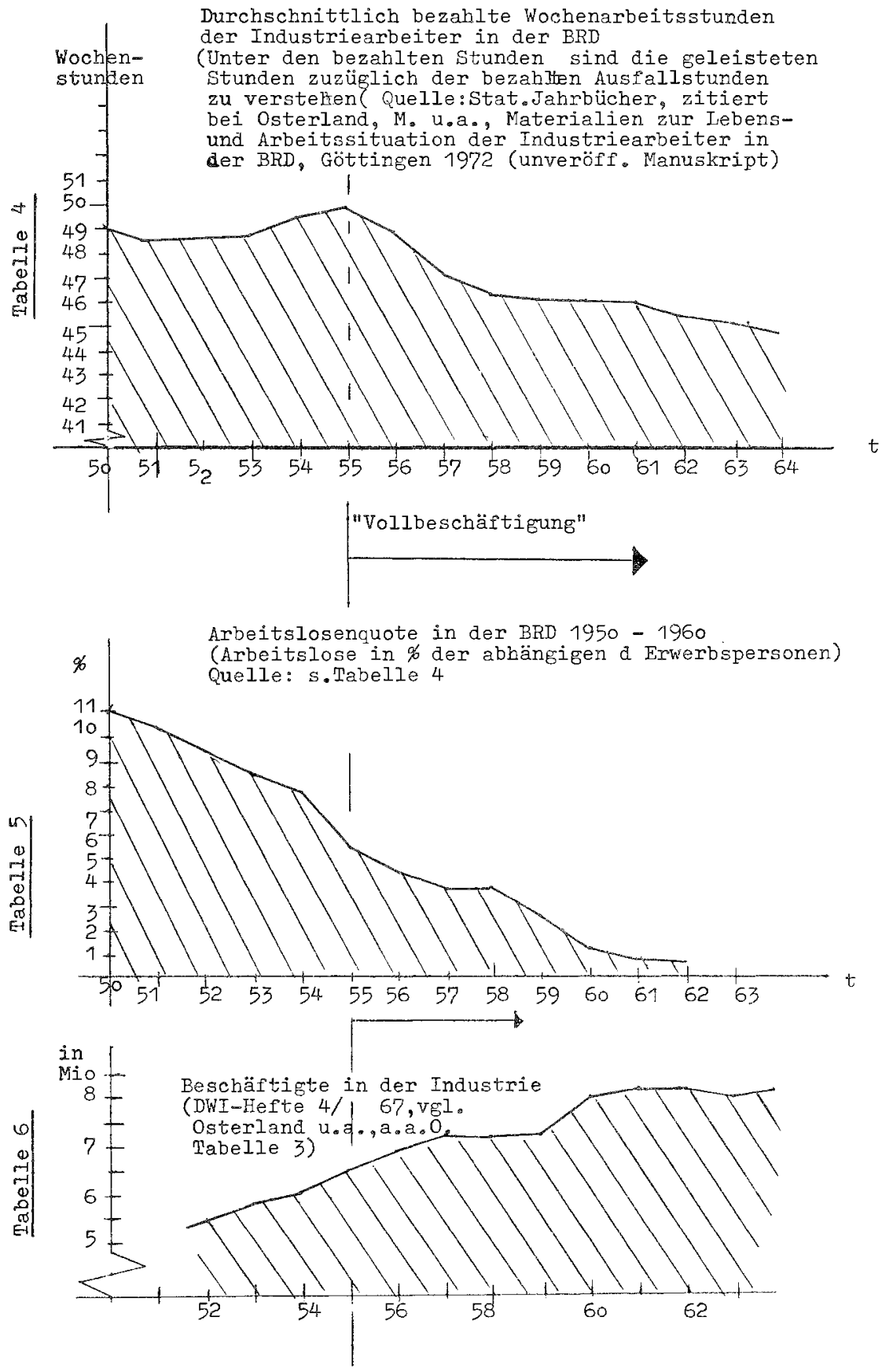
1. Die Verfahren worbestimmter Zeiten $(V v Z)$

Die Vorläufer der VvZ - heute bei der Akkordberechnung immer noch sehr verbreitet sind Zeit-Norm-Verfahren, die auf der Grundlage z.B. von Stoppuhrmessungen einzelner Arbeitsgänge mit Hilfe von Methoden des Leistungsgradschätzens Vorgabezeiten als Sollzeiten ermitteln. Diese bilden dann die Grundlage der verschiedenen Lohnformen wie des Stück-bzw. des Geldakkords sowie der Exmittlungen von Daten zur Kosten- und Personaleinsatzkalkulation. Mit dem Leistungsgradschätzen wird ein vom Zeitstudienmann subjektiv beurteiltes Verhältnis zü einer wiederum vage bleibenden, nach tarifvertraglichen Definitionen bestimmten Durchschnitts- bzw. Normalleistung hergestellt. Die Schätzung variert von einem Zeitstudienmann zum anderen und wird auch häufig als völlig subjektiv erkannt. An eben solchen Widersprïchlichkeiten setzen Auseinandersetzungen zwischen Unternehmern und Arbeitern an.

Während also die herkömmlichen Verfahren zur Vorgabezeitermittlung mit der Stoppuhr oder einfachen Arbeitsbeabachtungen ganze Arbeitsgänge messen, benutzen die VvZ kleinste Bewegungseinheiten, die nicht mehr durch einfache Zeitinstrumente erfaßt werden können. Nach bestimmten Zugehörigkeitskriterien werden diese dann zu Grundbewegungen zusammengefaßst; ihre ,Synthese ist die Zusammenfassung der gewonnenen Kleinstzeitnormen für jeden einzeinen erraßten Bewegungsteil zu einer Vorgabezeit. Die Systeme sind in den 20er Jahren in den USA entwickelt worden. Wegen der strukturelien Ahnlichkeit von WF- und MTM-System soll irr folgenden riur das MTM-System samt Untersystemen kuxz dargestellt werden. (Die Darstellung stïtzi sich auf: Wallner, Das MTM-System als Rationalisierungs- und Kalkulationsgrundlage 1968; Systente vorbestimmter Zeiten. Bericht über eine Tagung der IG-Chemie, Hannover 1967; Kleinzeit" und Bewegungselemente-Veríahren, Bericht der Internationalen Gewerkschaftskonferenz, Schriftenreihe der IG-Metall, 1969)

MTM ist eine Methode, bei der manuelle Arbeit in ihre Grundbewegungen zerlegt wird, wobei für jede Grundbewegung eine bestimmte Zeit vorher ermittelt ist. Dabei geht die Methode von dem Prinzip aus, dar\}, ,innerhalb prak tischer Grenzen ... die Zeit, die ein geübter Arbeiter braucht, um eine Grundbewegung auszuführen, konstant" ist. (vgl. Wallner, S 10) Dieses Prinzip der Vorgabezeitermittlung ist von der Art der Arbeit, der Arbeitsstelle und dem Geschlecht des Arbeiters unabhängig. Die Technik zur Ermittlung der , internationalen MTM Normalzeîtwerte ist

- die Zerlegung des Arbeitsabiaufs in Bewegungselemente, 
- die filmtechnische Ermittlung der Elementarzeiten

- und die Normierung der Zeitwerte auf eine Leistung von

$100 \%$ durch ein Leistungsschätzverfahren.

Die Bewertung der MTM-Grundbewegungen ergab sich aus der, Zeitlupenbeobachtung von Hunderttausenden von Arbeitsabläufen". Zuvor wurden die Grundbewegungen durch die Filmbilderzahl aus den Arbeitsverrichtungen heraus isoliert und vonIngenieuren und Arbeitswissenschaftlern, die in der Beurteilung von Leistungsgraden ,Erfahrung besaßen (auch hier zeigt sich wieder die Subjektivität des Leistungsgradschätzens), entsprechend bewertet. Die MTM-Zeiteinheit, nämlich TMU (Time Measurement Unit) ist eine willkürliche Setzung. Sie bedeutet eine hunderttausendstel Stunde und repräsentiert nur den ,Wert für die eigentliche Bewegung, ohne Zuschläge für irgendwelche Verzögerungen oder Verteilzeiten. Wallner geht davon aus, daß entsprechende Zeitzuschläge für Verteilzeiten (also z.B. Zeit für Toilettengang, Zigarettenpause) auf die Normzeit erfahrungsgemäß kaum unter $8 \%$ und selten über $20 \%$ lägen.

Um auch bei Einzel- und Kleinserienfertigung und bei überschlägigen Planungsaufgaben sowie bei Instandhaltung und Reparaturarbeiten eine Intensivierung der Arbeit zu ermöglichen, wird von der deutschen MTM-Vereinigung aus dem MTM-Grundverfahren ein vereinfachtes Verfahren abgeleitet. Durch eine Zusammenfassung von Grundbewegungen zu größeren Einheiten entstehen MTM Standarddaten (Richtwerte), die sich aus Zeitbausteinen verschiedener Größe zusammensetzen. Dies führt zur Bildung von

1. Basiswerten, die sich aus einigen wenigen Grundbewegungen zusammensetzen und

2. Mehrzweckwerten, die sich aus der Zusammenfassung mehrerer Basiswerte ergeben,

3. Spezialzweckwerten, die für spezielle Arbeiten entwickelt werden und Komplexgebilde sind.

Es können hier nicht die verschiedenen existierenden vereinfachenden MTM-Verfahren dargestellt werden. $\mathrm{Zu}$ ihrer Charakterisierung sei nur noch gesagt, daß sie es erlauben, längerzyklische und komplizierte Arbeitsgänge auf, Fehlzeiten ${ }^{6} \mathrm{zu}$ untersuchen und somit die Grundlage arbeitsorganisatorischer Rationalisierungen darstellen. Durch sie werden zunehmend Bereiche von Kleinserienproduktion, Instandhaltung, Reparatur, Wartung, Büroarbeiten sowie auch Schlïsselstellungen in der Produktion Rationalisierungs- und Beschleunigungsverfahren zugänglich gemacht.

\section{Anhang II}

Verhalten der Gewerkschaften zur Frage der Einfühning neuer Lohnformen und Lohnfindurgss. systeme am Beispiel der Geschäftsberichte der IG Metall Nürnberg 1957-1965

\section{Geschäftsbericht 1957/58}

„In den letzten Jahren konnte die aktive Lohn- und Tarifpolitik erfolgreich fortgesetzt werden." (Arbeitszeitverkürzung plus Lohnerhöhung) ..., ,Allen Warnungen und Irreführungen der Gegner einer Arbeitszeitverkürzung zum Trotz ist die Produktion und die Produktivität durch die Einführung der 45-Stundenwoche nicht abgesunken, sondern sowohl 1957 als auch 1958 noch weiter angestiegen. ${ }^{66}$ (S. 28)

\section{Betriebliches Lohnwesen:}

,In der abgelaufenen Geschäftsperiode wuchsen die betrieblichen Schwierigkeiten in der Lohnfindung, aber auch in der Auslegung und Durchführung tarifvertraglicher Vereinbarungen. Durch technische Veränderungen im Arbeitsablauf sind zwar die tariflichen Möglichkeiten zur Überprüfung und Neufestsetzung der Akkordvorgabezeiten gegeben, allein die Methoden einer einwandfreien, der Leistung und dem Tarifvertrag entsprechenden Lohnfestsetzung sind viel. fach recht zweifelhafter Art. Die Lohngruppenzuteilung, die Einführung zusätzlicher Lohn. gruppen, die Ermittlung der Normalleistung, des Leistungsgrades, der Zuschläge, der Einarbeitszeiten, die Wartezeiten sind die meistumstrittensten Probleme... Erfreulicherweise sind viele Betriebsräte nicht gewillt, ohne Rücksprache mit der Organisation diese Änderungen hinzunehmen ... Durchführung von Akkordschulungen und Arbeitskreisen für Arbeitsstudien." (S. 29)

,Wie alles im Leben irgendwann veraltet und von neuem abgelöst wird, so geht auch die Zeit der ,klassischen Entlohnungsformen ${ }^{6}$ langsam zu Ende. Dabei sind es drei Gesichtspunkte, 
die uns als Organisation veranlassen, der Entwicklung Rechnung zu tragen

Die Unzulänglichkeit in der Definition der einzelnen Gruppen

Die unerschiedliche Entlohnung nach dem Geschlecht

Die Lohnabschläge durch Altersstuîen.

Als IG Metall sind wir in der Lage, einerseits durch den Weitblick des Vorstandes und andererseits durch die Fähigkeiten der Kollegen Weng und Hagner auf dem Gebiet der Analyse des Arbeitsplatzes Bahnbrechendes für die Kollegen und Kolleginnen geschaffen zu haben" ${ }^{66}$ (S. 69)

\section{Geschäftsbericht 1959/60}

,Die Jahre $1959 / 60$ zeichnen sich durch eine wirtschaftliche Hochkonjunktur aus, wie wir sie noch selten erlebt haben." (S. 5)

„Es hat keinen Zweck, über die Reform des BVG zu diskutieren oder gar zu schimpfen, wenn wir in der Praxis immer wieder feststellen, daß ein Teil der Betriebsräte nicht einmal die positiven Bestimmungen des Gesetzes voll ausnützt . . “" (Stärkere Zusammenarbeit mit Ortsverwaltung notwendig) (S. 23) ....,Wieviele glauben, daß man im Zeichen der wirtschaftlichen Hochblüte nur Forderungen zu stellen braucht, die automatisch erfüllt werden... Politische Gleichgültigkeit und träge Sattheit sind die größ te Gefahr für die Arbeitnehmer . . . Aktion VK, zahlenmäßige Verstärkung。“" (S. 24) . . ,,Der Erfolg unserer Betriebsfunktionäre hängt wesentlich von ihrer Persönlichkeit ... ab ..." (S. 25) ,Größter tarifpolitischer Erfolg ${ }^{66}$. . „,Stufenplan zur Erreichung der 40-Stundenwoche . . neben der Verkürzung der Arbeitszeit konnte die aktive Lohn- und Gehaltspolitik erfolgreich fortgesetzt werden." (S. 27)

\section{Betriebliches Lohnwesen:}

,Durch die ibberaus günstige Wirtschaftslage und die manchmal recht zweifelhaften Methoden der Abwerbung werden in den Betrieben z.T. recht beachtliche Zulagen gewährt ..." „Im abgelaufenen Berichtszeitraum war ein verstärktes Bemühen der Betriebe, zu anderen Entlohnungsformen zu gelangen, festzustellen. Von allen Funktionären muß erwartet werden, daß sie bei geplanten Ânderungen die OV rechtzeitig in Kenntnis setzen und vor der Unterzeichnung betrieblicher Vereinbarungen eine Abstimmung mit uns herbeifüren." Auf wiederholte Mahnungen fand die "Bildung von Lohn- und Akkordkommissionen in fast allen Betrieben" statt. (S. 35)

\section{Arbeitsstudien:}

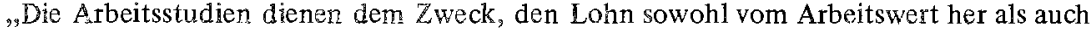
von der Leistung her festzuleger. Für beire Ausgangspunkte gibt es verschiedene „Svsteme'. Der Gedanke, den Grundlohn nicht mehr nach der klassischen Form, z.B. ungelernter bis bestaualifizierter Facharbeiter, sondern nach dem Wert der Arbeit festzusetzen, wurde erstmals im MTV für gewerbliche Arbeitnehmer zwischen IG Metall und VWM am 1.9.59 festgelegt. Diese neue Lohnfindung hat ihren realen Hintergrund in der Tatsache, daßs die Technik den Arbeitsplatz im Laufe der Zeit wesentich verändert. Dadurch treten Merkmale auf, die in den ,alten Entlohnungsformen ${ }^{6}$ keine Bericksichtigung finder. ${ }^{6}$ (S. 36) (Schulung als Konsequenz)

" "Refa ${ }^{\prime}$ ist ein eingetragener Verein, der in den 20 er Jahren gegründet wurde mit dem Zweck, den, gerechten Lohn zu finden". Erst seit 1945 sind die Gewerkschaften im DGB paritätisch in Refa verteten." (Weng und Hagner von der IG Metall)

Exschreckendes Ansteigen der Unfallziffern (Berichte der Gewerbeaufsichtsämter und Berufsgenossenschaften) (9.37)

Geschäftsbericht $1061 / 62$

Wirtschaftliche Konjunkinr (Konsum muỉ erhöht werden zur Stützung der Konjunktur). (\$.5) Leistungsgerechte Entlohnung für Frauen, Anhebung der untersten Lohngruppen, Beseitigung der Frasenlohngruppen. (\$. 13)

$\mathrm{BR}, \mathrm{VK}, \ldots$ weilere Bemüren der OV ... die Betriebsräte und die betrieblichen VK zu einem eirheitlichers Funktonärskreis zusammenzurihren." (S. 27)

"In unserer schnellebigen und materialistischen Zeit fehlt bedauerlicherweise die Bereitschaft zur Ubernahne von Funktionen und Aufgaben. ${ }^{66}$ ( $10 \%$ weniger Vertrauensleute gemeldet) (\$. 29)

(Im Verzeichmis der Bildungsveranstaltunger für VK (S. 30) findet sich keine einzige zu Fragen der innerbetrebilichen Konflikte.)

22. Juni 1962, Abschlußs: Grundlage der Entlohnung in der bayrischen Metallindustrie: 1. die sog. klassische Entiohnung mit nem Lohngruppen, 2. die analytische Arbeitsbewertung 
gemäß Anhang 4 des MTV für gewerbliche Arbeitnehmer in der badischen Metallindustrie. (S. 13)

\section{Geschäftsbericht 1963-65}

„Wohl der größte, ja ein epochaler Erfolg konnte durch die tarifliche Vereinbarung auf Verlängerung des Urlaubs und die erstmalige Gewährung eines Urlaubsgeldes errungen werden." (S. 17)

„Zahlreiche Betriebsrätekörperschaften erkannten die Bedeutung einer richtigen Eingruppierung und schufen in harten monatelangen Verhandlungen mit ihren Geschäftsleitungen eine Basis, die im wesentlichen unseren Vorstellungen entspricht. Wir wollen aber auch nicht verschweigen, daß allzu viele Betriebsräte und vor allem Arbeitnehmer selbst, angesichts der guten Verdienstmöglichkeiten, bedingt durch Arbeitskräftemangel, überquellende Auftragsbestände, Abwerbemaßnahmen der Unternehmer und hohe Locklöhne wenig Wert auf eine leistungsgerechte Eingruppierung legten." (Deshalb Einführung von Lehrgängen)

,Für die analytische Arbeitsplatzbewertung gemäß Anhang 4 des MTV interessierten sich 5 Betriebe. Nur ein Großbetrieb hat bisher nach $11 / 2$ jähriger Tätigkeit einer paritätischen, eigens für die Lohnfindung freigestellten Kommission, diese Entlohnungsform eingeführt.

Im Berichtszeitraum schob sich die Leistungsbewertungsmethode in den Vorderorund. Sie ist gekennzeichnet durch den Begriff ,Vorbestimmte Zeiten'. Diese Methode richtet ihr Augenmerk zuerst auf die Arbeitsgestaltung. Diese soll so perfekt wie nur möglich gestaltet werden. Das führt in vielen Fällen dazu, daß der betreffende Arbeitnehmer zugleich zwei Arbeitsvorgänge anstelle von bisher nur einem ausführt. Durch diese Umstellung, d.h. die stete Betätigung der zwei Hände, womöglich noch beider Füße, wird eine erhöhte Konzentration verlangt. Nach der Gestaltung des Arbeitsplatzes wird mit Hilfe von Standardwerten die Vorgabezeit vorbestimmt. (S. 18)... Anerkennenderweise hat der Vorstand bereits wertvolle Vorarbeit für das frei im Tarifraum schwebende MTM geleistet. Für das WF hat Refa die Lizenz erworben. Dadurch ist für die Arbeitnehmerschaft bzw. den Betrieb eine große Sicherheit nach beiden Seiten gegeben." (S. 19)

„Auch die Mitglieder der Akkordkommission nahmen zu den tarifpolitischen Bestimmungen des Leistungslohnes Stellung. Größtes Interesse wird dabei der Entwicklung des Prämienlohns entgegengebracht." (S. 19) 